\title{
La riforma normativa sulla violenza sulle donne in relazione alla natura dei crimini perpetrati*
}

\author{
Michelangelo Pascali
}

\section{Riassunto}

Il nostro legislatore, con la legge 15 ottobre 2013, n. 119, di conversione del decreto legge 14 agosto 2013, n. 93, ha inteso emanare, sulla scorta di una supposta emergenza in materia, un nuovo provvedimento in tema di violenza sulle donne, con particolare attenzione agli "eventi di gravissima efferatezza" commessi in loro danno, tema che, giustamente, ha occupato da qualche tempo un punto di rilievo nella discussione collettiva italiana.

L'autore si interroga sulla reale presenza di tale emergenza, rilevando se questa effettivamente si sia tradotta nell'acuirsi di siffatti episodi violenti o, piuttosto, se le questioni connesse non siano "ontologicamente" presenti.

\section{Résumé}

Avec la loi n¹19 du 15 octobre 2013, le but du législateur italien était de promulguer une nouvelle loi sur la violence faite aux femmes, à cause d'un soi-disant état d'urgence du phénomène. Cela pour accorder une attention particulière à la gravité extrême des crimes commis contre elles, un thème au premier plan du débat public italien, depuis un certain temps.

L'auteur questionne la réelle existence de cette urgence, et se demande si elle constitue réellement une conséquence de l'aggravation de tels crimes violents ou plutôt, si ce phénomène est « ontologiquement » présent.

\section{Abstract}

The aim of Italian legislator, with the Law No 119 of 15 October 2013, was to issue a new act on violence against women on the basis of a supposed emergency of this phenomenon. This was in order to devote particular attention to the extreme cruelty of the crimes committed against them, a topic which has rightly occupied the Italian collective debate.

The author questions where the real emergency is, noting that if this emergency is in fact due to an aggravation of such a kind of violent crimes rather than to the fact that this phenomenon is "ontologically" existing.

Key words: violence against women; Italian legislation; emergency; nature of crimes committed.

"I kiss'd thee ere I kill'd thee: no way but this; Killing myself, to die upon a kiss" (William Shakespeare, The Tragedy of Othello, the Moor of Venice)

"Ci sono amori che sono più molestia che amore" (Alda Merini, intervistata in La pazza della porta accanto di Antonietta De Lillo)

\footnotetext{
* Il presente articolo è una rielaborazione della relazione presentata al convegno dedicato a "La violenza contro le donne: dallo stalking al femminicidio", tenutosi il 25 novembre 2013 presso il Dipartimento di Giurisprudenza dell'Università Parthenope di Napoli.

• Ricercatore (settore scientifico-disciplinare SPS/07 - sociologia generale) presso l'Università "Parthenope" di Napoli.
} 


\section{Il femminicidio come emergenza} normativa e costanza sociale.

Il nostro legislatore, con la legge 15 ottobre 2013, n. 119, di conversione del decreto legge 14 agosto 2013, n. 93, ha inteso emanare un nuovo provvedimento in materia di violenza sulle donne, con particolare attenzione agli "eventi di gravissima efferatezza" commessi in loro danno $^{1}$, tema che, giustamente, ha occupato da qualche tempo un punto di rilievo nella discussione collettiva italiana.

Nel promulgare il testo si è dichiaratamente affermato di agire sulla scorta di una supposta emergenza in materia, che avrebbe per l'appunto imposto di affrontare in tempi quanto più rapidi possibili il problema. Proprio questa urgenza avrebbe, dunque, giustificato l'adozione della disposizione nella forma di legislazione prescelta, peraltro inserendo le misure sulla repressione di tale grave fenomeno in un testo tematicamente eterogeneo ${ }^{2}$, cosa che ha prestato il fianco a critiche di "debolezza costituzionale"3.

${ }^{1}$ Così come espressamente menzionato nelle premesse del decreto legge, con particolare menzione al loro susseguitisi nel tempo. Ivi si ritrova poi menzione alla "violenza domestica".

${ }^{2}$ Per tale ragione il testo è stato accusato, da taluni, di contenere una strumentalizzazione del tema della protezione delle donne al fine di far passare senza adeguato dibattito parlamentare provvedimenti su questioni politicamente più controverse: cfr., per esempio, Sabaghi D., "Legge sul Femminicidio: il cavallo di Troia e la cultura della violenza sulle donne", in http://autori.fanpage.it/legge-sul-femminicidio-il-cavallodi-troia-e-la-cultura-della-violenza-sulle-donne/

${ }_{3}^{3}$ Proprio l'eterogeneità dei contenuti potrebbe di per se tradire il dettato costituzionale per violazione dell'art. 117, in particolar modo sulla presenza dei requisiti di necessità e urgenza richiesti. Sul punto, si veda anche la sentenza della Suprema corte n. 22 del 2012. Amplius, Marcenò V., "L'eterogeneità delle disposizioni come "male" da elusione delle fonti sulla produzione del decreto-legge",

http://www.forumcostituzionale.it/wordpress/images/stori es/pdf/documenti_forum/giurisprudenza/2012/0010_nota _sent_22_2012_marceno.pdf. Nondimeno, le cose sono un po' più complesse di quanto l'esasperata logica giuridico-formale, non priva di reticenze e contraddizioni, voglia far credere. Di contro, infatti, può osservarsi che $\mathrm{i}$
È necessario innanzitutto interrogarsi, pertanto, sulla reale presenza di tale emergenza, rilevando se questa effettivamente si sia tradotta nell'acuirsi (da un punto di vista qualitativo e ancor più quantitativo) di siffatti episodi violenti o, piuttosto, se le questioni connesse non siano 'ontologicamente' presenti. Inoltre, bisogna anche riscontrare se emergenza o costanza del problema non siano pure legate a una qualche inadempienza imputabile allo stesso legislatore.

In proposito, va preliminarmente notato che il nostro Governo verteva in una condizione di profondo ritardo relativamente all'attuazione delle raccomandazioni provenienti dal Comitato delle Nazioni Unite già nel 20114, in conformità alla Convenzione sull'eliminazione di tutte le forme di discriminazione contro le donne (CEDAW) adottata nel 1979 dall'Assemblea generale delle Nazioni Unite ${ }^{5}$, volte a predisporre

requisiti di urgenza e necessità vanno valutati rispetto al fenomeno sociale del femminicidio, in sé considerato, senza essere irrimediabilmente contaminati da eventuali infiltrazioni di norme non omogenee, riguardanti materie di dubbia urgenza e necessità, che potrebbero magari ritenersi di per loro viziate, ma non vizianti. Insomma, anche dal punto di vista sociologico, la norma eterogenea (e autonoma) priva di tali requisiti, inserita a forza (incidenter tantum) dal legislatore ordinario sulla "diligenza-vettore" della materia principale, potrebbe e forse dovrebbe essere censurabile e censurata solo essa, senza avere capacità di trasmettere i suoi vizi sull'intera normativa riguardante viceversa materia necessaria e urgente e perciò da pienamente conservare, tutelare, proteggere.

${ }^{4}$ Specificamente, nelle raccomandazioni presentate nella $49^{\circ}$ sessione di valutazione tenutasi nel luglio 2011 presso la sede delle Nazioni Unite a New York (pubblicate nell'agosto 2011) si è così affermato a proposito dell'Italia: "Il Comitato rimane preoccupato per l'elevata prevalenza della violenza nei confronti di donne e bambine nonché per il persistere di attitudini socioculturali che condonano la violenza domestica, oltre ad essere preoccupato per la mancanza di dati sulla violenza contro le donne e bambine migranti, Rom e Sinte. [...] È inoltre preoccupato per l'elevato numero di donne uccise dai propri partner o ex-partner, che possono indicare il fallimento delle autorità dello Stato-membro nel proteggere adeguatamente le donne, vittime dei loro partner o ex-partner".

5 Ratificata dall'Italia con legge n. 132 del 10 giugno 1985 (al protocollo opzionale ha aderito il 29 ottobre 
un programma quadriennale e uno biennale di azioni dirette a concretare misure più efficaci di protezione specifica delle donne ${ }^{6}$. Una situazione

2002). Ci si riferisca anche alla risoluzione n. 52 del 1986 dell'Assemblea generale delle Nazioni Unite su "Prevenzione dei reati e misure di giustizia penale per eliminare la violenza contro le donne". Ma si vedano pure, in un senso più generale, le prescrizioni contenute nella Convenzione sull'eliminazione di ogni forma di discriminazione contro le donne approvata il 18 dicembre 1979 dall'Onu, le quali si concentrano più sui vasti e compositi effetti sul piano sociale (in senso ampio inteso) che tale violenza, quale effettivo elemento di una pratica discriminatoria, può arrecare: "la discriminazione contro le donne viola i principi dell'uguaglianza dei diritti e del rispetto della dignità umana, ostacola la partecipazione delle donne alla vita politica, sociale, economica e culturale del loro Paese in condizioni di parità con gli uomini, intralcia la crescita del benessere della società e della famiglia e rende più difficile un pieno dispiegarsi delle potenzialità delle donne per il bene del proprio Paese e dell'umanità". Si ricordi anche che alla lettera $h$ del comma 1 dell'art. 7 dello Statuto di Roma della Corte penale internazionale, concluso il 17 luglio 1998, si menziona esplicitamente tra i crimini contro l'umanità la persecuzione contro un gruppo o una collettività dotati di propria identità, ispirata da ragioni di genere sessuale. Sul problema delle riserve apposte dagli Stati aderenti alle summenzionate convenzioni, può vedersi Balboni M., "Gli strumenti di protezione internazionale e comunitaria dei diritti delle donne", 2004, p. 2, in http://cedaw30.files.wordpress.com/2010/05/balboni_gli-strumenti-di-protezione-internazionale-e-comunitariadei-diritti-delle-donne.pdf, nonché "Il problema delle riserve alla CEDAW", in Archivio Pace Diritti Umani. Bollettino, 2004, n. 28, p. 7, leggibile in http://unipdcentrodirittiumani.it/public/docs/b28.pdf. In Zupi M., Hassan S., La Convenzione del Consiglio d'Europa sulla prevenzione e la lotta contro la violenza nei confronti delle donne e la violenza domestica, 2013, http://www.parlamento.it/application/xmanager/projects/ parlamento/file/repository/affariinternazionali/osservatori o/approfondimenti/85_CeSPI_Convenzione_Istanbul.pdf, si ricorda, invece, alla p. 17, che la violenza sulle donne non è ricompresa all'interno della lista dei cosiddetti "euro-crimini”, specificamente elencati nell'art. 83 del Trattato di Lisbona.

${ }^{6}$ Si ricordi anche la dichiarazione di Rashida Manjoo, relatore speciale sulla violenza contro le donne delle Nazioni Unite in visita nel nostro Paese nel 2012, secondo la quale "femmicidio e femminicidio sono crimini di Stato tollerati dalle pubbliche istituzioni per incapacità di prevenire, proteggere e tutelare la vita delle donne, che vivono diverse forme di discriminazioni e di violenza durante la loro vita" (riportato in Amabile F., "L'Onu: 'In Italia il femminicidio è crimine di Stato", da La Stampa del 25 giugno 2012). Le brevi note sull'omicidio di donne del Rapporto della relatrice speciale sulla violenza contro le donne, le sue cause e conseguenze sono leggibili in http://www.amnesty.it/flex/cm/pages/ServeAttachment.p $\mathrm{hp} / \mathrm{L} / \mathrm{IT} / \mathrm{D} / \mathrm{e} \% 252 \mathrm{~F} 9 \% 252 \mathrm{Fb} \% 252 \mathrm{FD} . \mathrm{f} 5 \mathrm{~b} 4 \mathrm{f} 05 \mathrm{cabad} 1 \mathrm{cdb}$ 0d10/P/BLOB\%3AID\%3D5996, p. 8. critica, dunque, atteneva indiscutibilmente già a tale piano. Obiter dictum, il dettame, nella sua tempistica, può essere letto anche in funzione di riabilitare un'immagine dell'Italia, in tema di rispetto delle donne, compromessa sul piano internazionale da alcune vicende mediaticamente (e sostanzialmente) gravi ${ }^{7}$.

La revisione normativa, nell'assenza di dati presentati sullo stato delle violenze tentate o perpetuate nei confronti delle donne ${ }^{8}$, ha pure fondato le sue ragioni, esplicitamente, sull'“insicurezza percepita", ovverosia su elementi non puramente oggettivi ma necessariamente basati anche su variegati indicatori di tipo soggettivo, pure mutuati da un generico e aprioristico discorso pubblico, nel migliore dei casi equiparabile alla $\delta \dot{\xi} \xi \alpha$, e forse distorti nel loro processo di rappresentazione mediatica 9 . Posto che non è certo la prima volta,

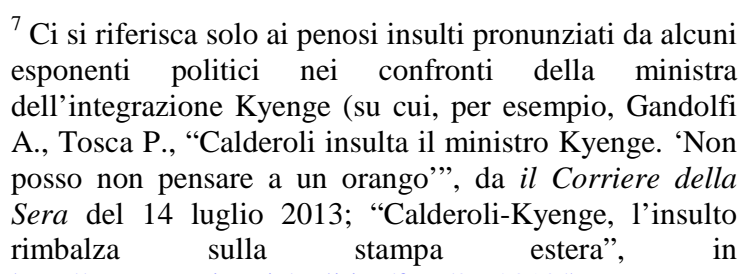
http://www.corriere.it/politica/foto/07-2013/kyengegiornali-internazionali/caso-calderoli/calderoli-kyengeinsulto-rimbalza-stampa-estera ed3b9d0e-ecaa-11e2b462-40c7a026889e.shtml\#1). In parte, si richiamino pure le varie forme di mercimonio sessuale che hanno riguardato in Italia anche figure istituzionali apicali.

8 Ambito, tra l'altro, vastissimo, come pure testimonia l'ampia definizione di "violenza" data dall'Organizzazione mondiale della sanità (Prevenzione della violenza: una priorità della sanità pubblica, Ginevra, 1996, documento WHO/EHA/SPI.POA.2). Comunque, come si avrà modo di tornare passim, scarse ricerche statistiche specifiche, l'utilizzo in forma attuale di dati risalenti nel tempo, e la presenza di una vasta area occulta e occultata non permettono di stimare esattamente (o, almeno, più precisamente) i confini del fenomeno delle uccisioni e violenze varie contro le donne, anche con riferimento a episodi connessi subiti in precedenza.

${ }^{9}$ In questo senso, il legislatore ha quasi lasciato trapelare una sua consapevolezza sull'assenza di elementi emergenziali oggettivi tali da giustificare l'adozione di un decretazione di urgenza ex art. 77 Cost., rifugiandosi in una contingenza meramente soggettiva. Ci si orienta, dunque, anche ammiccando al pubblico consenso, verso un "contrasto non tanto al fenomeno criminale in sé 
e anzi costituisce oramai un tema classico $^{10}$ di dibattito, che determinate contingenze, secondo le modalità con cui i media ne danno notizia, influenzino pesantemente $i$ tempi dell'iter amministrativo $^{11}$ e normativo ${ }^{12}$, anche in questo caso il legislatore è parso, almeno per certi versi, inseguire, nell'esercitare il suo potere di normazione, le scadenze di un'agenda impropriamente predisposta da altri.

quanto all'allarme sociale che esso procura" (Spinelli B., "Decreto femminicidio: la donna non è 'soggetto debole' ma 'soggetto reso vulnerabile' dalla violenza", in http://27esimaora.corriere.it/articolo/decreto-

femminicidio-ma-la-donna-non-e-un-soggetto-debolema-soggetto-reso-vulnerabile-dalla-violenza-e-questocambia-le-prospettive/). Si veda, in merito, anche il pensiero di Valerio Spigarelli, presidente dell'Unione delle Camere penali: "In campo penale si dovrebbe legiferare avendo di mira $\mathrm{i}$ beni costituzionalmente garantiti e non l'urgenza del momento e meno che mai quella della sicurezza percepita" (in Sabatinelli D., "Critiche al decreto legge anti femminicidio", leggibile in http://www.senzabarcode.it/2013/08/critiche-al-decretolegge-anti-femminicidio-nellultima-puntata-della-lid/). Nello stesso articolo la psicologa investigativa Valentina Morana ha lamentato un deficit di scientificità nei dati criminologici su cui il decreto si è basato.

${ }^{10}$ Cfr. anche soltanto Cohen S., Folk Devils and Moral Panics, MacGibbon \& Kee, London, 1972.

${ }^{11}$ Cfr., per l'appunto sul piano amministrativo, in tema di nesso talora strumentale tra politiche sicuritarie e violenza sulle donne, lo sgombero del campo rom di Tor di Quinto a Roma voluto dall'allora sindaco Veltroni dopo l'uccisione della povera Giovanna Reggiani, in quanto luogo di dimora del suo aggressore: si veda, per esempio, "Seviziata e uccisa, Mailat resta in carcere. Il delitto di Tor di Quinto. Al via lo sgombero del campo nomadi", dal Corriere della sera del 2 novembre 2007. Lo stesso Veltroni aveva poi sollecitato il Consiglio dei ministri a tramutare in decreto legge le norme sulle espulsioni degli irregolari contenute nel disegno di decreto di legge noto come "pacchetto Amato" (Battistelli F., Fay Lucianetti L., "La sicurezza urbana tra politics e policy", in Pajno A.(a cura di), La sicurezza urbana, Maggioli, Santarcangelo di Romagna, RN, 2010, p. 87), nonché aveva bloccato i progetti dei nuovi mega insediamenti romani destinati ad accogliere i rom (A. Col., "Roma: Veltroni presenta gli interventi sulla sicurezza effettuati nel corso dell'anno", in http://www.immigrazioneoggi.it/daily news/2007/dicem bre/07_4.html).

${ }^{12}$ Un esempio tra tanti: la riforma della legittima difesa con legge 13 febbraio 2006, n. 59, di modifica all'art. 52 c.p. in materia di diritto all'autotutela in un privato domicilio - frettolosamente, e per certi versi anche discutibilmente, introdotta a seguito della maggiore copertura mediatica degli episodi di cronaca legati alle rapine in abitazioni o in esercizi commerciali.
La riforma appare, dunque, particolarmente dedicata al tema del femminicidio, tema che è stato nei mesi precedenti al varo normativo al centro di molti notiziari, i cui toni possono aver influenzato il legislatore. Ad una peculiare copertura mediatica, peraltro non riservata all'omicidio di tutte le donne ${ }^{13}$, che in qualche modo ha allarmisticamente amplificato in un determinato spazio temporale la pur appropriata constatazione e segnalazione del problema procedendo poi, arbitrariamente, a una selettività negativa di quel che non appariva conforme alla linea "editoriale" prescelta - è corrisposta armonicamente una forte torsione securitaria rintracciabile in alcune parti del decreto ${ }^{14}$, peraltro in linea con una certa teorica penale

13 Una selettività mediatica negativa, con poche differenze rispetto a ciascun medium di massa, ha per esempio riguardato l'omicidio delle prostitute (interpretabili, peraltro, come uccisione di un individuo ancor più in quanto "femmina" che "donna": se le prostitute per una qualche 'sensibilità pubblica' non possono essere ricomprese quali "donne", all'opposto per i maniaci che le prendono di mira rappresentano un'estremizzazione di una caratteristica - desiderata o temuta - della donna stessa, chiaramente il suo essere sessualizzato). Bisogna poi chiedersi se in questa materia pesi una qualche "disattenzione", in particolare sulla protezione delle prostitute, da parte delle autorità amministrative, oltre che degli inquirenti e delle forze dell'ordine, che si manifesta nella reiterazione delle aggressioni talora a fronte di molte denunce avanzate e, ancor più, dinanzi a precedenti casi di violenze tentate $\mathrm{e}$ subite (anche con esiti mortali). Ciò, coerentemente con la politica sulla prostituzione che concretamente mira a non rendere di gestione pubblica quelle che comunque "pubblico" è, sebbene in una sfera nascosta.

${ }^{14}$ Un netto arretramento del sistema di garanzie pare una tentazione spesso accarezzata dinanzi a ciò che ipoteticamente "non piace". Ci si riferisca solamente alla proposta di una "presunzione di veridicità" (ossia di una sostanziale inversione dell'onere della prova) effettuata dalla sociologia francese della famiglia Irène Théry (in merito al caso Dominique Strauss-Kahn: Id., "La femme de chambre et le financier", da Le Monde del 23 maggio 2011) a proposito delle vittime di violenza, la quale nulla è - a nostro parere - che prova dell'ideologizzazione della questione e dell'imbarbarimento del diritto piegato a un fine che già anticipa arrogantemente le conclusioni di un processo penale tendenzialmente fittizio (declinato come processo inquisitorio/'ideologico’). 
$\begin{array}{lll}\text { contemporanea15 }^{15} & \text { (si pensi } & \text { solo, } \\ \text { esemplificativamente, } & \text { all'inasprimento } & \text { delle }\end{array}$

pene, all'arresto obbligatorio, all'anonimato del

terzo denunciante ${ }^{16}$, rilevando quanto possano

queste disposizioni operativamente cozzare

contro il dichiarato carattere accusatorio del

nostro processo penale, oltre che contro il

15 Seppure il diritto penale minimo, specificamente considerato, rappresenta una teorica che ha influenzato la riflessione sulla teoria del diritto penale, traducendosi, soprattutto nella seconda metà del Novecento, anche in importanti normazioni legislative (in tema di depenalizzazione, di decarcerizzazione, et similia), va detto che - prescindendo dalle più recenti produzioni legislative volte alla riduzione del contenzioso penale (che finanche hanno attenuato, in qualche modo, il principio dell'obbligatorietà della legge penale: ci si riferisca, in merito, all'ipotesi di non punibilità per particolare tenuità del fatto ex art. 131 bis c.p., che ha in qualche modo adattato una previsione chiave del processo penale minorile anche per soggetti maggiori d'età) e al ridimensionamento dell'esecuzione penale in forma carceraria, intese tuttavia soprattutto quale risposta alle gravi deficienze italiane in tema di tutela del giusto processo e dei diritti delle persone sottoposte a detenzione preventiva o definitiva, anche sotto un profilo strettamente economico (si pensi, solo, alle potenziali conseguenze sul bilancio pubblico di una prosecuzione delle condanne ricevute dal nostro Paese in sede europea a causa della sua "persistente emergenza carceraria") nelle normative degli ultimi decenni si evidenzia come la direzione eletta dal legislatore in materia di devianza e criminalità sia andata in un senso tutto opposto a quello della minimizzazione dell'intervento penale, influenzata da considerazioni politico-mediatiche contraddistinte sovente da una logica esclusivamente securitaria (per cui il problema sociale è astrattamente risolto nella mera 'fortificazione della cittadella sociale'). Ciò, in un sostanziale, prasseologico scardinamento dai valori costituzioni (tanto che il vaglio di legittimità costituzionale diviene l'ultimo baluardo per la difesa dell'individuo da tali normative, con tutti i problemi che ciò continuamente pone sul piano della giusta armonia delle fonti del diritto). A latere, sembra quasi riproporsi, seppure senza tutta quella complessità e originalità che pure la caratterizzava fortemente, quella relazione spuria tra "violazione normativa" e "antagonismo a-sociale" o "incompatibilità sociale" che ha improntato molte riflessioni filosofiche negli ultimi secoli in tema di formulazione o riformulazione dell'assetto sociale. Proprio per tali ragioni, si ripropone la drammatica attualità di una riflessione su una teoria che sappia essere realmente critica, e non già su fondata su presupposizioni emotivo-ideologiche mascherate da "dati scientifici", in tema di crimine, devianza e ordine sociale.

${ }^{16}$ Precisamente, la normativa non consente puramente e semplicemente le segnalazioni anonime, così come si era pure ipotizzato, ma mantiene segreta l'identità di coloro che le fanno. Amplius infra. principio generale di presunzione d'innocenza ${ }^{17}$. Tra l'altro, neppure l'“eccezionalità" del fatto potrebbe giustificare eccezioni al rispetto dello stato di civiltà giuridica). D'altronde, anche in presenza di una gravità effettiva, i meccanismi mediatici tipici del panico morale ${ }^{18}$, paradossalmente, possono far perdere credibilità e peso al fenomeno, declinato impropriamente quale "emergenza"19 e, dunque, letteralmente, quale cosa "eventuale" e "non prevista". Così come, alla lunga, rischiano di ingenerare una perdita di attenzione nel pubblico, qualora la costanza dei toni usati finisca col produrre un'assuefazione 'emotiva' nello stesso.

In ogni modo, davvero possiamo affermare, rispetto alle violenze compiute ai danni delle donne, che ci si è trovati, ad un tratto, in una fase emergenziale?

Per quel che riguarda il nostro Paese, la maggior parte dei relativi dati in nostro possesso ${ }^{20}$,

\footnotetext{
${ }^{17}$ Anche l'espulsione dello straniero, con revoca del suo permesso di soggiorno, quando questi sia stato condannato per reati concernenti la violenza domestica si mostra per certi versi antigarantista, tenuto conto che all'uopo occorre anche una sentenza non definitiva (oltre che di applicazione della pena su richiesta delle parti).

${ }^{18}$ Cfr. Giomi E., Tonello F., "Moral Panic: the Issue of Women and Crime in Italian Evening News", in Sociologica. Italian Journal of Sociology on line, 2013, n. 3 ,

http://www.sociologica.mulino.it/journal/article/index/Ar ticle/Journal:ARTICLE:709/Item/Journal:ARTICLE:709. ${ }^{19} \mathrm{Si}$ veda, per esempio, il Tg3 dell' 8 marzo 2014 che ha dato ampio spazio alla notizia di due femminicidi, presentati in apertura di telegiornale, ma non ha parlato, se non solo il giorno dopo, di un contemporaneo figlicidio con autrice una donna. Anche le violenze compiute da donne verso donne hanno avuto, almeno nell'arco temporale in cui si è discusso di violenza maschile sulle donne, un'attenzione minore e, ancor più, quelle compiute da donne verso uomini. Pure in questi casi, poi, sarebbero evidentemente necessarie azioni (preventive e repressive) mirate. Dare un'immagine monolitica della donna, in dinamiche di violenza, come soggetto pacifico tendenzialmente vittima non ci pare poi che sia rispettoso della complessità dell'essere femminile. ${ }^{20}$ A seguito delle ricerche statistiche menzionate nelle note successive. Sulla questione dell'analisi e della presentazione dei dati in materia si veda comunque, per esempio, Patruno S., "Femminicidio", in
} 
sebbene con dei margini di incertezza apprezzabili21, sembrerebbero grossomodo qualificare questi accadimenti diacronicamente come costanti nel tempo ${ }^{22}$ e sincronicamente

http://noisefromamerika.org/articolo/femminicidio\#, nonché De Luca D., "I veri numeri sul femminicidio", in http://www.ilpost.it/davidedeluca/2013/05/20/i-verinumeri-sul-femminicidio/. In Tonello F., "Femminicidio, i numeri sono tutti sbagliati", in http://www.ilfattoquotidiano.it/2013/05/11/femminicidionumeri-sono-tutti-sbagliati/590171/, si afferma che, a fronte della costanza del numero di donne uccise, non può escludersi che il sottoinsieme dei femminicidi propriamente detti sia effettivamente aumentato, benché non vi siano dati sufficienti per avvalorare tale ipotesi. Ivi si rinvia anche sulla critica di parziale inattendibilità dei dati diffusi, non sempre raccolti in modo scientifico; sulla necessità di raccogliere $\mathrm{i}$ dati in materia in modo sistematico, si veda pure Somma N., De Maglie M., "Femminicidio, lettera aperta agli scettici", in http://www.ilfattoquotidiano.it/2013/05/11/femminicidiolettera-aperta-agli-scettici/590027/. Contra, in Lipperini L., Murgia M., L'ho uccisa perché l'amavo Falso!, Laterza, Roma-Bari, 2013, si afferma che i delitti maturati in famiglia o "per passione", che sono in gran parte costituiti da femminicidi, sono cresciuti in termini assoluti del $98 \%$ dal 1992 al 2006. Anche sulla scorta di tale dato critica i precedenti articoli citati Lipperini L., in "Il fact-screwing dei negazionisti", in http://loredanalipperini.blog.kataweb.it/lipperatura/2013/ 05/27/il-fact-screwing-dei-negazionisti/ (testo da più siti ripreso, come in "Negare l'evidenza: il femminicidio non esiste", http://blog.iodonna.it/marinaterragni/2013/05/27/negare-levidenza-il-femminicidionon-esiste/).

${ }^{21}$ Per l'appunto, si indica l'urgenza delle raccolta omogenea dei dati in tema affinché si riconosca il reale peso del fenomeno in Pronzato L., "Violenza sulle donne, l'Onu all'Italia: 'Crimine di Stato, fate di più'", in http://27esimaora.corriere.it/articolo/la-violenza-sulledonne-e-invisibilericonoscerla-e-un-diritto-umano/.

${ }^{22}$ In Fratini E., "Femminicidio, tra false emergenze e numeri gonfiati: cronaca di una legge discriminatoria" (da http://polinice.org/2013/10/23/femminicidio-tra-falseemergenze-e-numeri-gonfiati-cronaca-di-una-legge-

discriminatoria/) si afferma, persino, che sulla scorta delle dichiarazioni rilasciate dall'allora ministro per le pari opportunità nel maggio 2013 al telegiornale di Raitre, vi sarebbe stata, rispetto all'anno precedente, una netta diminuzione di tali omicidi di donne nei mesi antecedenti all'emanazione della normativa. L'incremento percentuale comunque registrato per gli omicidi delle donne sarebbe puramente comparativo, dovuto soltanto alla flessione del numero di uomini uccisi. Precisamente, "la crescita dipende da una relazione ben nota agli studiosi, per la quale la quota di donne sul totale delle persone uccise cresce al diminuire del tasso di omicidi. Questo accade perché, mentre il tasso di omicidi dovuto alla criminalità comune e a quella organizzata è molto variabile, gli omicidi in famiglia - la categoria in cui le donne sono colpite con maggiore frequenza - è invece più stabile nel tempo e nello spazio" (Barbagli M., Colombo A. (a cura di), Rapporto sulla come non maggiori rispetto a quelli di molti altri Paesi23 (anche se - si badi - numericamente

criminalità e la sicurezza in Italia del 2010, p. 3, leggibile in una breve sintesi in http://www.interno.gov.it/mininterno/export/sites/default/ it/assets/files/21/0501_sintesi_rapporto_icsa.pdf e in http://poliziadistato.it/poliziamoderna/download/inserto_ agosto_2011.pdf). Le percentuali di distribuzione degli omicidi per anni per genere sono leggibili in Percentage of male and female homicide victims, time series 20002012, a cura dell'Ufficio delle Nazioni Unite per il controllo della droga e la prevenzione del crimine, in http://www.unodc.org/documents/gsh/data/GSH2013 Se x_time_series.xlsx, mentre, per il periodo 1992-2008, in L'omicidio volontario in Italia, Rapporto Eures-Ansa, Roma, 2009 (da cui risulta una tendenza alla flessione del numero di uccisioni di donne nell'arco degli anni 20002008, pure per le categorie residualmente presenti una volta eliminati i raggruppamenti prodotti sotto le etichette "criminalità comune" e "criminalità organizzata"). Anche in Cascioli R., "Donne uccise, ecco cosa fare", in http://www.lanuovabq.it/it/articoli-donne-ucciseecco-

cosa-fare-5495.htm, si rileva la tendenza a un decremento degli omicidi delle donne nell'arco di tutto l'ultimo decennio. Si tenga comunque sempre presente che non tutti gli omicidi di donne sono quelli culturalmente orientati di cui qui ci si occupa. Un dato di segno opposto è invece presente nell'Indagine sui femicidi in Italia realizzata sui dati della stampa nazionale e locale: anno 2013, a cura del Gruppo di lavoro sui femicidi della Casa delle donne per non subire violenza di Bologna, in http://femicidiocasadonne.files.wordpress.com/2013/04/ri cerca-femicidi-dati_2013.pdf, p. 5, da cui risulterebbe che il 2013 sarebbe stato l'anno con maggiori femminicidi, benché, tuttavia, i dati siano stati raccolti in base agli eventi riportati dalla stampa, fonte scientificamente non affidabile, quantomeno in ordine alla sua potenziale esaustività. In Sabbadini L., "Violenza di genere, discriminazione, statistiche economiche: nuove sfide nella misurazione in un'ottica di genere", in http://en.istat.it/istat/eventi/2007/globalforum/lunedipome riggio/Sabbadini\%20italiano.pdf, p. 6, si afferma, comunque, che dagli anni ' 90 in poi il numero complessivo delle donne uccise da uomini è aumentato. ${ }_{23}$ Tale dato risultava per esempio, già dai confronti temporali e spaziali contenuti nel Rapporto sulla criminalità in Italia del 2007 del Ministero dell'Interno (leggibile http://www.interno.gov.it/mininterno/export/sites/default/ it/assets/files/14/0900_rapporto_criminalita.pdf), seppure con riferimento alla categoria generica degli omicidi con donne come vittima (su dati dell'Oms) e delle violenze contro le donne (rispettivamente pp. 162 ss e pp. 132 ss.). Dati non contrastanti con le asserzioni di cui sopra (in particolar modo, con riferimento a un' "emergenza Italia”), vengono fuori da Sanmartín Esplugues J., Iborra Marmolejo I., García Esteve Y., Martínez Sánchez P., Violencia contra la mujer en las relaciones de pareja, Centro Reina Sofía para el Estudio de la Violencia, 2006 (leggibile http://www.luisvivesces.org/upload/88/18/informe.pdf), da cui si evince che nel 2006 l'Italia ha occupato il trentaquattresimo posto su quarantaquattro Paesi considerati per percentuale di donne uccise (pp. 71 ss.) e 
imponenti in senso assoluto ${ }^{24}$, oltre che gravidi di conseguenze negative, anche in termini strettamente economici $\left.{ }^{25}\right)$.

il diciottesimo su ventotto Paesi considerati per uccisioni domestiche di donne (pp. 85 ss.), registrando un decremento rispetto al 2000 del $10,62 \%$ (p. 101). D'indicazione contraria è invece quanto riportato nel Rapporto Eures sul femminicidio in Italia del 2014 (Roma), da cui si evince un aumento dal 2012 al 2013 del $14 \%$ di donne uccise (di cui più del $50 \%$ per "motivi passionali" o legati alla "litigiosità quotidiana"). Sul punto, vedasi anche, sebbene non comprenda i casi di uccisione consumata di donne (proprio in quanto il metodo di ricerca era costituito da interviste a campione a donne), Violenza contro le donne: un'indagine a livello di Unione europea a cura dell'Agenzia dell'Unione europea per i diritti fondamentali, p. 19 (leggibile in http://fra.europa.eu/sites/default/files/fra-2014-vaw-

survey-at-a-glance_it.pdf), da cui risulta che l'Italia è uno dei Paesi a percentuale più bassa di violenze subite. Ovviamente, i dati possono aver in parte subito un differente occultamento totale, e non solo giudiziario, degli eventi. Per alcune possibili spiegazioni alla base delle differenze tra i Paesi circa i risultati dell'indagine sui tassi di violenza contro le donne, si veda ivi, p. 16. Peraltro, l'estrema varietà dei comportamenti inclusi nella violenza di genere (amplius infra) porta anche a un'eccessiva semplificazione dei risultati finali, con comparazioni numeriche che sostanzialmente includono fenomeni diversi. In ogni modo, dalla ricerca è risultato, complessivamente, che circa 13 milioni di donne nell'UE hanno subito violenza fisica nel corso dei dodici mesi precedenti le interviste dell'indagine, pari corrisponde al $7 \%$ delle donne di età compresa fra i 18 e i 74 anni presenti nell'Unione europea. In merito, si veda anche Heise L., Garcia-Moreno C., "La violenza da parte del partner", in Violenza e salute nel mondo. Rapporto dell'Organizzazione Mondiale della Sanità, pubblicato in Quaderni di sanità pubblica, 2002, p. 125, leggibile anche http://whqlibdoc.who.int/publications/2002/9241545615 ita.pdf, ove si afferma che le differenze tra Paesi possono essere, almeno in parte, derivate da differenze metodologiche con cui sono raccolti i dati (le stime di abuso riferite sono estremamente sensibili alle particolari definizioni utilizzate, al modo col quale le domande sono poste, al livello di riservatezza con cui vengono condotte le interviste e alla natura della popolazione oggetto dello studio), sicché diversi studi non sarebbero direttamente confrontabili (amplius, Ellsberg M., Heise L., Pena R., Agurto S., Winkvist A., "Researching Domestic Violence. Against Women: Methodological and Ethical Considerations", in Studies in Family Planning, 2001, n. 32 , pp. 1 ss.). Inoltre, l'occultamento riguarderebbe plausibilmente in modo diverso violenze di grado differente, cosa che si rifletterebbe notevolmente anche sulla conoscenza delle violenze commesse da donne (Heise L., Garcia-Moreno C., op. ult. cit., p. 128; amplius: Johnson M. P., Ferraro K. J., "Research on Domestic Violence in the 1990s: Making Distinctions", in Journal of Marriage and the Family, 2000, n. 62, pp. 948 ss.).

${ }^{24}$ A prescindere dai margini di incertezza più volte, e per motivi diversi, denunciati sull'entità di tale fenomeno, il
Chiaramente, occorre precisare, senza alcuna ambiguità, che l'assenza di una (chiara) fase emergenziale non è interpretabile come carenza di intrinseca gravità (tanto più se il fenomeno appare qualificabile come diuturno) o di delicate specificità, cui prestare particolar conto ${ }^{26}$. Ciò, ovviamente, assolutamente evidente per il femminicidio, la massima negazione del rispetto dei diritti umani delle donne, espressione, peraltro, troppo spesso celata ${ }^{27}$. Si pensi

numero di donne uccise per le cause prese in considerazione nel nostro lavoro si aggira comunque attorno al centinaio di casi annui. Più in generale, per esempio, l'Istat ha stimato nel 2006 "in quasi 7 milioni le donne italiane tra i 16 e i 70 anni che hanno subito nel corso della vita, dentro o fuori della famiglia, una forma di violenza, fisica o sessuale; 1 milione 400 mila donne hanno subito forme di violenza sessuale prima dei 16 anni; oltre 7 milioni di donne hanno subito o subiscono violenza psicologica. Spesso, inoltre, coloro che subiscono forme di violenza psicologica sono anche vittime di violenze fisiche o sessuali" ("Violenza sulle donne", scheda leggibile in http://noiitalia2010.istat.it/fileadmin/user_upload/allegati/102.pdf). ${ }^{25}$ In merito, sui vari costi, diretti e indiretti, nonché anche non monetari e sociali legati alla violenza sulle donne, vedasi Badalassi G., Garreffa F., Vingelli G. (a cura di), "Quanto Costa il Silenzio? Indagine nazionale sui costi economici e sociali della violenza contro le donne", leggibile

in http://www.intervita.it/public/CMS/Files/616/QuantoCost aIlSilenzio_Intervita.pdf. Riassumendo brevemente solo alcuni punti, costerebbe 604,1 milioni di euro la perdita di produttività delle donne vittime di violenza; le spese sanitarie sono state stimate in 460 milioni di euro, quelle per le cure psicologiche in 158,7 milioni di euro. I costi imputabili per l'impiego delle forze dell'ordine sarebbero quantificabili in 235,7 milioni di euro, mentre quelli sostenuti dal sistema giudiziario sono stati calcolati in 421,3 milioni di euro. A 14,3 miliardi di euro ammonterebbero i "costi umani e di sofferenza". Per uno sguardo alla tradizioni di ricerche specifiche sul punto al di fuori del nostro Paese, vedasi, per esempio, Browne A., Salomon A., Bassuk S. S., "The Impact of Recent Partner Violence on Poor Women's Capacity to Maintain Work", in Violence Against Women, 1999, pp. 393 ss. Si rilevi, poi, correlativamente, come l'aver subito violenza rende il fisico maggiormente vulnerabile: Heise L., Garcia-Moreno C., La violenza da parte del partner, cit., pp. 137 ss.

${ }^{26}$ In proposito, anche se più in generale, si ricordi che la già ricordata risoluzione dell'Organizzazione mondiale della sanità del 1996 individua nella violenza (sin dal suo stesso titolo, essendo appunto titolata: Prevenzione della violenza: una priorità della sanità pubblica) un problema primario di sanità pubblica a livello mondiale.

${ }^{27}$ Anche per questo Amartya Sen (in "More than 100 million women are missing", in The New York Rewiew of 
solamente, in merito, all'intollerabile qualificazione, in numerosi Paesi, quantitativamente ${ }^{28}$, della violenza perpetuata a loro danno prevalentemente in ambito domestico $^{29}$ e familiare ${ }^{30}$, per mano di un parente o di uomo comunque 'vicino' 31 , come una niente

Books del 20 novembre 1990) lo definisce "nascosto genocidio" (ma forse sarebbe meglio dire: "genericidio" $\mathrm{o}$, ancor più, "ginocidio"). Sulla sottostima di tutte le violenze condotte su donne, cfr., ad esempio, Gracia E., "Unreported cases of domestic violence against women: towards an epidemiology of social silence, tolerance, and inhibition. The 'iceberg' of domestic violence", in The Journal of Epidemiology \& Community Health, 2004, n. 58, pp. 536 ss., nonché Romito P., Un silenzio assordante, la violenza occulta su donne e minori, Franco Angeli, Milano, 2005. La piattaforma approvata dalla IV Conferenza mondiale sulla donna dell'ONU a Pechino nel 1995 indicava, per l'appunto, come passo preliminarmente importante ai fini del suo contrasto l'emersione conoscitiva del fenomeno.

${ }^{28}$ Nell'Atto di Sindacato Ispettivo n. 1-00719 della XVI Legislatura, pubblicato il 26 novembre 2012, nella seduta del Senato della Repubblica n. 842 (leggibile in http://www.senato.it/japp/bgt/showdoc/showText?tipodoc $=$ Sindisp\&leg=16\&id=687525), così come nella mozione della seduta della Camera n. 27 del 3 giugno 2013 (leggibile

in http://documenti.camera.it/leg17/odg/assemblea/xhtml/20 13/06/03/20130603.html) si afferma che "il rapporto ombra elaborato dalla piattaforma 'Lavori in corsa: 30 anni CEDAW' presentato il 17 gennaio 2012 alla Camera, insieme alle raccomandazioni del Comitato CEDAW, riferisce che la violenza maschile sulle donne è la prima causa di morte per le donne tra i 16 anni e i 44 anni in tutta Europa e nel mondo e in Italia più che altrove. Nel nostro continente ogni giorno 7 donne vengono uccise dai propri partner o ex partner".

${ }^{29}$ Le mura domestiche rappresentano proprio il luogo dove le violenze avvengono con maggior frequenza. Per una correlazione tra tale dato e sistema culturale, Pitch T., "Violenza e controllo sociale sulle donne", in Villa R. (a cura di), La violenza interpretata, il Mulino, Bologna, 1979, pp. 147 ss.

${ }^{30}$ Amplius: Piacenti F., De Pasquali P., "Il femminicidio in Italia nel periodo 2000-2012", in Rassegna Italiana di Criminologia, 2014, n. 3, pp. 181 ss.

${ }^{31}$ Chi dunque ritenga che sia pericoloso affrontare il mondo con i suoi luoghi tortuosi e bui, e reputa che, tornato nel nido della propria casa, sia ormai (provvisoriamente) al sicuro, sappia che invece si è ficcato nel posto statisticamente più pericoloso per la propria vita e incolumità! E, soprattutto, è a contatto con le persone da cui statisticamente deve più temere! Questo, anche per la particolarità dell'habitat, ove si realizzano intensissime interrelazioni personali e, per l'appunto, per le specifiche qualità di tali relazioni. Sull'argomento, vedasi, in generale, Bandini T., Gatti U., Traverso G. B., Omicidio e controllo sociale, Franco Angeli, Milano, 1983 (ove si sottolinea come "la famiglia, nonostante le trasformazioni del mondo affatto trascurabile causa di morte o di invalidità ${ }^{32}$, in condizione di pace ${ }^{33}$.

La rilevata cronicità, inoltre, fa sì che possiamo parlare, in una qualche misura, di un problema strutturalmente grave.

Se, però, non si tratta di emergenza ${ }^{34}$, i tempi e i modi della doverosa risposta legislativa (doverosa pure dinanzi all'interpretazione estensiva fatta dalla Corte europea dei diritti dell'uomo dell'art. 8 della Convenzione europea sui diritti dell'uomo, dedicato al diritto al rispetto della vita privata e familiare, in senso non

moderno, continui ad essere un importante terreno di violenza e sopraffazione": pp. 194 ss.), Gulotta G., Famiglie e violenza, Giuffrè, Milano, 1984; Costanzo S., Famiglie di sangue, analisi dei reati in famiglia, Franco Angeli, Milano, 2003; Bagnara P., Violenza familiare: prevenzione e trattamento. Le radici nascoste dell'abuso su donne e bambini attraverso la clinica dei casi, Franco Angeli, Milano, 1999. Ci si riferisca pure ad Ansa, "In famiglia il maggior numero di omicidi", in http://www.ansa.it/sito/notizie/cronaca/2014/06/16/infamiglia-il-maggior-numero-di-omicidi_dc795116-931e4653-a116-478f7ab294c8.html. Sul tema, si veda anche Bartholini I., Violenza di prossimità, Franco Angeli, Milano, 2013. Si noti, che dal citato Rapporto sulla criminalità in Italia del 2007 del Ministero dell'Interno, p. 117 risulta, nel lasso temporale che va dal 1992 al 2006, un forte incremento dei casi propri della categoria "omicidi in famiglia e/o passioni amorose" (ma, sul punto, si legga pure De Donno A., Grattagliano I., Brunetti C., Introna F., "Gli omicidi in famiglia in Italia: un incremento reale o un incremento mediatico?", in Rivista italiana di medicina legale, 2008, n. 6, pp. 1253 ss.). Peraltro, si ricordi che il dato per cui gli omicidi "singoli" (esclusi ovviamente guerre, stermini e altre atrocità collettive) sono più frequentemente compiuti da parenti, amici o conoscenti, riguarda entrambi i generi. $\mathrm{Si}$ veda, per esempio, Gargiullo B. C., Damiani R., Vittime di un amore criminale. La violenza in famiglia: natura, profili tipologici, casistica clinica e giudiziaria, Franco Angeli, Milano, 2010.

32 Sul punto, si veda anche Heise L., Garcia-Moreno C., La violenza da parte del partner, cit., pp. $121 \mathrm{ss.}$

${ }^{33}$ Anche in guerra sono tipiche le violenze e le uccisioni di donne in quanto donne (altre, dell'altro), pure come affermazioni di impulsi già presenti liberamente esercitabili per un senso di impunità, spesso peraltro effettiva.

${ }^{34}$ Talora, quindi, i nostri legiferanti davvero rischiano di trattare approssimativamente la statistica come quella "signora compiacente la quale non nega nulla di quanto le viene richiesto" (Édouard Marie Herriot), anche per avvalorare la 'scientificità' delle loro riforme 'pregiuridiche'. 
solamente negativo ma anche positivo ${ }^{35}$ ) avrebbero dovuto, anche formalmente ${ }^{36}$, rapportarsi ai caratteri effettivi della questione.

\section{Caratteristiche del fenomeno. Profilo del} reo.

Nel calibrare conseguentemente l'intervento di legge, sarebbe stato quindi opportuno mettere anche in conto che la questione può, in qualche modo, essere intesa come tendente a una declinazione "strutturale" (nel senso che andremo di seguito a specificare), potendo aver risentito, nella sua genesi (oltre che riguardo al suo riconoscimento), di un generale cambiamento relativo ai rapporti tra $i$ generi in corso da tempo nella nostra, come in altre, società. Certo è che il mutamento della società ha fatto sì che lo stesso fenomeno della violenza nei confronti della donna passasse dall'essere "questione privata" al costituire "problema

\footnotetext{
35 Volta, cioè, a sancire un dovere attivo di salvaguardia dell'integrità psicofisica e dell'autodeterminazione dei componenti dell'ambito familiare e non solamente un obbligo di astensione da illiberali ingerenze arbitrarie: cfr., amplius, anche in ordine al combinato disposto di cui agli artt. 1 e 3 CEDU (oltre che all'art. 14), Parodi C., "La Corte di Strasburgo alle prese con la repressione penale della violenza sulle donne", in http://www.penalecontemporaneo.it/area/3-/21-/-/2291$\underline{\text { la_corte_di_strasburgo_alle_prese_con_la_repressione_p }}$ enale della violenza sulle donne/.

Esemplificativamente, ci si riferisca alla sentenza emessa dalla Corte Europea per i diritti umani nella causa n. 33401/02 (Opuz vs. Turchia) del 9 giugno 2009, ove si richiama anche la giurisprudenza in materia della Corte interamericana per i diritti umani (su cui, in particolare sulla sentenza "Campo Algodonero", può vedersi, Lorusso F., "Guerra sporca e feminicidios: storiche condanne contro il Messico", in Osservatorio America Latina del 17 dicembre 2009.

${ }^{36}$ Secondo Manente T., responsabile dell'ufficio legale dell' associazione "Differenza Donna", "per contrastare la violenza maschile nei confronti delle donne lo strumento del decreto legge non è condivisibile, data la natura strutturale e culturale del fenomeno che impone di abbandonare la logica dell'emergenza e della sicurezza" (commento riportato in "Femminicidio: che cosa trascura la legge", in http://www.avoicomunicare.it/blogpost/futuro/femminici dio-che-cosa-trascura-la-legge).
}

pubblico"37. In ogni modo, la perdita di un ruolo tradizionalmente ricoperto dall'uomo, in passato riconosciuto anche normativamente in posizione di sovradeterminazione (si pensi solo al diritto al soddisfacimento della propria sessualità in forma coatta $^{38}$ da parte del marito ${ }^{39}$, così come allo ius corrigend $i^{40}$, insito nella stessa potestà maritale ${ }^{41}$ ), con tutte le connesse modifiche giuridiche e sociali, ha da un lato consentito di qualificare come fattispecie di reato atti violenti in precedenza non reputati antigiuridici (con conseguente impennamento delle statistiche di delittuosità, derivanti anche da una accresciuta sensibilizzazione nello sporgere denuncia ${ }^{42}$ ), permettendo quindi una maggiore protezione (di quegli che ora sono pieni beni giuridici) della donna, dall'altro ha però acuito l'insicurezza e conseguentemente la 'necessità' di controllo

${ }^{37}$ Bandini T., Gatti U., Gualco B., Malfatti D., Marugo M. I., Verde A., Criminologia. Il contributo della ricerca alla conoscenza del crimine e della reazione sociale, Giuffré, Milano, 2003, vol. II, p. 557.

${ }^{38}$ Non "contro natura", però: cfr. Szegò A., "Quando lo stupro è legale: "la marital rape exemption", in Rivista italiana di diritto e procedura penale, 1995, pp. 853 ss.

${ }^{39}$ Correlativamente, si ricordi anche la causa speciale di estinzione dei delitti contro la libertà sessuale e di corruzione di minorenni di cui al vecchio art. 544 c.p. (cosiddetto "matrimonio riparatore"), abrogato solo con legge 5 agosto 1981, n. 442 (che eliminò anche la particolare mitezza sanzionatoria riservata $e x$ art. 587 c.p. al cosiddetto "delitto d'onore"). In tema, si rammenti poi anche l'art. 559 c.p., che prevedeva la punizione dell'adulterio esclusivamente compiuto dalla moglie (dichiarato incostituzionale con sentenze 19 dicembre 1968 n. 126 e 3 dicembre 1969, n. 147).

${ }^{40}$ Per cui non erano punibili le percosse date "ai fini educativi" alla moglie, giacché era riconosciuta l'applicabilità della causa di giustificazione di cui all'art. 51 c.p. (inerente all'"esercizio di un diritto o adempimento di un dovere"). Per un excursus giurisprudenziale in materia: Parmiggiani M. C., "Abuso dei mezzi di correzione e disciplina", in Cadoppi A., Canestrari S., Manna A., Papa M., Trattato di diritto penale, Utet, Milano, 2009, pp. 573 ss.

${ }^{41} \mathrm{E}$ in quella patriarcale, superata poi, relativamente ai figli, dapprima dalla "potestà genitoriale", di recente divenuta "responsabilità genitoriale".

${ }^{42} \mathrm{Si}$ tenga presente che tanto la qualità della relazione tra vittima e reo tanto la natura dei reati accorsi può tendenzialmente far nascondere quanto subito e favorire una certa riluttanza nella persecuzione del colpevole. 
(specie in forma morbosa) da parte di un certo 'maschio'43 dinanzi ad una maggiore libertà (e anche acculturazione ${ }^{44}$ ) della 'femmina'45, non più confinata in un rassicurante ruolo già dato, la quale - per rapportarci esemplificativamente a un singolo aspetto - anche quando già impegnatasi in una relazione amorosa, può lecitamente, e secondo un costume collettivamente accettato, recedere dal rapporto quando e come voglia, sicché il soggetto in procinto di rimanere solo ("abbandonato"46, "tradito", ecc.) può, più o meno consapevolmente, optare per provvedere e sopperire in forma 'personale'47 e magari più violenta a quanto gli era in passato socialmente e giuridicamente attribuito. Si ricordi, altresì, che come la violenza di genere è stata interpretata

43 Sulla violenza (globale) contro le donne come "riconquista" forzata dei "privilegi" maschili, cfr. Sofri A., "Inseguì una, perse tutte. La parabola dell'uomo che aveva cento donne", da la Repubblica del 21 novembre 2014.

44 "Quando eravamo fidanzati, il nostro era un rapporto completamente normale, non c'erano avvisi di nessun tipo di violenza, nessun legame morboso. I miei problemi erano di incompatibilità caratteriale (era molto più chiuso di me) e anche di tipo culturale: mentre io frequentavo $i$ primi anni di università, lui si occupava della ditta di uno zio, una ditta edile" (testimonianza di "Mi.", raccolta per conoscenza diretta, al di fuori del circolo delle associazione, corsivo nostro. La donna vive a Sant'Antimo, in provincia di Napoli, ha 30 anni, studia economia e commercio e lavora. È attualmente fidanzata e in procinto di sposarsi. È stata vittima di stalking da parte del suo ex fidanzato per cinque anni).

${ }^{45}$ Questa lettura permetterebbe di spiegare anche come mai proprio in Paesi in cui si registra una maggiore libertà femminile vi siano più femminicidi (sarebbero effetto di un contrasto tra "donne emancipate" e "uomini retrogradi", nell'assenza di meccanismi formali di controllo della donna).

46 Sui profondi traumi dell'abbandono da parte della persona amata (e dunque, come tale, potenzialmente fonte di ricercato riparo), Bowlby J., Attaccamento $e$ perdita, Bollati Boringieri, Torino, 1983, nonché, ancor più specifico, Id., Una base sicura, Raffaele Cortina, Milano, 1989.

47 Cfr. l'introduzione ad Aa. Vv., Amorosi assassini. Storie di violenze sulle donne, Laterza, Roma-Bari, 2008 (brano leggibile anche in http://www.laterza.it/index.php?option=com_laterza\&Ite mid=97\&task=schedalibro \&isbn=9788842085140). quale "uno dei meccanismi sociali cruciali per mezzo dei quali le donne sono costrette in una posizione subordinata rispetto agli uomini" 48 , la stessa violenza sessuale è stata letta come elemento integrante di un sistema maschile di intimidazione verso le donne (tutte) ${ }^{49}$; in questo senso, la violenza esercitata (o anche solo minacciata) rappresenterebbe la conservazione $\mathrm{O}$ la perpetuazione $e^{50}$ di un'attitudine ${ }^{51}$, di una pratica che rispecchia funzionalmente una tradizionale ${ }^{52}$ disparità di potere (volta a

${ }^{48}$ Dichiarazione sull'eliminazione della violenza contro le donne prodotta dall'Organizzazione delle Nazioni Unite il 20 dicembre 1993. Correlativamente, per Ventimiglia C., La fiducia tradita. Storie dette $e$ raccontate di partner violenti, Franco Angeli, Milano, 2000 , p. 17 , la violenza contro le donne va intesa come "una violenza da inscrivere nella relazione tra due generi in cui uno ricorre a modalità violente di esercitare il proprio ruolo all'interno di quel rapporto". Per lo stesso A., già lo stupro poteva interpretarsi psicologicamente come un "atto di conformismo": "Pensando alla violenza sessuale a partire dalla categoria della differenza", in Rivista di Sessuologia, 1989, n. 3, pp. 530 ss.

${ }^{49}$ Cfr. Brownmiller S., Against our Will: Men, Women, and Rape, Seeker \& Warburg, London, 1975.

50 "El feminicidio implica normas coercitivas, políticas expoliadoras y modos de convivencia enajenantes que, en conjunto, componen la opresión de género, y en su realización radical conducen a la eliminación material y simbólica de mujeres y al control del resto. Para que el feminicidio se lleve a cabo con el conocimiento social y no provoque la ira social, ni siquiera de la mayoría de las mujeres, requiere una complicidad y el consenso que acepte varios principios concatenados: interpretar el daño a las mujeres como si no lo fuera, tergiversar sus causas y motivos y negar sus consecuencias. Todo ello es realizado para sustraer la violencia dañina contra las mujeres de las sanciones éticas, jurídicas y judiciales que enmarcan otras formas de violencia, exonerar a quienes inflingen el daño y dejar a las mujeres sin razón, sin discurso y sin poder para desmontar esa violencia. En el feminicidio, hay voluntad, hay decisiones y hay responsabilidad social e individual" (Lagarde M., "Identidad de género y derechos humanos. La construcciòn de las humanas", leggibile in http://www.catedradh.unesco.unam.mx/SeminarioCETis/ Documentos/Doc_basicos/5_biblioteca_virtual/3_d_h_m ujeres/24.pdf).

$51 \mathrm{Si}$ richiamino, in merito, anche le disposizioni antidiscriminatorie contenute nella Convenzione interamericana sulla prevenzione, la repressione e l'eliminazione della violenza contro le donne, adottata dall'Assemblea Generale dell'Organizzazione degli Stati Americani a Belém (Brasile) nel giugno 1994.

${ }^{52}$ La violenza sulla donne come specchio di una stortura sociale e familiare si riscontra in Russell D., Radford J., 
sorreggere un'imposizione d'obbedienza ${ }^{53}$. Posto che il diritto è interpretabile pure come strumento di regolazione dei conflitti, in questa materia agirebbe, pertanto - secondo quest'ultima lettura -, per la neutralizzazione di comportamenti ascrivibili all'interno di un "conflitto di genere" 54.

In ogni modo, la costanza dei dati sotto il profilo quantitativo in ordine alla loro distribuzione temporale, assieme alle caratteristiche ricorrenti rintracciabili nella storia dei casi concreti, ci mostra, dunque, come tali episodi non possano, neppure nella più grave forma dell'omicidio, essere letti come imprevedibile eccezione né sociale né, soprattutto, individuale, cosa invece possibile per altri crimini violenti e d'impeto. Segnatamente, l'azione non appare legata ad un singolo momento in cui il responsabile è preda di un incontrollabile raptus, come comprova il fatto che si registra un'alta recidiva per il reato cosiddetto di stalking, un sostanziale continuum dei comportamenti violenti ${ }^{55}$ e una frequente escalation che dal compimento di atti persecutori arriva sino all'uccisione della vittima ${ }^{56}$. Dunque,

Femicide: The Politics of woman killing, Twayne Publishers, New York, 1992.

${ }^{53}$ Giacché - in astratto - la disubbidienza giustifica la punizione, posto un sistema distorto che riempie di contenuti impropri tali termini, proprio (l'irritazione, quasi l'offesa, per) la disobbedienza altri (che tradisce poi una mancanza di rispetto) avallerebbe [imporrebbe] una reazione (rabbiosa/violenta).

${ }^{54}$ Cfr. Lanna M., "Il Femminicidio: un 'conflitto di genere'? Un'analisi socio-giuridica", Rivista di Conflittologia,

http://www.conflittologia.it/Upload/Editoriale/201321/nu meroeditoriale.pdf.

${ }^{55}$ Sicché i singoli atti non hanno valore catartico (cfr. Steinmetz K. S., Straus M. A.(a cura di), Violence in the Family, Harper \& Row, New York, 1974), ma sono viceversa inseriti in un percorso coerente.

${ }^{56}$ Per esempio, per una testimonianza su casi concreti in cui lo stalker, spesso già incriminato per atti persecutori, si rivela anche assassino: De Luca M. N., "Stalking. L'amore fatale", da la Repubblica del 2 luglio 2010. Sul punto, si veda più ampiamente Baldry A. C., Ferraro E., la violenza agita non è generata (anche solo) da una momentanea perdita di controllo ${ }^{57}$ e anzi la presenza di segnali precedenti (e premonitori), in vario modo dati - siano essi singolarmente sanzionabili o meno - che testimoniano una certa coscienza e una singolare 'progettualità' nel voler commetter l'atto, rendono in molti casi addirittura plausibile la contestazione della predeterminazione a delinquere.

Soffermandoci ancora in relazione al profilo del soggetto attivo, appare interessante che da quanto a nostra disposizione vengano fuori dati costanti che in qualche modo contrastano con quanto si potrebbe astrattamente ipotizzare (anche in virtù di una certa rappresentazione culturale del prototipo dell'“uomo violento”). Il soggetto attivo di tali modi di agire in meno del $10 \%$ dei casi appare avere problemi psichici acclarati $^{58}$ (in coerenza al noto dato generale per cui la stragrande maggioranza di violenze nella società sono compiute da persone "sane" 59 ); parimenti, assume una rilevanza esigua l'abuso da parte sua di alcol ${ }^{60}$ o di droga ${ }^{61}$ (anche se

Uomini che uccidono. Storie, moventi e investigazioni, Centro Scientifico, Roma, 2008.

${ }^{57}$ In Robertson I., Elementi di sociologia, il Mulino, Bologna, 1995, p. 130, si menziona la critica allo stupro come desiderio sessuale impulsivo e sfrenato (essendo invece interpretabile come un rituale di potere che affonda le radici nei modelli di interazione tra i sessi socialmente approvati: si veda, per esempio, Chappel D., Geis R., Geis G., Forcible Rape: the Crime, the Victim and the Offender, Columbia University Press, New York, 1977).

58 Monacelli N., Mancini T., "Dalla violenza intrafamiliare alla violenza contro le donne", in Violenza sulle donne. I giovani come la pensano?, a cura della Commissione per la realizzazione delle pari opportunità tra uomo e donna della Regione del Veneto, in http://www.unipd.it/forumpolitichegenere/documenti/stud io_giovani.pdf, p. 40.

59 Ponti G., Merzagora Betsos I., Compendio di criminologia, Raffaello Cortina, Milano, 2008, pp. 350 ss.

${ }^{60} \mathrm{Si}$ noti, nondimeno, che nella citata indagine sulla Violenza contro le donne condotta dall'Agenzia dell'Unione europea per i diritti fondamentali è stato rilevato un nesso causale tra esperienze di violenza contro 
questo rimane comunque un fattore di rischio ${ }^{62}$, dal momento che alcuni determinati fattori, così come peraltro taluni accadimenti, possono slatentizzare la violenza, in soggetti, comunque, appunto già in nuce violenti) ${ }^{63}$.

le donne da parte del partner e abitudini in materia di consumo di alcol degli autori delle violenze, benché - in ipotesi - tale comportamento può maggiormente riguardare alcuni Paesi con un peculiare modello di consumazione di alcolici.

${ }^{61}$ Più precisamente, solo in minima parte gli uomini violenti sono patologicamente dipendenti da queste sostanze. In Piacenti F. (a cura di), Il femminicidio in Italia nell'ultimo decennio. Dimensioni, caratteristiche e profili di rischio, Eures, Roma, 2012, si rileva che oltre il $63 \%$ dei persecutori non fanno in genere uso di alcol o di droghe

62 Dall'intervista fatta a "T.", donna napoletana ventiseienne, che non ha proseguito gli studi oltre la Terza media in quanto a 16 anni è rimasta incita del suo ex marito e si è sposata. Domanda: "Quando sono iniziati i comportamenti violenti?". Risposta: "Solo il fidanzamento e l'inizio matrimonio è stato tranquillo, dal primo mese al settimo. Dopo la nascita di mio figlio è iniziato il mio inferno, poiché mio marito ha iniziato a bere e a usare sostanze stupefacenti". D.: "Qual è stata la durata dei comportamenti violenti?"; R.: "Nove anni, la durata del mio matrimonio". L'intervista è stata raccolta presso "Casa Lorena" - il cui nome è dedicato a Lorena Cultraro, la quattordicenne stuprata e assassinata nel 2008 a Niscemi, in provincia di Caltanissetta, da tre suoi coetanei -, con sede a Casal di Principe (Ce), in quella che in passato è la stata la villa di Dante Apicella, esponente del clan dei casalesi, confiscata nel 2012, gestita dalla cooperativa E.V.A., che ha progettato e realizzato servizi di prevenzione e contrasto della violenza, in particolare di quella intrafamiliare ed extrafamiliare, sostenendo le donne vittime e i loro figli minori, garantendo loro un luogo sicuro dove poter vivere lontano dalla violenza. Oltre alla gestione di centri antiviolenza e case per donne maltrattate, gestisce anche servizi per la prevenzione e il contrasto degli abusi e il maltrattamento all'infanzia. L'intervista è stata effettuata presso l'associazione "Spazio Donna onlus", attiva sul territorio di Caserta dal 1989, che si occupa, tra le altre attività svolte a favore delle donne per la loro autonomia e libertà (offre colloqui informativi, attività di consulenza e assistenza psicologica, costituzione di gruppi di autoaiuto, consulenza sociale ai fini dell'inserimento scolastico, lavorativo e nel contesto di vita sociale, consulenze ginecologica, ostetrica e pediatrica), anche del problema della violenza su di loro attraverso un apposito Centro di accoglienza per donne maltrattate sorto nel maggio 2008 nell'ambito delle attività previste dalla legge regionale 8 novembre 2000, n. 328 .

${ }^{63}$ In proposito, ci riferisca ad alcuni contenuti dello Spousal Assault Risk Assessment, strumento di valutazione del rischio di violenza tra coniugi.
Si ricava, per la qual cosa, che vi è una patologia in sé e non si ha un soggetto in una particolare condizione patologica.

Dall'insieme di casi, necessariamente variegato, risulta quasi sempre nell'ipotesi di omicidio la presenza di dinamiche ossessivo-compulsive di gelosia/possesso ${ }^{64}$ o comunque legate a un evento traumatico per l'autore del reato ${ }^{65}$. L'agente tipo è, quantitativamente, un maschio italiano $^{66}$ (quindi ben lontano da alcuni stereotipi mediatici e politici 67 , specie di qualche anno fa, che vedevano nell'immigrato il carnefice

${ }^{64}$ Casi particolari (non considerati specificamente dal provvedimento normativo) sono dati da quegli episodi di suicidio/omicidio familiare scatenati da gravi disturbi depressivi non riconducibili direttamente al rapporto di coppia, ma sulla coppia riversati (per esempio, scatenati da una condizione di disoccupazione, dalla presenza di gravi patologie di salute, eccetera).

${ }^{65}$ Casale A. M., "Il femminicidio", in Id., De Pasquali P., Lembo M. S., Profili criminali e psicopatologici del reo, Maggioli, Santarcangelo di Romagna (RN), 2014, p. 193. ${ }^{66}$ Per una specificazione territoriale, la già citata ricerca Istat del 2006 sulla Violenza sulle donne indica che "le quote più elevate di donne che hanno subito violenza fisica o sessuale da un uomo qualsiasi si rilevano nelle regioni del Nord, in alcune del Centro e, in particolare, nei centri metropolitani (42 per cento): in EmiliaRomagna e nel Lazio le vittime sono oltre il 38 per cento della popolazione femminile, in Liguria il 35,4 per cento (a fronte di un valore medio nazionale pari a 31,9 per cento)". Ivi si rinvia per la rappresentazione grafica delle differenze territoriali italiane. Solo nel 2013 si sarebbe avuto un netto incremento di casi compiuti in alcune regioni del Sud, secondo il menzionato Rapporto Eures sul femminicidio in Italia del 2014. In ogni modo, se dagli ultimi dati complessivi l'agente tipo (individuato) sarebbe rappresentato da un cittadino del Centro-Nord Italia, tuttavia la violenza contro le donne viene generalmente considerata territorialmente trasversale: Baldry A. C., "La violenza domestica: il lato oscuro della famiglia", in Barbagli M. (a cura di), Rapporto sulla criminalità in Italia, il Mulino, Bologna, 2003, p. 185.

${ }^{67}$ Una tentata strumentalizzazione (fallita) del Ministro dell'Interno Roberto Maroni per l'approvazione di norme per accelerare l'espulsione di immigrati, eludendo i dati statistici per cui la violenza è agita soprattutto da italiani e in casa è ricordata da Simone A., in "Incontro alla casa internazionale delle donne di Roma2, da Il Manifesto del 20 ottobre 2013. Sempre a proposito dell'uccisione di Giovanna Reggiani, si ricordi che Maroni aveva affermato che "se i militari fossero stati impiegati dal governo Prodi, forse la signora Reggiani a Roma non sarebbe morta" ("Sicurezza, Maroni: 'Mai più indulti e sanatorie. Con i militari la signora Reggiani non moriva", da Il Messaggero del 25 agosto 2008). 
privilegiato $\left.^{68}\right)$, del tutto trasversale socialmente ${ }^{69}$, legato alla vittima da rapporti familiari e/o affettivi $^{70}$, prevalentemente il partner (o ex $)^{71}$ della vittima $^{72}$, il quale frequentemente usa la prima

${ }^{68}$ Cfr., sul punto, Sabbadini L., Violenza di genere, discriminazione, statistiche economiche: nuove sfide nella misurazione in un'ottica di genere, cit., p. 5. In proposito, un'analoga affermazione si riscontra in $I$ femicidi in Italia, a cura del Gruppo di lavoro sui femicidi della "Casa delle donne per non subire violenza" di Bologna,

http://femicidiocasadonne.files.wordpress.com/2013/11/f emicidio-2012.pdf, p. 9.

${ }^{69}$ Sabbadini L., Violenza di genere, discriminazione, statistiche economiche: nuove sfide nella misurazione in un'ottica di genere, cit., p. 6.

${ }^{70}$ L'indagine Istat sulla sicurezza in Italia del 2013 (leggibile

http://www.istat.it/it/files/2013/03/7_Sicurezza.pdf

in

afferma, basandosi su dati in possesso alle forze dell'ordine, che, nel 2010, il 44,9 delle donne ammazzate è stato ucciso da un partner o un ex partner (il 54,1\% nel 2009 e il 38,5 nel 2002), il $23,7 \%$ da un parente e il $5,1 \%$ da un amico, mentre soltanto il $14,1 \%$ da un estraneo, percentuale che arriva al 39,5\% degli uomini, per i quali, anche in conseguenza di ciò, si registra il 44,5\% degli omicidi di cui rimane ignoto l'autore, contro solo il $17,3 \%$ degli omicidi femminili. Nel citato Rapporto sulla criminalità e la sicurezza in Italia del 2010 del Ministero dell'interno può leggersi (p. 121, in http://www.interno.gov.it/mininterno/export/sites/default/ it/assets/files/14/0900_rapporto_criminalita.pdf), a proposito dei rapporti di parentela fra autori e vittime di omicidi commessi in ambito familiare in Italia fra il 2001 e il 2006, che nel 62,9\% dei casi l'uccisore è il "coniuge, convivente, fidanzato", cui va aggiunto un 3,8\% di omicidi compiute a danno di donne da parte di un soggetto legato da "relazioni (sentimentali extraconiugali)". Per gli uomini queste percentuali sono rispettivamente del $26 \%$ e del 10,3\%. Per il citato Rapporto Eures-Ansa del 2009, nel 2008 l'omicidio in famiglia è stata la categoria in cui includere il maggior numero di casi di donne uccise in Italia, con 28 punti percentuali. Per la nostra indagine, si veda anche, per esempio, Pasinetti C., Verucci C., Urso F., Venturini M., "Donne uccise dai loro cari: indagine sul femminicidio in Italia nel 2008", in http://www.thamaia.org/documenti/ricerca_femminicidio $\frac{2009 . p d f}{71}$.

71 Tale dato pare essere confermato anche ponendo coordinate spaziali e temporali diverse. In merito, si veda Traverso G. B., Marugo M. I., "L'omicidio della donna a Genova. I risultati di una ricerca", in Rassegna di criminologia, 1984, pp. 385 ss., Russo G., "Femicidio, Studio su 82 vittime", in Archivio di medicina legale e delle assicurazioni, 1982, pp. 187 ss., nonché Wilson M., Daly M., Wright C., "Uxoricide in Canada: Demographic Risk Patterns", in Canadian Journal of Criminology, 1993, pp. 263 ss.

${ }^{72}$ I quali "risultano responsabili della quota più elevata di tutte le forme di violenza fisica" (Istat, Violenza sulle donne, cit.). arma a disposizione, spesso confessa e altrettanto spesso si uccide ${ }^{73}$.

In tutte le dinamiche violente (cui non sfugge l'ossimorico fenomeno della "violenza affettiva") fondamento dell'azione risiede principalmente nel controllo dell'altro: quanto fatto appare un modo per confermare quella che è percepita come la propria "autorità" 74 . Questo bisogno di dominio $^{75}$ va inteso, però, in modo ampio: può essere letto, propriamente, come diretto alla (ricerca della) padronanza della propria stessa vita e dunque (solo in questo senso anche) dell'altro. La violenza diviene, di conseguenza, elemento di una strategia riparativa (costitutiva) dell'identità $^{76}$ (in individui comunque emotivamente dipendenti ${ }^{77}$ ). In più, in alcuni casi, la brutalità esercitata è avvertita come replica dinanzi a una 'sorprendente' incomprensione - se non proprio ingratitudine altrui, in un soggetto convinto di aver "razionalmente" offerto se stesso nella relazione immaginata nel migliore dei modi e, pertanto,

\footnotetext{
${ }^{73}$ Per l'accadenza dell'omicidio-suicidio, si veda ancora il Rapporto Eures-Ansa del 2009.

${ }^{74} \mathrm{La}$ violenza di coppia come tentativo di affermare o confermare il proprio potere è postulata in White J. W., Kowalski R., "Male Violence towards Women: An Integrated Perspective", in Russell G. G., Donnerstein E. (a cura di), Human aggression: Theories, Research, and Implications for Social Policy, California Academic Press, San Diego, 1998, pp. 203 ss.

$75 \quad$ "Inevitabilmente, anche se passa del tempo hai paura di relazionarti con gli altri, di conoscere un'altra persona e di intraprendere una nuova relazione, perché in primo luogo pensi: 'E se anche questa persona si dovesse rivelare così?'. In secondo luogo: 'Non posso intraprendere una nuova relazione perché c'è comunque ancora in giro una persona che ha il dominio su me", (dalla già citata intervista a "Mi.", corsivo nostro).

${ }^{76} \mathrm{La}$ teoria dell'auto-atteggiamento indica nella violenza un modo di compensare un basso livello di autostima: si veda Kaplan A., "Domestic Violence and Welfare Reform”, in Welfare Information Network Issue, n. 8, pp. $1 \mathrm{ss}$.

${ }^{77}$ Cfr. Kantor G. K., Jasinski J. L., "Dynamics and risk factors in partner violence", in Jasinski J. L., Williams L. M. (a cura di), Partner violence: a comprehensive review of 20 years of research, Sage, Thousand Oaks, 1998.
} 
stupito per il rifiuto "insensato" del proprio 'amore'. Alla base vi è dunque una (distorta) "pretesa di corrispettività", come se amare, di per sé, significasse dover ricevere amore. Gli atti violenti, inoltre, sono decriptabili anche come elusione, aggiramento di un'angosciante incapacità comunicativa, fondata su una ferma diversità di genere: dinanzi all'inafferrabile $\left(\right.$ fobico $^{78}$ ) mistero della donna, alla sua irriducibilità nella categorie (di comprensione) maschili $^{79}$ soccorre la violenza che riduce il soggetto a oggetto ${ }^{80}$ e, pertanto, a cosa controllata/controllabile, "ferma, sicura, certa". Ovviamente, all'interno di una funzione di sfogo per le proprie frustrazioni riservata anche in forma violenta dal reo alla donna ${ }^{81}$, influiscono in tutto questo pure le tensioni legate alla gestione della vita in comune (comprese qui, senza alcuna tentazione di riduttività, anche le aspettative riguardanti lo svolgimento del lavoro domestico), mentre sullo sfondo si stagliano anche stati di nervosismo connessi al lavoro (o al non lavoro o al quasi-lavoro ${ }^{82}$. Anche specifiche

${ }^{78} \mathrm{Si}$ pensi che la parola deriva dal nome Febo, rappresentazione divina della paura, significativamente figlio di Ares, dio della violenza connessa alla guerra, della lotta come bramosia di sangue, e di Afrodite, dea dell'amore, della bellezza, della generazione e della fertilità.

${ }^{79} \mathrm{Di}$ comprensione limitata, poi, quando non premettono l'accettazione di quella parte femminile insita nel maschio (anima, junghianamente espressa); così come nella femmina è presente l'elemento maschile (animus). Anche alla luce di questo, Jung parla della necessità nell'individuo di una "individuazione", volta al "divieni quel che sei”.

${ }^{80}$ Cfr. Recalcati M., "La lingua straniera che non riusciamo ad imparare davvero", da la Repubblica del 22 novembre 2013.

${ }^{81}$ Quale "antagonista" formale o " vittima sacrificale": cfr. Corradi C., Sociologia della violenza. Modernità, identità, potere, Meltemi, Roma, 2009, p. 131. Ivi si propone anche una lettura della violenza come 'rimedio' alla smaterializzazione moderna dei corpi.

${ }^{82}$ In sintesi, alla base delle violenze e degli omicidi di donne vi sarebbero principalmente tre distinti ordini di moventi: passionali, legati al conflitto quotidiano o pretese di tipo economico, astrattamente compatibili o meno rispetto al cambiare della società, sono prese quale causa (o pretesto) delle proprie affermazioni violente ${ }^{83}$. Si esercita, in alcuni casi, quello che si ritiene essere un 'legittimo' potere di correzione, tanto più in relazioni che subiscono una distribuzione asimmetrica di potere ${ }^{84}$ (anche in questo senso, oltre che sul suo versante più materiale, il fenomeno disegna prevalentemente una forma di violenza "di tipo asimmetrico"), in qualche modo non del tutto, o non in tutte le sue forme, disapprovata socialmente ${ }^{85}$. Provocatoriamente, almeno in alcuni suoi prodromi, sembra

connessi all'area ampia del disagio. In merito, Casale A. M., Il femminicidio, cit., p. 196.

83 "Quando eravamo fidanzati non ha mai dimostrato questo carattere violento, era solo geloso. Tutto è iniziato subito dopo sposati, con il rinfacciarmi la mia poca partecipazione economica nel preparare il matrimonio e la poca dote che la mia famiglia mi ha dato"; Domanda: "Qual è stata la durata dei comportamenti violenti?"; Risposta: "Nove anni, la durata del matrimonio". D.: "Potresti provare a ricordare e a descrivere i sentimenti che hai provato in quei momenti?"; R.: "Mi sentivo mortificata, perché sapevo che non meritavo quel trattamento". D.: "A quali pensieri ti affidavi per andare avanti?"; R.: "La speranza che lui cambiasse, e soprattutto l'amore per mia figlia". D.: "Quale è stata la causa che ha fatto scattare in te la volontà di denunciare il suo ex marito?"; R.: "Oltre al suo solito comportamento violento, che mi danneggiava non solo fisicamente ma anche mentalmente, che non sopportavo più, iniziò ad avere pretese economiche nei confronti della mia famiglia" (testimonianza raccolta presso Casa Lorena di "S.", donna napoletana di 43 anni, madre di una bambina, la quale ha proseguito la scuola fino alla licenza media, poi con la morte del padre e susseguenti problemi economici non ha potuto continuare a studiare).

${ }^{84}$ Per una panoramica teorica sui rapporti tra squilibrio di potere nelle coppie e casi di violenza si veda Monacelli N., Mancini T., Dalla violenza intrafamiliare alla violenza contro le donne, cit., pp. 47 ss.

${ }^{85}$ Qualora invece il soggetto riconosca il disvalore sociale delle sue azioni (ed esempio evidente si ha quando alle violenze seguono richieste di perdono) possono essere messe in atto idonee tecniche (autoingannatorie) di 'smarcamento' da principi condivisi. Ci si riferisca solo all'applicabilità in alcuni casi della teorica sul "disimpegno morale" elaborata in Bandura A., Social Foundations of Thought and Action: A Social Cognitive, Prentice Hall, Englewood Cliffs, 1986. 
rientrare, così, in una "normalità"86 (per come autorappresentata) di "rapporti di genere" (quantunque la maggioranza non violenta delle relazioni - numero oscuro a parte, che per le caratteristiche del fenomeno, almeno per i casi meno efferati, si presume per nulla esiguo ${ }^{87}$ - per fortuna ci indica essere un modello comportamentale, almeno in questo grado così grave, per quanto esteso comunque minoritario $\left.{ }^{88}\right)$.

Il femminicidio, in sintesi, può essere letto tanto quale estrema forma di controllo (volontà di potenza del debole, debole proprio in quanto deve ricorrere alla violenza per affermare la propria forza e la propria centralità sulla vita dell'altro, qui letteralmente) tanto, e ancor più,

\footnotetext{
${ }^{86}$ Cfr., sul nesso profondo tra maschilità e violenza, per cui la violenza maschile contro le donne può essere letta come "la grammatica che struttura il linguaggio delle relazioni tra i generi", Magaraggia S., Cherubini D. (a cura di), Uomini contro le donne? Le radici della violenza maschile, Utet, Torino, 2013. Una "normalità", o quantomeno una percezione della stessa, è comunemente indicata anche per casi non relativi al nostro Paese, tra cui, per esempio, Dobash R. E., Dobash R. P., Cavanagh K., Lewis R., "Not an ordinary killer just an ordinary guy. Men who kill their intimate female partner", in Violence Against Women, 2004, n. 6, pp. 577 ss.

${ }^{87}$ Per alcuni riferimenti su appositi studi sul punto, Bandini T., Gatti U., Gualco B., Malfatti D., Marugo M. I., Verde A., Criminologia, cit., pp. 559 ss.

${ }^{88}$ Per questo motivo, non andrebbe assolutizzata, per tutti i possibili campi di riferimento, al di là del suo senso intrinseco, la validità della definizione della violenza di genere quale "manifestazione di un rapporto tra uomini e donne storicamente diseguali che ha condotto gli uomini a prevaricare e discriminare le donne" (accolta nelle premesse della Dichiarazione delle Nazioni Unite sull'eliminazione della violenza contro le donne del 1993): se è una dinamica pure discendente da tale storico squilibrio, da questo non discende necessariamente una dinamica violenta. Inoltre, non può leggersi una persistenza temporalmente monolitica del binomio "squilibrio culturale-violenza". Infine, non può ritenersi che la violenza agita sia soltanto effetto di una socializzazione sociale a una conforme mascolinità violenta $(o$, secondo un'ottica più circoscritta, l'unica emozione lecitamente manifestabile dall'uomo nei momenti di difficoltà: Lisak D., Hopper J., Song P., "Factors in the cycle of violence: Gender rigidity and emotional constrictions", in Journal of Traumatic Stress, 1996, pp. 721 ss.), proprio perché, altrimenti, non potrebbe spiegarsi la presenza di una maggioranza di uomini non violenti (anche in fasi difficili della loro vita).
}

come reazione alla consapevolezza della perdita di controllo dell'altro (violenza come opposizione simbolica alla propria impotenza verso l'altro). L'autore dei reati patirebbe, a seguito di un dissidio o di una separazione dall'altro, un profondo senso di inferiorità provocato dal drastico crollo dell'immagine narcisistica costruita su di sé e la difesa dall'angoscia provata sarebbe rintracciata in un'annullante aggressività mossa verso il soggetto che se ne ritiene causa ${ }^{89}$. In altri termini, tutte queste azioni annichilenti possono recare in filigrana la linea di un lacerante dissidio tra (personalissima) idealità e (oggettivissima) realtà, risolto nella maniera più negativa possibile ${ }^{90}$.

\footnotetext{
${ }^{89}$ Filetti L., "La psicologia degli uomini maltrattanti", in Casale M., De Pasquali P., Lembo M. S., Profili criminali e psicopatologici del reo, cit., p. 202.

90 Plausibilmente, il punto non è disconoscere alcuni caratteri o comportamenti come virtuosi (un esempio su tutti, la fedeltà), ma non confondere il piano della ricerca, della volizione con quello della necessarietà (altrui): continuando l'esempio, una cosa è volere accanto una donna fedele, altro ritenere la fedeltà una caratteristica delle donne tout court, altro ancora postulare la fedeltà come doverosa caratteristica della propria donna (concreta, non ideale). Il problema, dunque, da quest'ottica, è la reazione dinanzi allo scarto tra piano reale e astratto. Se si scopre l'infedeltà in una donna che si desiderava fedele (e bisogna innanzitutto comprenderne i motivi e i trascorsi), il tradimento può essere accettato pienamente o non pienamente (per esempio, chiedendo una futura fedeltà, che comunque non è mai formalmente vincolante), oppure lecitamente riprovato ripudiato ( $\mathrm{ma}$ in questo caso è comunque necessario agire in base a quello che non si può non stimare come un fatto assolutamente presente e reale). $\mathrm{Si}$ può decidere, quindi, di troncare la relazione, "annullando" il rapporto che ha tradito l'idealità prescelta, in quanto ciò risiede perfettamente nella sfera della volontà soggettivamente esercitabile, ma non si può (né eludere il fatto né tantomeno) annullare la donna, al fine di annullare il carattere fedifrago del rapporto e riequilibrare così, patologicamente, ambito ideale e dato materiale (mediante una paradossale affermazione tramite negazione della negazione). Riassumendo, in questo senso la violenza registrata prende le mosse da una lacerazione insanata tra il piano ideale vissuto e quello reale subito. Va poi detto che l'idealità risiede anche nella presentazione di se stessi: si parte, pertanto, dalla definizione della propria idealità per giungere alle conseguenze relative alla non accettazione della non
} 


\section{Previsione e prevedibilità.}

Dunque, per certi aspetti il fenomeno si manifesta come una patologia che affonda le sue radici nel contorno generale di una società che poco insegna cosa può essere una sana, paritaria e solidaristica relazione affettiva (e quali siano i

idealità, in altri termini della realtà (di per sé, necessariamente, se non altro diacronicamente, non ideale). Il problema può essere, così, quello di una definizione di una idealità distorta ma, anche alla luce di un robusto decennale processo di emancipazione $\mathrm{e}$ parificazione tra i sessi, la definizione di questa idealità, di questi valori (familiari, relazionali, eccetera) può anche esser largamente già condivisibile $\mathrm{o}$ comunque accettabile (non è detto, in altri termini, che gli atti violenti discendano da un piano ideale del tutto non condivisibile: possono essere condivisibili i valori ma non le conseguenze legate alla violazione di questi valori; nondimeno, il piano ideale distorto torna quando la legittimità delle violenze connesse a tali violazioni è ancorata essa stessa a un ambito valoriale). Ciò che non è affatto accettabile è indi la reazione violenta di fronte a quello che è percepito come un "tradimento all'ideale" (e dunque a se stessi; pure lo stesso tradimento fisico è del resto il tradimento a un'idea di sé, dell'altro e della coppia). Insomma, non possono esserci "buone ragioni" per la violenza (come si considerava in passato anche in Italia e come tuttora si considera in molti Paesi ove la differente considerazione sociale e anche giuridica della donna la avvicina concettualmente a un bambino o un animale da educare e punire più che a un essere autonomo); al più, "buone ragioni" per l'interruzione del rapporto affettivo e familiare. Affrontando la questione da un punto di vista culturale, dovremmo, dunque, distinguere i presupposti ideologici presenti nell'individuo dalle conseguenze a cui questi conducono. Non può deterministicamente pensarsi che dalla qualità dei primi discenda necessariamente un solo tipo di conseguenza. Da piano distorto ideale può derivare un atto patologico, ma questo può derivare anche da un'estremizzazione idealizzata di un piano conforme ideale (rectius: di un piano ideale in cui possono riscontrarsi dei presupposti accettabili; ovviamente, agire violentemente richiama sempre una patologia concettuale di fondo, qualunque siano gli altri valori presenti). L'esempio più lampante è rappresentato, ancora, dalla violenza messa in moto da un uomo tradito (il quale insegue quello che può essere un ideale legittimo di coppia - reciprocamente sincera e fedele -, ma in forma impropria: dovrebbe semplicemente allontanarsi da una donna che ha negato nei fatti il suo progetto astratto di coppia; la tragedia messa in campo da Otello non è riducibile all'uccisione erronea di una donna virtuosa, ma è rappresentata dall'uccisione di una donna tout court, che anche se non virtuosa non meritava, e soprattutto non poteva, essere uccisa). Egualmente, da un piano ideale distorto (ma non violato: cfr. donna "devota") non deriva necessariamente un fatto più grave rispetto a quello che accadrebbe se il piano ideale fosse conforme (se vi è coerenza tra piano e conseguenze non vi è necessità di risolvere la lacerazione; certo, una forma di violenza è già implicita: "donna forzatamente fedele"). modelli di risoluzione non violenta delle controversie e come valutare $\mathrm{i}$ rischi presenti in ogni rapporto), possibile solo se si acquisisce una valida individualità e un profondo equilibrio. [Del resto, l'individuo può descriversi come oscillante fra l'angoscia dell'abbandono e la paura della fagocitazione; tra il desiderio di una fusione con l'altro e il bisogno di individualizzazione: solo dal risolvere coniugare, contemperare - questi conflitti si formerebbe un'individualità matura. La violenza volta alla distruzione dell'altro, inoltre, si pone nell'uomo come rimedio alla propria impossibilità di creazione (in quanto comunque "superamento della vita”), per sfuggire a quella (idea di) "passività animale" cui è costretto quale punto di partenza da cui trascendere verso l'unità -; è, in tal modo, il paradosso disonorevole di un essere vivente dotato di autocoscienza].

Alla base della maggior parte dei casi, dunque, paiono esservi necessariamente profonde patologie 'non occasionali' e profondamente radicate anche in una certa 'quotidianità'. Patologie che possono pertanto essere declinate pure come di tipo relazionale ${ }^{91}$ giacché, talora, tutta una catena di eventi in questa sede rilevanti può altresì poggiare su una qualche 'anormalità' del rapporto condivisa da tutti coloro che ne fanno parte. Secondo questa lettura chiaramente operante solo per casi specifici, da individuare nel concreto - nella serie di episodi comportamentali patologico-violenti, di cui

\footnotetext{
91 Nel disegno n. 3390 presentato al Senato della Repubblica nel corso XVI Legislatura (leggibile in http://www.senato.it/leg/16/BGT/Testi/Ddlpres/00691660

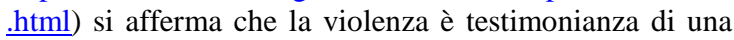
crisi di identità nelle relazioni amorose. In questo senso avrebbe "radici moderne e non è quindi frutto di arcaismi".
} 
emblema sarebbe quel che esternamente può leggersi, alquanto erroneamente, quale mero "scoppio d'ira", una qualche compartecipazione nella determinazione dei fatti spetterebbe pure, soprattutto in via indiretta, a una certa condotta, di silente sopportazione o sostanziale acquiescenza, della stessa vittima, rispetto a una dinamica tendente alla reificazione della propria persona $^{92}$.

Tutto ciò, in ogni caso, imporrebbe, allora, di ragionare in termini di prevedibilità del fenomeno trattato - e questo sia individualmente sia socialmente. Statisticamente, dunque, bisogna domandarsi se la rilevanza quantitativa del fenomeno possa indicarci per certi versi una possibilità statistica di impedimento, di decremento numerico di tali casi. Tale prevenzione sarebbe poi agibile, e a quali condizioni, sotto il profilo dei singoli casi? Le norme introdotte possono essere utili a tal fine? Invero, queste a noi paiono anzitutto dotate, in realtà, di uno scarso potere general- e specialpreventivo. In particolare, la sanzione minacciata, chiaramente elaborata nell'ottica "economico-razionale" del sistema di penalità, può essere adeguata dinanzi a un reato (distortamente) "passionale" 93 (inteso qui non

\footnotetext{
${ }^{92}$ Per incidens, si consideri che la riduzione della donna a cosa di propria pertinenza familiare, capace, per la sua non-autonomia soggettiva di fondo, di rappresentare l'uomo e la famiglia, è alla base della storia e delle persistenza delle sue uccisioni per motivi tradizionali cosiddetti d'onore (o anche dei suicidi rituali che hanno riguardato la vedova).

${ }_{93}$ Sulla cautela con cui deve essere inteso il termine (e per una critica a narrazione mediatiche superficiali e stereotipate dell'omicidio di donne), si vedano alcuni passi presentati in Bettidi L., "Femminicidio: il ruolo dell'informazione, la rivittimizzazione mediatica e la Convenzione di Istanbul", in http://www.coe.int/t/dghl/standardsetting/conventionviolence/Seminars/Rome2014/Speeches/BETTI\%20\%20RELAZIONE\%20CONFERENZA\%20ISTANBUL. pdf.
}

come di solo impeto ${ }^{94}$, e certamente non come imprevedibile ${ }^{95}$, ma quale frutto di uno stato monomaniacale $\left.{ }^{90}\right)$ ? La "programmazione" dell'evento illecito, compiuta da un soggetto certo dotato nella maggior parte dei casi di coscienza e volontà (e, quindi, penalmente sanzionabile), ma altrettanto certamente interessato da una formazione patologicomorbosa della stessa coscienza e volontà (il soggetto non appare affatto vicino a un nostro modello di equilibrio), può essere realmente intaccata in presenza di una risposta sanzionatoria (e indi di un'azione comunque ontologicamente ex post) più dura? Emblematicamente, che potere dissuasivo può avere la maggior pena ipotizzata in presenza di dinamiche illecite che assai frequentemente si concludono perfino con il suicidio del colpevole

\footnotetext{
${ }^{94}$ Per una possibile lettura di alcuni degli episodi in considerazione come effetto di un temporaneo allentamento dell'attività di controllo di un super-io altrimenti adeguato, ci si riferisca alla classificazione della "delinquenza affettiva" (e "occasionale") proposta in Alexander F., Straub H., Il delinquente, il giudice e il pubblico, Giuffrè, Milano, 1976.

${ }^{95} \mathrm{Ma}$ anzi, in una certa misura, secondo anche quanto accennato di seguito, presumibile e prevenibile. Si ricordi, comunque, già da subito, il già menzionato protocollo canadese Spousal Assault Risk Assessment, utilizzato anche in Italia. Per un'analisi sui concreti indicatori del pericolo di subire violenza o uccisione, Baldry A. C., Dai maltrattamenti all'omicidio. La valutazione del rischio di recidiva e dell'uxoricidio, Franco Angeli, Milano, 2006. In breve, Baldry A. C., "Gli strumenti di valutazione del rischio", in Karadole C., Pramstrahler A. (a cura di), Femicidio. Dati e riflessioni intorno ai delitti per violenza di genere, Centro Stampa della Regione Emilia-Romagna, Bologna, 2011, pp. 101 ss.

${ }_{96}$ Una generale criticità normativa dal punto di vista criminologico riguarda l'inasprimento sanzionatorio, se pensato con finalità puramente dissuasive, e non solo "preventive ex post" in quanto volte alla segregazione del reo, in relazione a quei reati alla cui base vi è ossessività e lo scopo imperativo degli atti illeciti è (patologicamente) elaborato dall'autore nel senso del risolvere insopprimibilmente una grave situazione di disagio. Peraltro, il soggetto può tendere a una pregressa distorsione della realtà causata dalla comparsa o dal consolidamento di inconsapevoli meccanismi percettivi, di selezione e mnemonici selettivi, volti tutti a confermarsi a un modello operativo mentale distorto.
} 
(generalmente dopo che ha compiuto l'uccisione della donna e talora anche delle persone e dei familiare a lei vicini, compresa la prole)?

Effettivamente, il Capo dello Stato, nell'emanare il decreto qui in esame, ravvisandone necessità e urgenza, ha dichiarato ${ }^{97}$ che la volontà normativa andava rintracciata nell'intenzione di "inasprire, per finalità dissuasives,8, il trattamento punitivo degli autori di tali fatti, introducendo, in determinati casi, misure di prevenzione finalizzate alla anticipata tutela» ${ }^{99}$. Rispetto ai brevi cenni fatti sul profilo criminologico del reo $^{100}$, tuttavia, ci pare che poco effetto possa produrre l'escalation sanzionatoria101 (di cui, peraltro, andrebbe valutata la sostenibilità rispetto ai criteri di proporzionalità e di ragionevolezza della pena ${ }^{102}$ ). L'anticipata tutela legislativamente ricercata - come vedremo - al più può essere intesa come tutela 'materiale' dinanzi ad altri e più gravi atti da colui che ha già articolato gesti illeciti o comunque "preoccupanti" e giuridicamente rilevanti. Nondimeno, non si tralasci che una reazione istituzionale, tanto più se messa in moto dalla vittima stessa, a volte ha un effetto immediatamente controproducente, esponendo la stessa, se non adeguatamente "messa in

\footnotetext{
${ }_{97}^{97}$ Nelle premesse dell'emanazione del decreto legge.

98 Corsivo nostro.

${ }^{99}$ Si ricordi che l'art. 45 della Convenzione del Consiglio d'Europa sulla prevenzione e la lotta contro la violenza nei confronti delle donne e la violenza domestica approvata il 7 aprile 2011, cosiddetta Convenzione di Istanbul, ratificata dal nostro Paese solo con la legge 27 giugno 2013, n. 77, indicava la necessità di fornirsi di "sanzioni efficaci, proporzionate e dissuasive".

${ }^{100} \mathrm{Su}$ cui, più ampiamente, anche per una classificazione degli autori di tali reati, Merzagora Betsos I., Uomini violenti, I partner abusanti e il loro trattamento, Raffaello Cortina, Milano, 2009.

101 In particolare, rispetto all'aumento della pena pecuniaria relativamente al reato di minacce di cui all'art. 612 c.p.

${ }^{102}$ Criteri utili anche nella stessa ottica di prevenzione dei reati.
}

sicurezza", al rischio di patire una controreazione ancor più violenta rispetto ai precedenti atti.

Inoltre, per quel che concerne l'aspetto preventivo, che forse costituisce la pietra focale su cui orientare una seria azione di contrasto, va rilevato che, se (e per la parte in cui) tale manifestazione violenta è intesa come problema culturale, abbisognerebbe probabilmente di adeguate risposte in primis su un piano culturale (ciò relativo anche alle Forze dell'ordine, agli operatori del diritto e agli stessi servizi sociali103); se è (per altri versi, pure) problema individuale (psicopatologico) relazionale, ciò rende necessario affrontare il tema del trattamento del soggetto ${ }^{104}$. Appare imprescindibile, infatti, una riflessione complessiva sulla strategia terapeutica da adottare (innanzitutto di recupero, più che meramente vendicativo-punitiva; tanto più che è certo meglio il recupero del violento non ancora - assassino, che la punizione del violento uccisore). Da questo punto di vista, va detto che non mancano esempi normativi cui prestare

\footnotetext{
$103 \mathrm{E}$, in parte, anche per una quota, quantunque minoritaria, del personale sanitario, specie di pronto soccorso (un interessante protocollo, specifico però della sola violenza sessuale, può leggersi in Bentivoglio L., Quistini M., "La violenza sessuale. L'utilità di un protocollo per l'infermiere di Pronto Soccorso", http://www.infermierionline.net/index.php?option=com content \&view=article \&id=573:la-violenza-sessualelutilita-di-un-protocollo-per-linfermiere-di-prontosoccorso\&catid=34: area-critica\&Itemid=67). Sul tema del riscontro degli effetti di una richiesta di aiuto ai vari soggetti istituzionalmente coinvolti, più approfonditamente, Danna D., "Violenza maschile contro le donne e risposte delle istituzioni pubbliche", in Studi sulla questione criminale, 2009, n. 2, pp. 25 ss.

104 Per il prefetto di Pisa, Francesco Tagliente, bisognerebbe rivolgere una maggiore attenzione al persecutore, in quanto "vero portatore di un problema comportamentale" ("Tagliente sul femminicidio. 'Strumenti giuridici insufficienti',, in http://firenze.repubblica.it/cronaca/2013/05/25/news/tagli ente_sul_femminicidio_strumenti_giuridici_insufficienti59643476/).
} 
attenzione $^{105}$. In merito, ci si riferisca solo alle previsioni normative presenti in Paesi come la Gran Bretagna e la Spagna dal 2004, da cui risulta la promozione di un percorso di recupero del condannato, in alternativa alla pena, a esclusiva facoltà del reo o su decisione del magistrato $^{106}$ Chiaramente, tale obbligo potrebbe essere letto, in una qualche misura, come una sorta di cura coatta incostituzionalmente incompatibile, a meno che non si reputi che il soggetto abbia un qualche vulnus dal punto di vista della sua piena capacità di intendere e volere (considerazione che, tuttavia, non potrebbe che spiegare conseguenze sul pieno della sua responsabilità penale. Inoltre, qualora si rilevi una qualche sua incapacità, anche attenuata, tale $\mathrm{da}$ consentire un trattamento obbligatorio, ciò non potrebbe non contrastare pure con la generale concezione culturale del soggetto violento). Tuttavia, la

${ }^{105}$ Per una panoramica sui programmi normativamente previsti verso gli autori di violenza in alcuni Paesi occidentali, si veda Bozzoli A., Mancini M., Merelli M., Ruggerini M. G., "Uomini abusanti. Prime esperienze di riflessione e intervento in Italia", 2012, pp. 20 ss., leggibile in http://lenove.org/wpcontent/uploads/2013/01/Lenove-Uomini-abusanti_20-

dic012.pdf. Ivi, pp. 85 ss., anche un quadro degli interventi rivolti ai maltrattanti in Italia.

${ }^{106}$ Come esempio d'interventi degni di interesse, anche per il coordinamento tra istituzioni diverse, ci si riferisca alla conduzione dell'attività del consultorio gestito dalla Caritas nella provincia autonoma di Bolzano dedicato agli uomini maltrattanti di concerto con la locale procura e tribunale per i minorenni, così come al contributo dato dall'ufficio dell'esecuzione penale esterna (che per l'appunto svolge il compito di favorire il reinserimento sociale delle persone che hanno subito una condanna definitiva) della provincia autonoma di Trento al centro di Rovereto e di quello milanese al carcere di Bollate (su cui, Bozzoli A., Mancini M., Merelli M., Ruggerini M. G., Uomini abusanti, cit., pp. 89 ss.). Incidentalmente, si noti la non disponibilità di intervenire su soggetti condannati per pedofilia da parte di coloro che si sono viceversa offerti nell'ambito del comune di Roma a trattare uomini violenti verso le donne (op. ult. cit., p. 140); in merito, reputiamo che se si ritiene necessario agire su elementi soggettivamente patologici, avendone le competenze, non si possono incoerentemente discriminare le situazioni per una loro diversa odiosità. questione potrebbe essere risolta ricercando una formale volontarietà della scelta terapeutica (magari per l'appunto vista come alternativa in tutto $\mathrm{o}$ in parte alla carcerazione, sia questa comminabile in via cautelare che in forma definitiva). In effetti, in un'ottica di premialità, circoscritta però alla fase cautelativa, dal provvedimento in oggetto è stato previsto ${ }^{107}$ che quando l'imputato si sottopone positivamente a un programma di prevenzione della violenza organizzato dai servizi socio-assistenziali del territorio, il responsabile del servizio ne dà comunicazione al pubblico ministero e al giudice $^{108}$ ai fini della valutazione di un'attenuazione delle esigenze cautelari ex art. 299, comma 2, c.p.p. Per inciso, va detto che più complicato apparirebbe sancire (la necessarietà di) un percorso terapeutico incentrato sulla persona offesa (o anche sulla "coppia"), benché le patologie relazionali rendono assai spesso necessario un intervento su entrambe i poli del rapporto. Chiaramente, non vanno sopravvalutati gli effetti del trattamento (tanto più quando questo è liberamente interrompibile dal soggetto violento ${ }^{109}$ ), sì che a esso si attribuisca semplicisticamente un potere

107 Mediante modifica dell'art. 282 quater, comma 1,

c.p.p. "giudice", tanto che l'Ufficio del Massimario della Cassazione, con Relazione n. III/03/2013, p. 9 (leggibile in $\quad$ http://www.cortedicassazione.it/cassazioneresources/resources/cms/documents/Relazione_III_03_20 13.pdf) ha così sintetizzato: "o si ritiene che il giudice delle indagini preliminari, ricevuta la comunicazione, debba trasmetterla al pubblico ministero (che peraltro l'ha già ricevuta) per le sue valutazioni ovvero deve concludersi che prima dell'esercizio dell'azione penale l'unico destinatario della comunicazione sia il pubblico ministero"

${ }^{109}$ In merito, Gondolf E. W., "A 30-Month Follow-Up of Court-Referred Batterers in Four Cities", in International Journal of Offender Therapy and Comparative Criminology, 2000, n. 44, pp. 111 ss. Altri riferimenti bibliografici sul punto in Heise L., Garcia-Moreno C., $\mathrm{La}$ violenza da parte del partner, cit., pp. 145 ss. 
taumaturgico. Non da ultimo, bisogna poi definire bene cosa debba intendersi per "trattamento", soprattutto per il soggetto portatore di istanze violente, al fine di evitare che possano aprirsi, anche solo sul terreno dell'astrazione intellettuale, derive - peraltro costituzionalmente incompatibili110 - che ipotizzino "forzature empatiche", 'omeopatiche', dal netto (e arcaico) sapore semplicisticocomportamentista $^{111}$, in cui il modello di essere umano prescelto appare ridursi a un coacervo di impulsi (incontrollati o controllabili), a una mera somma di spinte di segno eguale od opposto incapace di una sintesi originale - in breve, più "cosa "naturale" che "soggetto culturale" -, e ove anche la tortura (o, quantomeno, gli effetti di questa) trovi un'anomala ospitalità in un percorso formativo-terapeutico ${ }^{112}$.

\footnotetext{
${ }^{110}$ In virtù del principio di umanità delle pene $e x$ comma 3 dell'art. 27 Cost. Se il trattamento non si qualifica pena, ma cura, ai sensi dell'art. 32 Cost. abbisogna del consenso del soggetto, salvo eccezioni che egualmente subiscono, relativamente alle modalità dell'intervento, $\mathrm{i}$ limiti imposti dal rispetto della persona umana. Se poi si ritiene di superare la necessità del consenso attraverso la dichiarazione di incapacità si apre la via a un'ipotesi di non punibilità penale, come già suaccennato.

${ }^{111}$ Inevitabile qui il riferimento ad Arancia meccanica, romanzo di Anthony Burgess del 1962 trasposto in film nel 1971 da Stanley Kubrick, sui paradossi e sulle forzature della "terapia dell'avversione".

${ }^{112}$ De Gregorio C. in "Donne. Perché non succeda più", da la Repubblica del 22 novembre 2013 - articolo che pare liquidare il problema della violenza verso le donne come questione esclusivamente maschile, e includerlo nella disapprovazione di una società squilibrata per genere, che però non spiega la predominanza di non violenti e anzi ripudia la punizione dei colpevoli secondo "il principio di eccezionalità" - cita positivamente (e stigmatizza le critiche contrarie su) il lavoro condotto da una neurofisiologa spagnola esperta di realtà virtuale immersiva di concerto col locale Ministero di giustizia con il quale, grazie a un casco che agisce sugli impulsi celebrali, si fanno sperimentare agli autori di violenza sulle donne gli stessi segnali traumatici delle vittime, con risultati quali "sudorazioni, palpitazioni, pianto", non controllo dell"'atto di urinare". Ricordando che l'esperimento verrà pilotato anche nella direzionale di far sentire i rei nella condizione dei bambini che assistono alle violenze, si afferma che "uno degli scopi del lavoro è di evitare che il modello di comportamento si replichi di padre in figlio". Tuttavia, tendendo conto che, per
}

Insomma, se detti episodi appaiono di matrice assieme culturale e psicopatologica (sociopatologica) richiedono insieme adeguati interventi culturali, educativi e terapeutici.

I pochi brani delle interviste passim riportate mirano, senza alcuna pretesa di esaustività, a offrire uno sguardo concreto sulle situazioni astrattamente descritte nel testo, in particolar modo riguardo agli effetti e alla genesi di alcuni casi di violenza sulle donne, per come raccontati. Una considerazione delle condizioni reali delle vittime dei fenomeni considerati, oltre a contribuire alla formazione di un'adeguata coscienza in merito, può poi, quantomeno in via provvisoria, offrire strumenti utili per decomporre la questione reale e la conseguente azione legislativa trattata. Queste brevi testimonianze, pur nella loro frammentarietà da cui si evidenziano, secondo quanto riferito, comportamenti patologici113 innestati su "normalità di genere" (da cui scaturirebbe, generalmente, il bisogno di una necessaria educazione in proposito) - paiono dunque corroborare le tesi secondo le quali il problema trattato appare di stampo relazionale e culturale e che riguarda, almeno in parte, una sfera più larga dei soggetti generalmente normativamente considerati. Sarebbe bene, quindi, agire pure su un piano ampio, mirando a mutare la "sensibilità comune" e, non ultimo, evitando di ridurre il

l'appunto, non pochi uomini violenti sono stati a loro volta vittime dirette $o$ indirette di violenza, plausibilmente non vi è solamente la scarsa conoscenza delle sensazioni negative alla base della violenza agita; anzi, far provare una violenza potrebbe continuare a compromettere un percorso verso un pacifico equilibrio del soggetto.

${ }^{113}$ Per una panoramica sui problemi di personalità che affliggerebbero l'uomo maltrattante, Giannini M. C., "La violenza domestica e i cicli della violenza", in Mastronardi V.(a cura di), Criminologia psichiatrica forense e criminologia giudiziaria, Antonio Delfino, Roma, pp. 195 ss. 
tutto a superficiali modifiche terminologiche e interventi "a effetto". Data la profondità del problema, e le sue forti radici sociali e culturali, bisogna, in fin dei conti, fare attenzione a che l'intervento operato non si risolva solo in provvedimenti a carattere simbolico o illustrativo.

\section{Esegesi della riforma.}

Nel merito della riforma presentata, va sottolineato che il legislatore interviene non sulla fattispecie estrema dell'omicidio ${ }^{114}$, bensì su quelli che possono essere definiti "delitti spia” o anche "reati sentinella", presi in esame, pertanto, non solo per la loro intrinseca gravità ma anche in quanto segnale d'allarme di un determinato comportamento patologico che abitualmente si protrae e anzi potenzialmente degenera ${ }^{115}$. Mediante, dunque, un ripensamento normativo sui casi dei maltrattamenti in famiglia, delle minacce, degli atti persecutori, della violenza sessuale, e via dicendo - ripensamento che comprende sostanzialmente anche il diretto inasprimento della risposta istituzionale - in qualche modo si mira a prevenire l'evento più grave (agendo, quindi, in un'ottica "secondariamente preventiva", ossia in direzione della prevenzione di altri e più gravi atti). Tuttavia, in relazione a una modifica volitiva nella condotta del soggetto attivo, se utile può essere una sua sensibilizzazione della gravità della rilevanza penale - di quanto commesso (e qui gioca anche la tempestività della reazione

114 Come letteralmente poteva supporsi dalla presentazione di un testo di legge sul "femminicidio" (amplius infra).

${ }^{115}$ Proprio la stretta relazione che la cronaca registra tra precedenti atti violenti e l'ammazzamento di donne fa sì che si possa parlare in molti casi di "cronache di morti annunciate". istituzionale), non possono non avanzarsi dubbi sul potere deterrente in sé della pena maggiorata per i singoli atti, stante la già rilevata patologia soggettiva di fondo.

Più nel dettaglio, va esposto che, oltre al già ricordato aumento delle pene minime, il legislatore è intervenuto - peraltro attraverso una normazione che si è attirata pure critiche di frammentarietà e settorialità116 - con norme che sicuramente possono contribuire, almeno astrattamente, a contenere il problema ma che mostrano, alcune di loro, da subito specifiche problematicità.

Certamente interessante pare l'introduzione ${ }^{117}$ della circostanza aggravante comune ${ }^{118}$ ex art. 61, comma 1, n. 11 quinquies, della violenza assistita nei casi di maltrattamenti e delitti non colposi contro la vita e l'incolumità, sicché è maggiormente sanzionato l'atto violento compiuto in presenza di minori119 (la cui sofferenza e i pregiudizi che possono patire per aver assistito a scene, udito racconti o scorto segni di violenza ${ }^{120}$ a danno di figure significative

116 "Decreto violenza, lontani da Convenzione di Istanbul", comunicato dell'associazione "Donne in rete contro la violenza", in http://www.globalist.it/Detail News Display?ID=48231 \&typeb $=0$.

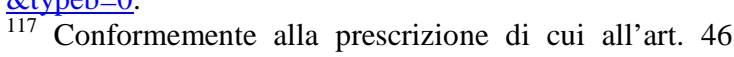
della Convenzione di Istanbul.

${ }_{118} \mathrm{O}$, meglio, "semi-comune", in quanto applicabile solo per reati definiti.

${ }_{11}$ Cfr.: Domanda: "Potresti provare a ricordare e a descrivere i sentimenti che hai provato nei momenti in cui subivi violenza?"; Risposta: “All'inizio non era odio, ero una ragazzina innamorata che non si rendeva conto di quello che stava iniziando. Ma poi quel sentimento di amore che provavo si è trasformato in odio, perché quando iniziai a capire che anche i miei figli erano diventati vittime di quei comportamenti iniziai a odiarlo. [...] I miei figli erano vittime di violenza psicologica; lui non li ha mai toccati. Ma vedere la mamma picchiata e maltrattata tutti i giorni, vedere che la mamma lavorava e il padre stava a casa, vivere tensioni in famiglia quotidianamente, li faceva vivere nella paura" (intervista a "T.", precedentemente citata).

${ }^{120}$ Tuttavia, la nuova norma ricomprenderebbe solo i casi di violenza direttamente assistita da parte di un minore in 
affettivamente e fondamentali per lo sviluppo di un loro equilibrio affettivo-relazione è stata, per motivi diversi, in passato troppo spesso occultata $\left.^{121}\right)$ e di donne in stato di gravidanza (per le quali è stata anche aggravata la condotta di coloro che compiano in loro danno violenza sessuale). Rispetto a queste ultime, tuttavia, può sorgere, concretamente e giudiziariamente, la questione sull'accertamento del loro stato di gestazione. Inoltre, si consideri che per giurisprudenza consolidata $^{122}$ la violenza $\operatorname{assistita~}^{123}$ è già stata qualificata come maltrattamento contro familiari e conviventi (già "maltrattamenti in famiglia verso fanciulli") $e x$ art. 572 c.p. Qualche altro contrasto interpretativo può venire fuori dall'estensione dell'aggravante ${ }^{124}$ soggettiva della violenza sessuale $^{125}$ compiuta dal coniuge (ivi compreso chi viva more uxorio) o da colui che è con la vittima in una "relazione affettiva" 126 ; ferma la naturale difficoltà di una formale definizione

grado di averne cognizione (e, dunque, non di un infante): sul punto, si veda la circolare n. 13/2013, a firma di Amato G., emessa dalla Procura della Repubblica presso il Tribunale di Trento, pp. 4 ss. (leggibile http://www.procuratrento.it/allegatinews/A 2549.pdf).

${ }_{121}$ Donati D., "La violenza contro le donne. Una lettura del fenomeno come discriminazione di genere", in http://www.questionegiustizia.it/articolo/la-violenzacontro-le-donne_16-12-2013.php.

${ }^{122}$ Ci si riferisca, ad esempio, alla sentenza n. 2318 del 22 novembre 2010 emessa dalla Corte di Cassazione, quinta sezione penale.

${ }^{123} \mathrm{Su}$ cui, Luberti R., Pedrocco Biancardi M. T. (a cura di), La violenza assistita intrafamiliare, Franco Angeli, Milano, 2005.

${ }^{124}$ Che ha novellato l'art. 609 ter, comma 1, n. 5.

${ }^{125}$ Aggravata anche qualora sia commessa nei confronti di persona che non ha compiuto gli anni diciotto, della quale il colpevole sia l'ascendente, il genitore, anche adottivo, il tutore, e nei confronti di donna in stato di gravidanza (comma 5 ter).

${ }^{126}$ Anche gli atti persecutori sono risultati, per effetto di una precedente riforma, aggravati dallo status di coniugio, anche se commessi da coniuge legalmente separato o divorziato (oltre che da persona che sia stata legata da relazione affettiva alla persona offesa). incontrovertibile di tale relazione ${ }^{127}$ (sicché spetterà, di volta in volta, ai singoli giudici procedenti l'onere di definirla, e circoscriverla, nei casi in esame, superando così l'oggettiva lacuna della norma), sembrerebbe avere un trattamento sanzionatorio più mite l'estraneo molestatore, con plausibili contrasti con il principio di eguaglianza ${ }^{128}$ dinanzi alla legge. In più, sembra potersi leggere una biforcazione fra la donna che subisce violenza in famiglia sotto gli occhi di eventuali minori, in stato di gravidanza o con relazione affettiva e la donna che non si trova in tali posizioni ${ }^{129}$. In un'ottica di sostanziale salvaguardia della vittima pare opportuna la previsione della comunicazione in suo favore ${ }^{130}$ della richiesta di revoca $\mathrm{O}$

${ }^{127}$ Un accenno alla difficoltà nel rinvenire in relazioni meno convenzionali la sussistenza di una relazione affettiva rilevante ai fini della consumazione del reato vi è in Rizzato E., "L. 119/13, le novità in materia di contrasto al c.d. femminicidio", in http://www.questionegiustizia.it/articolo/1_11913-lenovita-in-materiadi-contrasto-al-c_d_femminicidio_2810-2013.php.

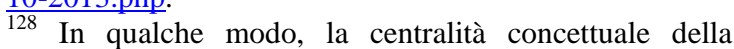
famiglia ha orientato una protezione privilegiata per le violenze familiari?

129 Peraltro, l'Associazione nazionale dei magistrati, accanto alla propria perplessità per "l'appesantimento di alcune procedure", ha criticato la previsione selettiva di aggravanti per alcuni reati (De Luca M. N., Femminicidio, critiche alla legge, cit.). Una perplessità specifica rispetto all'introduzione di una delle nuove aggravanti per il reato di atti persecutori riguarda l'attribuzione di un giudizio di maggiore gravità al fatto commesso attraverso strumenti informatici o telematici rispetto a quello commesso nelle forme tradizionali: Rizzato E., "L. 119/13, le novità in materia di contrasto al c.d. femminicidio", cit. D'altronde, la Suprema Corte, con sentenza n. 32404 del 16 luglio 2010 emessa dalla VI sezione, aveva già stabilito che integrava l'elemento materiale del delitto di atti persecutori il reiterato invio alla persona offesa di sms e di messaggi di posta elettronica o di messaggi inoltrati su social network. Nello stesso articolo si manifesta incomprensione rispetto alla disparità di competenza del reato di lesioni commesse contro il coniuge, il fratello e la sorella, il padre o la madre adottivi, o il figlio adottivo, o ai danni di un affine in linea retta (di cui all'elenco dell'art. 577, comma 2, c.p.; competente il Tribunale) o avverso il discendente e l'ascendente (secondo l'art. 577, comma 1, c.p.; competente il Giudice di Pace).

${ }^{130}$ Oltre che nei confronti dei servizi socio-assistenziali. 
sostituzione in melius delle misure cautelari applicate nei confronti di colui che ha agito in suo danno violentemente ${ }^{131}$ (sia al fine che essa possa nel concreto tutelarsi sia affinché questa, anche tramite il suo difensore, possa portare all'attenzione del giudice procedente memorie in merito $^{132}$, instaurando, così, un inedito contraddittorio) ${ }^{133}$. Onerato della notificazione appare il richiedente medesimo, a pena di inammissibilità della stessa richiesta; onere che, pervero, qualora la richiesta sia effettuata dal difensore dell'indagato, può rivelarsi nei fatti oltremodo malagevole (si pensi solo alla lenta o difficile ricerca di una parte offesa nei fatti irreperibile134), oltre che impraticabile allorquando la richiesta sia effettuata nel corso dell'udienza di convalida ${ }^{135}$. Quando poi la richiesta sia effettuata dallo stesso soggetto sottoposto alla misura, l'adempimento di quanto prescritto appare non percorribile. Qualora la revoca o sostituzione della misura sia disposta $e x$ officio, poi, sembra non sussistere tale obbligo. Si rilevi, poi, sempre in tema di possibile difesa della vittima, che l'ammonimento tramite

\footnotetext{
131 Nello specifico, la normativa parla (così come per l'ipotesi di archiviazione infra considerata), imprecisamente, di "delitti commessi con violenza alla persona", dando luogo ad ambiguità interpretative: Amato G., Circolare n. 13/2013, cit., p. 15.

132 Attività, ai sensi dell'art. 121 c.p.p., che può, comunque, compiersi appena nei due giorni successivi.

${ }^{133} \mathrm{Si}$ rilevi anche che alla persona offesa da questi reati deve essere, grazie alla riforma, sempre notificato l'atto di richiesta di archiviazione (e non solo qualora ne abbia fatto richiesta, come da regola generale). Questa adesso potrà opporsi entro venti giorni (e non dieci, come generalmente previsto). Alla stessa dovrà ora essere notificato anche l'avviso di conclusione delle indagini preliminari.

${ }^{134}$ Tuttavia, sebbene su questa non incomba un obbligo di elezione o dichiarazione di domicilio, l'assenza di una dichiarazione o elezione di domicilio esautora dalla prefata notificazione.

${ }^{135}$ L'obbligo è invece espressamente escluso nei casi di richiesta durante l'interrogatorio di garanzia.
}

questore $^{136}$ verso chi stia compiendo azioni censurabili può ora essere effettuato (già sulla scorta della previsione dell'art. 8 del d.l. 23 febbraio 2009, n. 11, convertito nella legge 23 aprile 2009, n.38, in materia di atti persecutori) anche in assenza di querela da parte della persona offesa ${ }^{137}$. Parallelamente, si ricordi la questio che ha accompagnato il percorso progettuale di riforma normativa sulla procedibilità dell'azione penale, che alcuni auspicavano d'ufficio, al fine di riparare la vittima da improprie sollecitazioni altrui o da un suo stesso immobilismo ${ }^{138}$, altri a querela di parte, opzione vista come più rispondente al rispetto della donna stessa. La questione è attinente anche allo stesso inquadramento dei beni giuridici tutelati e, come può agevolmente intravedersi, ha sullo sfondo una concezione differente del ruolo della donna, visto come individuo libero di autodeterminarsi o quale soggetto (almeno in queste dinamiche necessariamente) debole e non pienamente capace (anche perché possibilmente esposto a

\footnotetext{
${ }^{136}$ Il quale, peraltro, attualmente, a seguito della riforma, nell'ipotesi di atti persecutori adotta i provvedimenti in materia di armi e munizioni (non più "valuta l'eventuale adozione"). Inoltre, può adesso richiedere al prefetto del luogo di residenza del destinatario dell'ammonimento l'applicazione della misura della sospensione della patente di guida per un periodo di tempo che va da uno a tre mesi.

${ }^{137}$ Benché, sul punto, non si dimentichi che non sempre le procedure amministrative sono apparse efficienti proprio relativamente alla loro finalità protettiva della vittima. Un solo esempio (e non tra i più gravi): "Milano: pm Torino perseguitata e violentata da ex compagno", in http://notizie.tiscali.it/regioni/lombardia/feeds/13/12/16/t 16_02_ADN20131216135652.html?lombardia.

138 "Appena il 7,3 per cento di coloro che subiscono violenze fisiche o sessuali dal partner le denuncia; ciò è giustificato dal fatto che solamente una donna su tre le considera reati. Le quote di donne che sporgono denuncia sono inferiori alla media nazionale, non solo in tutte le regioni del Sud (a eccezione della Puglia), ma anche in alcune regioni del Nord (Piemonte 5,8 per cento ed Emilia-Romagna 5,1 per cento)" (Istat, Violenza sulle donne, cit.).
} 
indebite ingerenze) ${ }^{139}$. Tuttavia, va ricordato che la stessa Convenzione di Istanbul chiarisce che l'iniziativa per la persecuzione dei reati contro le donne non può essere riservata alle vittime ${ }^{140}$. Ovviamente, non può negarsi che la complessità di tale scelta risenta, fermamente, di una necessaria considerazione astratta della donna di riferimento, della sua distillazione in un tipo ideale in cui far confluire individui sicuramente assai diversi tra loro, pronti nella reazione e nella prevenzione o supini nell'accettazione dell'inaccettabile ${ }^{141}$. In ogni modo, l'ipotesi di prevedere una querela irrevocabile (sul modello dei casi di violenza sessuale) a fini di tutela (se l'azione non è liberamente disponibile ribadiamo - "protegge" da successive pressioni e da resistenze, anche interne, benché non lascia una responsabilità totale alla donna, sulla quale, per il suo personale momento, pesa il dubbio se sia, o possa essere, effettivamente, pienamente e continuativamente capace), anche dinanzi al rilievo per cui l'irrevocabilità assoluta avrebbe potuto paradossalmente produrre effetti antitetici rispetto alle intenzioni del legislatore ${ }^{142}$, ha ceduto il passo a un modello generale di

\footnotetext{
${ }^{139}$ Ovvero, comunque, in uno stato concreto di debolezza e pericolo: cfr. l'art. 570 c.p. relativo alle violazioni degli obblighi di assistenza familiare, ove si prevede che nei confronti di colui che malversa o dilapida i beni del coniuge si proceda di ufficio.

140 Precisamente, all'art. 55. In qualche modo, sembrerebbe dunque che la traduzione applicativa più conforme a tale indicazione sia quella consistente nella procedibilità di ufficio.

${ }^{141}$ Secondo la testimonianza di molti medici che prestano i primi soccorsi a donne con evidenti e ripetute lesioni, vi sono parecchi casi in cui queste scelgono un atteggiamento completamente o quasi omertoso. Più ampiamente, Arcidiacono C., Di Napoli I. (a cura di), Sono caduta dalle scale. I luoghi e gli attori della violenza di genere, Franco Angeli, Milano, 2012.

${ }^{142}$ Di una scoraggiante "via senza ritorno" ha parlato l'Unione delle Camere penali (De Luca M. N., "Femminicidio, critiche alla legge. Avvocati e magistrati: da ripensare", da la Repubblica dell'11 settembre 2013).
}

querela revocabile "processualmente"143 per la fattispecie base di atti persecutori, scelta "di compromesso" che apre tuttavia la strada ad alcune difficoltà interpretative (innanzitutto sulla definizione/delimitazione della "fase processuale"144). Per le ipotesi di atti persecutori commessi mediante minacce reiterate più gravi $^{145}$, tra cui quelle in cui sono stata adoperate armi, invece, la propria volontà di procedere e richiedere la punizione del reo è, invece, effettivamente irrevocabile ${ }^{146}$ (disposizione, questa, comunque non del tutto comprensibile, tenuto che per le minacce aggravate, non reiterate, che posso costituire un antecedente delle condotte supra considerate, il comma 2 dell'art. 612 c.p. dispone la procedibilità di ufficio $)^{147}$. Ancora, la previsione della pratica del braccialetto elettronico per controllare i potenziali violenti (nelle ipotesi di lesioni personali aggravate e minacce aggravate), che

${ }^{143}$ Dunque, in qualche modo "limitatamente revocabile". 144 A parere dell'Ufficio del Massimario della Cassazione, se la normativa mirava ad affidare al giudice il compito di svolgere una verifica effettiva sulla spontaneità della remissione della querela, giacché va qualificata quale remissione processuale della querela anche quella resa dinanzi alla polizia giudiziaria o mediante il proprio procuratore speciale, lo strumento introdotto non sembra particolarmente funzionale allo scopo: Relazione n. III/03/2013, cit., pp. 4 ss. La relazione ha avuto una notevole eco, commentata anche, per esempio, in "La Cassazione contro le norme sullo stalking: sbagliato il passo indietro sulla querela irrevocabile", da Il Sole 24 ore del 20 ottobre 2013.

${ }^{145}$ Nei modi di cui all'art. 612, comma 2, c.p., e all'art. 612 bis, comma 4, c.p.

146 Mentre - si ricordi - la procedibilità è d'ufficio qualora il fatto sia commesso contro un minore o una persona con disabilità ai sensi dell'art. 3 della legge 5 febbraio 1992, n. 104, nonché quando il fatto sia legato ad altro delitto per il quale si deve procedere in tal senso. ${ }^{147}$ Così come nelle ipotesi di violazione di obblighi di assistenza familiare $e x$ art. 570 c.p. e di maltrattamenti $e x$ art. 572 c.p. Altra questione deriva dall'estensione, secondo un primo orientamento giurisprudenziale, della fattispecie dello stalking ad ambiti non legati alla sfera domestico-familiare. In proposito, Diddi A., "Luci ed ombre della nuova legge sulla tutela delle vittime dei reati domestico-familiari", pp. 6 ss., relazione al citato convegno dedicato a La violenza contro le donne: dallo stalking al femminicidio. 
apparirebbe utile anche ai fini del rispetto della misura dell'allontanamento dalla casa familiare ${ }^{148}$, pare essere più un sedativo per l'opinione pubblica (una "norma-manifesto"149) che un reale rimedio da attuare, quantomeno tenuto conto che le esperienze di controllo in tal senso $^{150}$ si sono sinora risolte nel nostro Paese prevalentemente in un notevole danno all'erario, per sostanziale inutilizzo di questi strumenti assai caramente costati151. Riguardo alla previsione sorge, inoltre, una perplessità interpretativa rispetto al rinvio effettuato a norma che prevede il consenso al controllo elettronico da parte del soggetto cautelato: nel caso questi non lo presti, non paiono essere state previste idonee

148 Conformemente all'art. 52 della Convenzione di Istanbul (volta alla "priorità alla sicurezza delle vittime o delle persone in pericolo"). Sulla misura, amplius più innanzi.

${ }^{149} \mathrm{O}$ anche "norme illustrative".

${ }^{150} \mathrm{Si}$ ricordi che attualmente il servizio viene svolto (sino al 31 dicembre 2018) da Telecom Italia in virtù di una Convenzione quadro siglata dal Dipartimento della pubblica sicurezza del Ministero dell'interno in vigore dal $1^{\circ}$ gennaio 2012 .

${ }^{151}$ Sarebbero stati meno di venti reclusi coloro ai quali è stato applicato, dal 2001 alla fine del 2013, questo strumento per il controllo a distanza dei detenuti, i cui costi sono stati stimanti in oltre 120 milioni di euro (Tortorella M., "Lo scandalo del braccialetto elettronico per i detenuti", http://www.panorama.it/news/marcoventura-profeta-di-ventura/braccialetto-elettronicodetenuti-scandalo/, nonché Biloslavo F., "I braccialetti elettronici mai usati dai giudici. Sprecati più di 110 milioni”, in http://www.ilgiornale.it/news/i-braccialettielettronici-mai-usati-dai-giudici-sprecati-pi.html). Per la Corte dei Conti vi era una notevole sproporzione tra gli elevati costi e il numero veramente esiguo dei bracciali utilizzati, tanto che la gestione della misura era definita nel 2012 "una reiterata spesa anti-economica e inefficace". Si veda, in merito, anche la denuncia del sindacato di polizia COISP ("Carceri, lo scandalo dei braccialetti elettronici”, in http://www.ivg.it/2013/05/carceri-lo-scandalo-deibraccialetti-elattronici/). A proposito dell'affidamento senza gara del servizio alla Telecom, Francesco Cirillo, vice-capo della polizia, nel 2011, durante un'audizione alla commissione Giustizia del Senato, così commentò i costi derivanti: "Se fossimo andati da Bulgari avremmo speso di meno" (Bronzo E., "Svuota-carceri, i braccialetti elettronici (ora) si applicano e il costo si dimezza", da $I l$ Sole 24Ore del 23 febbraio 2014). alternative $^{152}$. Pure la determinazione dell'arresto obbligatorio in flagranza per $i$ delitti di maltrattamenti contro familiari e conviventi e di atti persecutori (pensato anche per vincere alcune resistenze culturali a procedere alla persecuzione del reo) lascia qualche perplessità, non solo perché la flagranza può essere difficile da accertare per le previsioni di cui ai reati abituali, ontologicamente fondati su una serialità di atti, per di più legati alla causazione di un perdurante turbamento emotivo, ma anche dinanzi all'emergenza carceraria che attanaglia il Paese e che ha indotto all'emissione di provvedimenti di tutt'altra direzione (innanzitutto, di decarcerizzazione). Inoltre, da tempo molti studi hanno da più parti avanzato dubbi sulla validità delle leggi relative all'arresto obbligatorio soprattutto in situazioni in cui sono presenti particolari difficoltà sociali (come disoccupazione e povertà), dove, anzi, l'applicazione del provvedimento può provocare - a differenza di quel che accade con la diffida un'impennata di violenza ${ }^{153}$. Per di più, la disposizione sarà operativa in una materia, quella dei rapporti familiari, nella quale non può escludersi possa prestarsi anche ad accuse strumentali. Si noti, inoltre, che i requisiti per l'applicazione della nuova misura precautelare dell'allontanamento dei maltrattanti ${ }^{154}$ ex art. 384

\footnotetext{
${ }^{152}$ Cfr. Relazione n. III/03/2013, p. 10.

${ }^{153}$ Cfr. Heise L., Garcia-Moreno C., La violenza da parte del partner, cit., pp. 144 ss. (ivi dettagliati riferimenti).

${ }^{154}$ Si ricordi che l'allontanamento dalla casa familiare era già previsto dall'art. 282 bis c.p.p. per le fattispecie per le quali la legge stabilisce la pena dell'ergastolo o della reclusione superiore nel massimo a tre anni, nonché era già stato esteso a molti reati inerenti alla violenza di genere, familiare o specificamente sessuale anche al di fuori di tali limiti di pena (l'elenco è comunque stato ampliato dal provvedimento in esame). La polizia giudiziaria può ora disporre la misura a carico di colui che è colto in flagranza dei reati di violazione degli obblighi di assistenza familiare, di abuso dei mezzi di
} 
bis c.p.p. (da parte della polizia giudiziaria, dietro assenso del pubblico ministero procedente e in flagranza di reati gravi, qualora sia in pericolo la vita, l'integrità fisica o psichica della vittima) sono ancora più stringenti ${ }^{155}$ di quelli richiesti per l'arresto o anche per il fermo (per i quali, per l'appunto, non è disposta l'autorizzazione preventiva del pubblico ministero, ma soltanto una successiva comunicazione da parte della polizia giudiziaria156), situazione che fornirà, pertanto, la possibilità dell'applicazione di una misura concretamente più afflittiva, invertendo il caposaldo della residualità della restrizione carceraria (o che va interpretata nel senso, però null'affatto scontato, che la misura dell'allontanamento sia residualmente adottabile solo al di fuori delle ipotesi che consentano l'arresto obbligatorio o facoltativo; quest'ultimo poi applicabile, come l'allontanamento, in base a una valutazione di pericolosità soggettiva). In relazione a detto allontanamento ${ }^{157}$, in ogni modo, bisognerà capire dove finiranno coloro che sono stati allontanati (andranno tutti ai servizi sociali?), rimarcando come debba prestarsi attenzione al fatto di non far venire meno, per indiretto effetto di un allontanamento, la loro attività economica,

correzione o di disciplina e di altri delitti di violenza, nonché nei casi di prostituzione e pornografia in danno di minori, qualora sussistono timori fondati di reiterazione delle condotte e di pericolo per le persone offese.

${ }^{155} \mathrm{Si}$ veda pure il generico riferimento ai "fondati motivi".

${ }^{156}$ In Diddi A., Luci ed ombre della nuova legge sulla tutela delle vittime dei reati domestico-familiari, cit., pp. 18 ss., si ipotizza invece un'incostituzionalità della misura precautelare, in quanto disponibile al di fuori dei limiti di necessità e urgenza di cui al comma 2 dell'art. 13 Cost.

157 È comunque opportunamente sancito il divieto da parte della polizia giudiziaria di assumere sommarie informazioni dalla persona su cui sono condotte le indagini allorché sia applicato tale provvedimento. nonostante tutto utile per la loro famiglia ${ }^{158}$, tanto più se questa stessa è stata da loro vittimizzata $^{159}$. Va poi ricordato che, in concreto, spesso si è avuto il mancato rispetto degli ordini di allontanamento ${ }^{160}$, esperienza che dovrebbe essere meglio analizzata per evitare che semplicemente si ripeta. Interessante appare prevedere un giudizio per via direttissima nei casi in cui può applicarsi tale misura, sia al fine di agire tempestivamente contro questi atti particolarmente odiosi sia, probabilmente, per evitare che il passare del tempo possa fiaccare la volontà della persona offesa, con inevitabili conseguenze, se non altro, in sede di suo esame e controesame processuale ${ }^{161}$. La disposta

158 Peraltro, un problema connesso è rappresentato dall'assenza di idonei indennizzi pubblici a beneficio di coloro che siano rimasti orfani a seguito di un suicidioomicidio che abbia riguardato $i$ genitori. Per una testimonianza in merito, De Luca M. N., "Io, orfana del femminicidio ora sogno di fare il magistrato", da la Repubblica del 21 novembre 2014.

${ }^{159} \mathrm{E}$ in questo processo può essere anche rientrata una studiata subordinazione economica. Proprio un'indipendenza economica rappresenta un elemento grazie al quale evitare a monte situazioni squilibrate potenzialmente (in maggior misura) foriere di degenerazioni anche in forma violenta. In proposito, per una disamina empirica, cfr. Levinson D., Family violence in cross-cultural perspective, Sage, Thousand Oaks, 1989. Sull'argomento, si veda anche, a testimonianza di un'attenzione istituzionale sul punto, Van Buren A.,"Lavoro e autonomia, ribellarsi è giusto", intervista alla presidente della Camera Laura Boldrini, da la Repubblica del 21 novembre 2014.

${ }^{160} \mathrm{Ci}$ si riferisca, ad esempio, ai casi riportati in Ghezzi S., "Misure di protezione contro la violenza nelle relazioni familiari. Rimedio civilistico", leggibile in http://www.apieffe.it/files/avvsabrinaghezzi.pdf, p. 15.

${ }^{161} \mathrm{Ci}$ si deve rendere conto che, processualmente, non basta che vi sia verità, occorrre che questa venga creduta tale e, pertanto, che sia convincentemente raccontata come tale. "Un processo è una specie di partita di poker in cui tutti gli attori mentono e il giudice deve saper cogliere la verità in mezzo a tanti bluff. [...] Non fanno eccezione l'imputato innocente e il testimone sincero che mentono [...] perché desiderano essere creduti e pensano che la menzogna sia più seducente della verità. La verità per essere verosimile deve essere mescolata a un po' di menzogna. [...] Un giudice quando ha un dubbio non aspetta altro che essere sedotto da una bella bugia" (Amadori G., "Francesco Caringella: 'Troppi pm si sentono divi'”, 
ammissibilità delle intercettazioni telefoniche e ambientali nel caso in cui si proceda per il delitto di atti persecutori, poi (ma questo è discorso generale, non specifico per tale previsione), dovrà realmente rapportarsi con l'estrema costosità delle stesse. Oltre a ciò, i prescritti avvisi procedurali alle parti offese rischiano di allungarne i tempi e sino a invalidare il processo stesso $^{162}$. Incidentalmente, si rifletta anche sul possibile uso strumentale di alcune norme: l'allontanamento dalla casa familiare, come già ricordato, potrebbe essere ricercato anche per altri e variegati casi, in assenza di dinamiche violente $^{163}$; così come si potrebbero avere denunce strumentali da parte di un'immigrata irregolare o 'semiregolare' ai fini di ottenere dal questore $^{164}$ il permesso speciale di soggiorno in qualità di vittima di violenza domestica ${ }^{165}$

http://www.liberoquotidiano.it/news/italia/11714703/Fran cesco-Caringella---Troppi-pm.html).

${ }^{162}$ Tra l'altro, si noti, sulle sanzioni processuali connesse al mancato rispetto di obblighi di informazione alla parte offesa, soprattutto da parte degli uffici procedenti, che la posizione della dottrina prevalente è dell'avviso che dia luogo a una mera irregolarità.

${ }^{163} \mathrm{Si}$ pensi solo alla forte conflittualità che possono esprimere entrambi i coniugi nei frangenti di una separazione e che può esprimersi anche in modi strumentalmente e gravemente calunniosi (per le diffusissime false accuse di pedofilia sporte prevalentemente dalle ex mogli: Mazzola M. A., "Separazioni conflittuali, a perdere è sempre il padre", in http://www.ilfattoquotidiano.it/2014/01/18/separazioniconflittuali-a-perdere-e-sempre-il-padre/848367/, ivi riferimenti bibliografici).

164 Il quale lo rilascia con il parere favorevole dell'autorità giudiziaria procedente ovvero su proposta di questa. L'impulso all'atto può aversi anche quando le situazioni di violenza o abuso emergono nel corso di interventi assistenziali dei centri antiviolenza, dei servizi sociali territoriali o dei servizi sociali specializzati nell' assistenza delle vittime di violenza.

${ }^{165} \mathrm{Si}$ noti, comunque, che un permesso del genere era già previsto per alcuni altri gravi reati. Il legislatore precisa, in ogni modo, che si intendono per "violenza domestica" uno o più atti, gravi o non episodici di violenza fisica, sessuale, psicologica o economica che si verificano all'interno della famiglia o del nucleo familiare o tra persone legate, attualmente o in passato, da un vincolo di matrimonio o da una relazione affettiva, indipendentemente dal fatto che l'autore di tali atti condivida o abbia condiviso la stessa residenza con la (benché - va detto - la sua condizione di non regolarità può spesso costituire un punto di forza e pressione della relazione violenta instaurata dall'uomo ${ }^{166}$ ). Ovviamente, presentare tali ipotesi distorsive non deve indurre a preferire un'assenza di tutela, per di più specifica, ma mira solo a invitare a essere doverosamente cauti nell'applicazione delle misure introdotte. Di converso, va detto che per procedere alla tutela dell'incolumità dello straniero sono richiesti requisiti maggiori rispetto a quelli necessari per proteggere il cittadino italiano, situazione che si profila evidentemente contrastante con la nostra Carta costituzionale ${ }^{167}$ e con tutta la normativa internazionale in tema di diritti dell'uomo.

\section{Risorse effettive e semplificazioni astratte.}

In ogni caso, un problema appare centrale, quello della carenza di fondi idonei, tanto per le Forze dell'ordine che dovranno costantemente e laboriosamente reprimere azioni disvolute ${ }^{168}$, quanto (nonostante vi siano finanziamenti programmati) per le case accoglienza ${ }^{169}$, che in

vittima. Si noti - e tale osservazione vale anche per il procedimento di ammonimento spettante al questore - la plausibile difficoltà pratica di chiarire ciò che debba effettivamente rientrare o no nei casi di "gravità" e "non episodicità".

${ }^{166}$ Tanto più se questo è italiano o comunque regolarmente residente sul territorio.

167 Sul punto, più ampiamente, Lo Monte E., "Repetita (non) iuvant: una riflessione 'a caldo' sulle disposizioni penali di cui al recente d.1. n. 93/13, con. in 1. n. 119/13, in tema di 'femminicidio",, in http://www.penalecontemporaneo.it/upload/1386696023 LOMONTE2013.pdf, p. 16.

${ }^{168}$ Invece, sul versante delle azioni virtuose messe in campo, ci si riferisca all'adozione del protocollo E.V.A. ("Esame delle Violenze Agite") da parte dell'Ufficio prevenzione generale della Questura di Napoli.

${ }_{169}$ Attualmente, i centri anti-violenza conterebbero circa 500 posti letto complessivi a fronte dei 5.700 previsti dalle direttive europee (dato riportato nell'interrogazione alla Camera dei deputati del 25 giugno 2013 concernente la prevenzione della violenza posta in essere nei confronti delle donne). 
molti casi dovranno accogliere le vittime ${ }^{170}$ (essendo peraltro prescritto l'obbligatorio interessamento dei servizi sociali) o, più in generale, per tutti quei soggetti e strutture atti ad accompagnare materialmente le donne nel loro percorso di emancipazione dalla violenza. Si noti, in proposito, che il soggetto ammonito del questore (e ciò tanto più utile qualora abbia già compiuto atti di una certa violenza) deve essere edotto sulla presenza di centri di recupero e servizi sociali territorialmente competenti. La carenza di strutture e operatori idonei non può che indebolire l"“anticipata tutela" di cui appunto parla il legislatore. Inoltre, operativamente, bisogna insistere su un coordinamento più tempestivo rispetto al passato tra operatori del sistema penale ${ }^{171}$ ed effettiva funzionalità della macchina della giustizia ${ }^{172}$. Il problema finanziario, del resto, riguarda pure la stessa vittima di reato ed è reso più acuto anche a fronte della revocabilità condizionata della denunzia nei casi indicati; problema che non può essere risolto solo ampliando l'ammissibilità del

\footnotetext{
${ }^{170}$ Ci si rammenti del caso del centro antiviolenza in provincia di Caserta, Nidorosa, sorto sul territorio di Casagiove nel 1988, fino a pochi anni fa a lungo unica struttura con uno spazio di ospitalità per donne vittime di violenza, sole o con figli, in tutto il Meridione (sino a Roma).

${ }^{171}$ In questo senso, è stato comunque stabilito, mediante riforma dell'art. 132 bis disp. att. c.p.p., di attribuire una priorità nella formazione dei ruoli di udienza anche ai delitti di maltrattamenti in famiglia, atti persecutori e violenza sessuale. Al di là che la giustizia dovrebbe essere celere verso tutte le situazioni poste sotto la sua lente, la disposizione appare comunque utile, soprattutto in senso specialpreventivo, per i comportamenti che configurino ipotesi di reato e possano essere un prodromo di comportamenti criminosi ancor più gravi. È stato altresì stabilito, allo stesso fine, il limite della durata di un anno per le indagini preliminari concernenti i reati di maltrattamenti e atti persecutori, indicazione che tuttavia può essere astrattamente controproducente, per l'inutilizzabilità degli atti d'indagine, sulla scorta dell'art. 407, comma 3, c.p.p., prodotti dopo detto termine.

${ }^{172} \mathrm{Ma}$ "si sa che la giustizia si amministra con una logica, e un'etica, vicine parenti dell'arrangiarsi delle caserme"... (Salvatore Mannuzzu, Procedura).
}

gratuito patrocinio per la persona offesa al di fuori dei generali limiti reddituali (cosa, comunque, che si presta a critiche per sperequazione), ma andrebbe affrontato anche mediante un adeguato sostegno al fine dello svolgimento di attività lavorative o con la concedibilità di aspettative previdenziali per motivi gravi. Tutto ciò, però, non pare essere stato considerato né si intravede una sua possibile riconsiderazione, tanto più nell'attuale fase, sempre più proclamata, di sofferenza lavorativa e pericoli di dissesto previdenziale gravanti sul Paese.

In definitiva, alla luce di quanto visto, si invita a rivalutare se sia proprio l'utilizzo del piano penale e se questo, anche per come modificato, possa essere funzionale e attuabile nel nostro quadro generale (e se non sia forse il caso di valorizzare l'intervento di tutte le agenzie di controllo presenti, anche di quelle informali) ${ }^{173}$. È poi necessario chiedersi, adesso, se vi era proprio la necessità dell'introduzione di nuove norme, in un sistema già disorganicamente proliferato (che vede regimi differenziati nell'ambito di materie omogenee ${ }^{174}$ ) o se, invece o in contemporanea, non ci si fosse dovuti concentrare sull'utilizzo di quelle esistenti ${ }^{175}$. Ci si riferisca, per esempio, alla poco praticata previsione di cui alla legge 4 aprile 2001 n. 154 (non a caso titolata «Misure contro la violenza nelle relazioni familiari») sugli ordini di

173 A un anno dall'approvazione del nuovo testo normativo, in uno speciale de la Repubblica del 21 novembre 2014, può leggersi (p. 34): "Il 25 novembre è la giornata contro la violenza sulle donne: non servono leggi" (corsivo nostro).

${ }^{174}$ Diddi A., Luci ed ombre della nuova legge sulla tutela delle vittime dei reati domestico-familiari, cit., p. 28.

175 In merito, poi, si poteva forse anche valorizzare l'aggravante dei motivi abietti o futili o quella di aver sfruttato circostanze atte a ostacolare la difesa. 
protezione su piano civile ${ }^{176}$, emessi ai sensi degli articoli, appositamente introdotti, 342 bis e ter c.c. (oltre che, sotto il profilo procedurale, secondo il dettato dell'art. 736 bis c.p.c.), che si affianca e non è residuale rispetto a un'eventuale azione penale ${ }^{177}$, anche perseguibile d'ufficio ${ }^{178}$, intendendo portare alla luce e tutelare (mediante, ad esempio, l'ordine, da parte del giudice civile, di cessazione di condotta antigiuridica di un coniuge, la prescrizione dell'allontanamento dalla casa a carico dell'autore delle violenze e il divieto di avvicinamento ai luoghi frequentati dalle persone offese, dai prossimi congiunti, dai loro conviventi, da coloro che sono legati a essi da una relazione affettiva, nonché di loro contatto, con qualsiasi modalità ${ }^{179}$, oltre che attraverso l'ordine di pagamento di un assegno periodico in favore delle persone conviventi che per effetto del provvedimento rimangano sprovviste di mezzi di sostentamento adeguati, eventualmente con obbligo di versamento diretto al datore di lavoro ${ }^{180}$ situazioni che per motivi e timori vari

\footnotetext{
${ }^{176}$ Su cui, Aa. Vv., Stalking e violenza sulle donne. Le risposte dell'ordinamento, gli ordini di protezione, Franco Angeli, Milano, 2009.

${ }^{177}$ La sanzione penale scatta poi, ai sensi dell'art. 6 della legge, qualora si eluda l'ordine di protezione previsto dall'art. 342 ter c.c. ovvero non si rispetti un provvedimento di eguale contenuto assunto nel procedimento di separazione personale dei coniugi o nel procedimento di scioglimento o di cessazione degli effetti civili del matrimonio.

${ }^{178}$ Ciò, ai sensi della novellazione di cui all'art. 1 della legge 6 novembre 2003, n. 304.

${ }_{179}$ Analoghe misure sono anche previste dal magistrato sul piano penale per l'imputato, ai sensi degli introdotti artt. 283 bis e 291 bis, comma 2, c.p.p. Si ricordi, comunque, che già precedentemente all'introduzione della normativa si faceva in questi casi ricorso alla misure coercitive del divieto e dell'obbligo di dimora $e x$ art. 283 c.p.p. a tutela di esigenze analoghe (Figone A., Commento alla legge 154/2001, in Famiglia e diritto, 2001, n. 4, p. 356).

${ }^{180}$ Gli ordini di questo tipo, tuttavia, sono risultati poco efficaci nei casi in cui il soggetto violento risultava già pregiudicato per gravi reati: Cfr. Keilitz S. L., Davis C., Efkeman H. S., Flango C., Hannaford P. L., "Civil Protection Orders: Victims' Views on Effectiveness", in National Institute of Justice Washington, gennaio 1998
}

potevano restare in ombra e magari non erano sempre idoneamente affrontabili attraverso l'istituto della separazione personale dei coniugi $^{181}$ (tanto più nelle ipotesi di convivenza) o anche, per l'appunto, mediante lo strumento 'squisitamente' penale, ma che è rimasto sostanzialmente inapplicato per carenza di organico oltre che per la nota lentezza della nostra macchina della giustizia. Dunque, il problema in materia era dato soltanto dall'assenza di strumenti per intervenire efficacemente o (come affermato anche dall'Onu e da associazioni varie, su piano internazionale e nazionale ${ }^{182}$ ), pure da un'inadeguata applicazione delle misure esistenti? Se le norme non sono prodotte per essere del tutto applicate nel concreto, in ipotesi di violazione reale, il diritto penale resta inteso per finalità meramente di dissuasione, all'interno, peraltro, di una declinazione impropria del processo penale quale puro strumento di controllo sociale.

(sunto leggibile in https://www.ncjrs.gov/pdffiles/fs000191.pdf) e Littel K. M. A. (a cura di), Assessing the Justice System Response to Violence Against Women. A Tool for CommunityBased Victim Service. Programs Developing Effective Responses, Pennsylvania Coalition Against Domestic Violence, Pennsylvania, 1998 (leggibile in https://www.ncjrs.gov/pdffiles1/Archive/221760NCJRS. pdf).

${ }^{\frac{\mathrm{pd}}{181}}$ Sul punto, si veda anche Conforti R., "Misure contro la violenza nelle relazioni familiari: la legge 154/2001", in http://www.overlex.com/leggiarticolo.asp? $i d=1580$.

${ }^{182} \mathrm{Nel}$ già menzionato rapporto di Rashida Manjoo può per l'appunto leggersi che, nonostante il quadro giuridico fornisca sufficiente protezione alle vittime, "l'estrema lungaggine delle procedure penali, il mancato rispetto delle misure di protezione civile, delle sanzioni pecuniarie e la detenzione inadeguata contro gli autori indebolisce la natura protettiva di tale misura. [...] Inoltre, la mancanza di coordinamento tra giudici dei rami civile, penale e minorile, durante la gestione di misure di protezione, fa sì che possono emettersi sentenze contrastanti" (leggibile anche in Violenza su donne, rapporto Nazioni Unite. "In Italia buone leggi, ma poca protezione", da la Repubblica del 9 ottobre 2013). 


\section{Le "questioni culturali" sottese alla genesi} e al mancato contrasto della violenza sulle donne.

In ogni modo, dopo l'approvazione della normativa in esame, stando a quanto riportato ${ }^{183}$, non possiamo registrare una diminuzione di siffatti omicidi, dai dati viceversa decisamente costanti.

Tornando adesso a una riconsiderazione culturale della questione, va ricordato che la Convenzione di Istanbul, che si muove in modo ampio sul fenomeno della 'tutela' delle donne, affermando all'art. 17 che "le parti incoraggiano il settore privato, il settore delle tecnologie dell'informazione e della comunicazione e i mass media, nel rispetto della loro indipendenza e libertà di espressione, a partecipare all'elaborazione e all'attuazione di politiche e alla definizione di linee guida e di norme di autoregolazione per prevenire la violenza contro le donne e rafforzare il rispetto della loro dignità", evidentemente ravvisa e sottolinea l'aspetto culturale sotteso al problema ${ }^{184}$,

183 "Alfano: nel 2014 omicidi in calo, ma non i femminicidi”,

http://www.corriere.it/cronache/14 marzo 08/alfano2014-omicidi-calo-ma-non-femminicidi-0ccf1a54-a6e311e3-bbe4-676bb1ea55e1.shtml.

${ }^{184}$ In tema, si rilevi pure che la citata Dichiarazione sull'eliminazione della violenza contro le donne prodotta dall'Organizzazione delle Nazioni Unite il 20 dicembre 1993 riconosce "che la violenza contro le donne è una manifestazione delle relazioni di potere storicamente disuguali tra uomini e donne, che ha portato alla dominazione e alla discriminazione contro le donne da parte degli uomini e ha impedito il pieno avanzamento delle donne". Nello studio approfondito del Segretario generale su tutte le forme di violenza contro le donne presentato all'Assemblea generale delle Nazioni Unite il 9 ottobre 2006 si è poi così affermato: "Evidence gathered by researchers of the pervasive nature and multiple forms of violence against women, together with advocacy campaigns, led to the recognition that violence against women was global, systemic and rooted in power imbalances and structural inequality between men and women. The identification of the link between violence against women and discrimination was key" (http://daccess-dds- innanzitutto in ordine alla sua potenziale producibilità e riproducibilità da parte degli strumenti attraverso cui avvengono odiernamente i quotidiani processi di mediazione simbolica nelle nostre comunità.

A tale proposito, se pure va, ovviamente, distinta e rinvenuta una profonda "fisicità" nei comportamenti violenti messi in atto, sicché potrebbe supporsi che questi siano mere degenerazioni di atti biologici o una nociva esasperazione di spinte (distortamente) naturali, è bene premettere come $\mathrm{i}$ diversi piani in esame siano assolutamente intrecciati, essendo chiaramente di stampo biologico-naturale gli impulsi, culturali (sociali) le forme. I 'sentimenti' non si formano solo a partire da un dato biologico naturale, ma si conformano ai modelli culturali dati da una determinata società. Chiaramente, vi è un'estrema delicatezza nella determinazione di cosa (approssimativamente) può essere inteso come "naturale" (si pensi solo alla definizione tradizionale di alcuni comportamenti sessuali ampiamente praticati al giorno d'oggi come atti "contro natura", giacché volti esclusivamente a dare piacere, non potendo avere alcuna valenza riproduttiva; così come ci si riferisca al periodico aggiornamento del Manuale diagnostico e statistico dedicato ai disturbi mentali, ivi comprese le patologie sessuali, curato dall'American Psychiatric Association, ove appare arduo riscontrare un criterio 'oggettivo' per identificare i modi di agire "insani", spessi ritenuti tali in base a un ipotetico disagio soggettivo o a eventuali ripercussioni relazionali), tenuto anche conto che le forme sociali possono

ny.un.org/doc/UNDOC/GEN/N06/419/74/PDF/N064197 4.pdf?OpenElement, p. 14). 
influire su comportamenti percepiti come 'naturali'.

A questo punto, in ogni caso, non possiamo non rilevare i limiti dati dall'affrontare un problema culturale esclusivamente su un piano normativo, specie di stampo puramente repressivo-cautelare penale, che in qualche modo in prevalenza agisce necessariamente a valle del fenomeno considerato (benché - sia chiaro - lo ius non è solo la pura registrazione del già dato, ma ontologicamente mira anche a modificare la res...: non a caso, nel provvedimento si riscontra la previsione di stanziamenti per un "piano antiviolenza", precisamente titolato "piano d'azione straordinario contro la violenza sessuale e di genere, elaborato dal Ministero per le pari opportunità, destinato ad azioni di prevenzione, educazione e formazione; tuttavia la nominata "straordinarietà" dell'azione, nonché una certa genericità dei suoi contenuti, lo espongono a sicure critiche). In ogni modo, la questione della violenza maschile contro le donne è stata letta come esempio eloquente dell'ineffettività delle norme, della distanza oggettiva intercorrente fra legge penale e sua implementazione ${ }^{185}$.

Il problema, inoltre, anche quando culturalmente declinato, è apparso in larga misura inteso come relativo al solo soggetto violento, o al più a una generica o generale categoria data da un'indistinta soggettività violenta veteromaschilista - mentre sembra attenere a un insieme più ampio di referenti, ivi compresi quelli che sostanzialmente o apparentemente si ritrovano in una posizione formalmente antitetica rispetto a quella del reo.

185 Graziosi M., "Femminicidio: i rischi delle leggimanifesto", in Studi sulla questione criminale, 2013, n. 2, p. 7.
In particolare, a fronte di rilevamenti presenti sul punto $^{186}$, sembra esservi una questione culturale da risolvere all'interno delle stesse forze istituzionali di contrasto (chiaramente, di alcune specifiche ed eventuali parti di esse), testimoniata anche dalla registrazione di spinte alla dissuasione dalla denuncia della vittima da parte di alcuni esponenti delle Forze dell'ordine, a causa di un certo diffuso 'giustificazionismo' o di un'apparente 'vittimizzazione' del reo percepita come reale ${ }^{187}$ (mero frutto di un vetusto stereotipo concettuale e diretta, conseguentemente, a una vittimizzazione secondaria delle donne ${ }^{188}$ ), nonché, quantomeno

${ }^{186} \mathrm{Si}$ veda, per esempio, quanto riportato in Eduati L., "Femminicidi? Aiutiamo i poliziotti e i mariti violenti", in http://www.huffingtonpost.it/2013/08/24/femminicidiaiutiamo-i-poliziotti-e-i-mariti-violenti- n 3808879.html. 187 "Allora uno inizia a pensare a come sopravvivere, perché si sopravvive non si vive. Diciamo che non è facile, perché anche se chiami i carabinieri non vengono nell'immediatezza e non raccolgono la tua denuncia, specie alle 20 o 21 di sera, allora ti senti indifesa. [...] Non avevo pensieri, non riuscivo neanche a vedere il giorno dopo. Se io dovevo in quel periodo pensare al giorno o alla settimana successivi non riuscivo a farlo. I miei pensieri erano rivolti a cosa fare, a dove andare e a quale strada fare per evitarlo. [...]. La prima sentenza è arrivata dopo dodici o tredici denunce. Non mi sono neanche rivolta ai carabinieri del mio paese perché ritenevano che non fosse una cosa grave: più volte mi hanno invitato a sorvolare perché erano per loro atteggiamenti di un innamorato deluso, una persona innocua, senza considerare che queste persone hanno una doppia personalità. Queste persone hanno la capacità di non solo farti del male ma di passare anche da vittima; hanno la capacità di essere così bravi a nascondere quello che stanno facendo e di fare passare te per carnefice. Non mi sono più rivolta ai carabinieri del mio paese ma a quelli del paese vicino. Comunque, quando succedeva qualcosa, io chiamavo i carabinieri ma, appena stavano arrivando, scappava. Non poteva essere arrestato se non veniva colto in flagranza di reato. L'episodio che ha fatto scattare l'arresto è accaduto quando lavoravo al comune. Scesi e mi accorsi che lui era appostato, cercavo di andare in un negozio o in un bar per evitarlo, ma lui sempre dietro. Ricordo che a un certo punto salì sul marciapiede con la macchina per investimi o per bloccarmi. Dopo quella denuncia con testimoni scattò l'arresto. Ci sono state delle mozioni di allontanamento ma non sono mai state rispettate" (testimonianza di "Mi.").

${ }^{188} \mathrm{Si}$ ricordi che molti studi iniziali sul fenomeno della violenza contro le donne mettevano tradizionalmente in luce un comportamento patologico dell'uomo, tuttavia 
in passato, da una sovente assenza di interventi tempestivi, anche di sostegno, nonostante una pregressa denunzia. Ciò, peraltro, in luce con una documentata disincentivazione alla proposizione di un'azione repressiva su cui si sono appuntati studi classici in tema di violenza coniugale $^{189}$. Nell'ottica di quanto riportato - che certo indica la necessità di lavorare maggiormente sul versante di una loro formazione - viene da chiedersi se serva davvero aumentare $\mathrm{i}$ poteri delle polizie, in assenza di detti interventi culturalmente mirati. Inoltre, anche alcune procure sono state accusate di archiviare troppo spesso i casi segnalati alla loro attenzione, non distinguendo adeguatamente fisiologici conflitti di coppia e violenze familiari vere e proprie e propendendo sovente a rinviare i casi di violenza alla mediazione familiare, con conseguente, anche in questo caso, secondaria vittimizzazione della donna ${ }^{190}$.

Non ultimo, va tenuto in considerazione che un problema di tipo culturale può esistere anche nelle stesse vittime, cosa che rende ipotizzabile una riflessione sul modello di individuo e di rapporto affettivo che alcune tra le donne stesse abbiano potuto assimilare e rielaborare ${ }^{191}$. 亡̀

potenzialmente scatenato da alcune caratteristiche o comportamenti della donna stessa, tra cui Snell J. E., Rosenwald R. J., Robey A., "The Wifebeater's Wife: A Study of Family Interaction", in Archives of General Psychiatry, 1964, n. 11, pp. 107 ss.

${ }_{189}$ Gelles R. J., "Domestic Criminal Violence", in Wolfgang M. E., Weiner N. A. (a cura di), Criminal Violence, Sage, Beverly Hills, 1982, pp. 201 ss.

${ }^{190}$ Prandi S., "Violenza sulle donne a Milano, 'la procura non prende sul serio le denunce", http://www.ilfattoquotidiano.it/2013/05/14/violenzasulle-donne-a-milano-procura-non-prende-sul-seriodenunce-delle-maltrattate/594179/. In taluni casi pare echeggi una posizione tesa prioritariamente alla salvaguardia dell'istituzione matrimoniale piuttosto che della salute psicofisica della donna (Rafter, Natalizia, 1981).

${ }^{191}$ Le donne medesime possono essere depositarie e trasmettitrici di un modello educativo di repressione della comunque innegabile che in determinati casi affiori persino l'esigenza di un loro trattamento $^{192}$. Tenuto conto di alcune caratteristiche, difatti, viene addirittura fuori una certa prevedibilità nell'individuazione della vittima delle violenze193; in più, non di rado si può riscontare una sorta di sua distorta $\mathrm{O}$ ambigua "complicità" o "connivenza"194 (dato, questo, che, in parte, riporta alla discussione sul modello di procedibilità penale più opportuno da adottare), anche derivante da una insana dipendenza emotiva ${ }^{195}$. Da alcune interpretazioni applicative della teoria dell'attribuzione ${ }^{196}$ (per cui l'assegnazione della totale responsabilità di

libertà femminile (anche corporalmente inteso, come si vede nella storia della conservazione di tradizioni corporalmente mortificanti, quali quella dei piedi di loto o quelle relative alle minorazioni genitali femminili).

${ }^{192}$ Problema parallelo è rappresentato dalla presenza di ostacoli culturali in chi astrattamente dovrebbe aiutare. Per esempio: "Mia madre non era d'accordo sulla denuncia. Quando i carabinieri le domandarono se fosse vero che mio padre aveva questi comportamenti violenti nei confronti delle figlie lei negò tutto... Ha sempre negato tutto" (dall'intervista fatta presso Casa Lorena a "M.", ragazza napoletana ventisettenne - prima di sei figli, che ha proseguito gli studi fino al secondo anno della scuola superiore in un istituto professionale per $\mathrm{i}$ servizi alberghieri - la quale dall'età di 12 anni ha subito violenza sessuale, fisica e psicologica da parte del padre, un uomo da lei descritto come da sempre violento con tutta la famiglia, ivi compresa la sorella più piccola di qualche anno).

$193 \mathrm{Si}$ veda, per esempio, per le ipotesi più gravi, L'omicidio volontario in Italia. Rapporto Eures, Roma, 2013, pp. 95 ss. e pp. 167 ss. Cfr., per un caso concreto di riproduzione di situazioni di sottoposizione a violenze: "Ero una bambina, non sapevo tante cose, non avevo una mamma che mi dava consigli, non avevo nessuno su cui fare affidamento, avevo solo lui. Poi, una volta separata, prima della morte del mio ex marito violento ho avuto un'altra convivenza, che si è rivelata peggiore della prima, ancora più violenta" (intervista a "T.", cit.).

${ }^{194}$ Cfr.: "Ciò che predomina nella relazione tra la vittima e il carnefice è la mancanza del 'principio di realtà'. Credo che, a volte, le vittime diventino carnefici di se stesse" (questo il parere dello psicoterapeuta Cristian Chiappetta riportato in Porco F., Il sangue rosa. La strage delle donne, Luigi Pellegrini, Cosenza, 2014, p. 190).

195 Cfr. Norwood R., Women Who Love Too Much, Pocket Books, New York, 1985.

196 Cfr. Hotaling G. T., "Attribution processes in husband-wife violence", in Straus M. A., Hotaling G. T. (a cura di), The social causes of husband-wife violence, University of Minnesota Press, Minneapolis, 1980, pp. 136 ss. 
un evento è spostata su di sé197, con formazione di un paradossale senso di colpa, o su altri, e non sul soggetto violento) alla teoria sul ciclo della violenza $^{198}$ (che ordina in fasi ben precise l'andamento relazionale tra la persona perseguitata e il reo, date dalla tensione, dall'esplosione, e dalla riconciliazione ${ }^{199}$, particolarmente adatta per comprendere l'apparente stasi delle vittime di violenza psicologica) a quella sulle strategie di coping (con cui il soggetto oppresso attua da sé, adattivamente, con esiti spesso impropri, il proprio fronteggiamento delle situazioni problematiche $)^{200}$ a quelle, ancora, che interpretano la vulnerabilità della vittima secondo la teoria della non difesa acquisita ${ }^{201}$,

${ }^{197}$ Cfr. Kalmuss D. S., "The Attribution of Responsability in a Wife-abuse Context", in Victimology, 1979, n. 4, pp. 284 ss. Nella menzionata indagine Istat in tema di Violenza sulle donna risulta che il 4,1\% delle donne da 16 a 70 anni che hanno subito violenza fisica o sessuale da un partner e che non hanno denunciato il fatto alle forze dell'ordine nel periodo in cui si è verificato l'episodio afferma di non averlo fatto per vergogna, imbarazzo o poiché pensava fosse propria colpa. Contra, invece: Domanda: "Ti sei mai sentita colpevole e o causa del suo comportamento?"; Risposta: "Ho sempre saputo di non essere io a provocare mio padre, non ero io la causa delle sue reazioni violente" (dall'intervista a "M." già menzionata). Tuttavia, i tempi di reazione della donna sono stati lunghi: "La violenza è durata dai 12 anni fino ai 27 anni, cioè fino alla denuncia... 15 anni di violenza, poi non ho più resistito!". Si noti, poi, che l'ambiente in cui sono state raccolte queste testimonianze ha individuato, in partenza, donne che hanno già reagito alle situazioni violenti cui erano costrette.

198 Walker L. E., Battered Woman, Paperback, New York, 1980

${ }^{199}$ Questa detta anche fase della "luna di miele".

${ }^{200}$ Si pensi solo alla teoria della sopravvivenza espressa in Gondolf E. W., Fisher E. R., Battered women as survivors: An alternative to learned helplessness, Lexington Books, Lexington, 1988, che intrepreta l'incapacità di troncare il rapporto con il soggetto violento come il fallimentare esito di richieste d'aiuto.

${ }^{201} \mathrm{Si}$ veda, Seligman M. E. P., Learned Helplessness, Freeman, San Francisco, 1975, nonché Walker L. E., Battered Woman, cit. Ripetute offese possono cagionare un senso di impotenza traslata a una vera e propria incapacità di difesa. Allorquando un tentativo di reazione non arriva alla risoluzione del problema, questo può generale un'"attribuzione interna", volta a una paradossale accettazione di colpa per gli eventi traumatici secondo cui un soggetto esposto a eventi traumatici ripetuti e non controllabili sviluppa come conseguenza una incapacità di difesa ${ }^{202}$, imputandola conseguentemente allo sviluppo di precisi deficit, motivazionali, cognitivi203 o emozionali ${ }^{204}$, risulta che in più casi sia leggibile una profonda e inscindibile dialettica

subiti, o un'“attribuzione esterna", quando si imputa semplicemente a cause esterne ciò che si vive. Questa, poi, può essere qualificata - semplificando - come "stabile", volta a una sopportazione indeterminata fondata proprio sulla propria capacità di sopportazione, oppure "transitoria", secondo la quale la sofferenza provata è legata a fattori episodici e/o casuali. In più, l'attribuzione può essere "globale", se il soggetto produce un senso di impotenza anche in situazioni differenti da quella che l'hanno originariamente generata, o "specifica", limitata solamente a quella situazione.

${ }^{202} \mathrm{Si}$ ricordi, in tema, nondimeno, la declinazione più generale della teorica della vulnerabilità acquisita come specifico modello formativo delle donne, le quali sin dall'infanzia sono sempre (almeno potenzialmente) oggetto e non soggetto di violenza. Non molto diversa la critica sull'educazione delle donne alla passività.

${ }^{203} \mathrm{Su}$ una dissonanza cognitiva che attanaglierebbe le vittime di violenza prolungata, Carver J. M., "Love and Stockholm Syndrome: the Mystery of Loving and Abuser",

http://drjoecarver.makeswebsites.com/clients/49355/File/1 ove_and_stockholm_syndrome.html (con paragoni pure alla sindrome di Stoccolma), nonché, più in generale, Festinger L., A Theory of Cognitive Dissonance, Stanford University Press, Palo Alto, 1957. Del primo, ci si riferisca anche all'esplicazione dei vari "investimenti" che la vittima del rapporto avrebbe fatto su questo.

${ }^{204}$ Una condizione di maggiore vulnerabilità dovuta a una specifica patologia fisica, la quale, in un contesto caratterizzato dall'esiguità di risorse idonee a garantire un adeguato sostegno educativo-sociale, ha anche indirettamente ostacolato una maggior crescita culturale e individuale, viene fuori dall'intervista condotta presso Casa Lorena su "G.", ragazza madre di 37 anni, originaria di Torre del Greco (Na), affetta da una malformazione agli occhi tale da percepire la pensione di invalidità, la quale ha proseguito gli studi fino alla licenza media, non potendo continuare gli studi per l'assenza di un docente di sostegno. La stessa è stata vittima di violenza, psicologica, fisica e sessuale, da parte del padre. "Mio padre ha iniziato ad abusare di me da quando avevo 7 anni fino a 35 anni. Solo quando mio fratello è tornato a casa (era andato via perché mio padre era violento anche con lui) si è accorto di tutto quello che è successo in sua assenza ed è stata fatta la denuncia". In questi anni di violenza "G." è rimasta più volte incinta. "Provavo rabbia, anche perché mio padre non abusava solo di me ma anche dei miei figli”. Il padre della donna è attualmente detenuto presso la Casa circondariale di Poggioreale, mentre lei è in attesa di poter rivedere i figli. 
"circolare"205 tra l'elemento "negativo" e quello "positivo" nella prosecuzione di uno stato di violenza ${ }^{206}$. Chiaramente, ciò non implica assolutamente un'indicazione di piatta corresponsabilizzazione nella donna vittima ${ }^{207}$, anche tenuto conto che uno stato di vulnerabilità può essere del tutto successivo agli stessi episodi di violenza (i quali poi possono anche essere solo una fase finale di un processo di "anestitizzazione psicologica" subdolamente messo in atto nei confronti della donna $\left.{ }^{208}\right)$, come ci testimonia la registrata incidenza, tradizionalmente giudiziariamente rilevante ${ }^{209}$, della battering syndrome ${ }^{210}$, in un percorso nel quale la donna sovente introietta un proprio senso di debolezza, se non proprio di annullamento volitivo $^{211}$. Si tenga anche presente che, a volte,

${ }^{205}$ Per questa aggettivizzazione, Guidantoni I., intervista relativa alla Giornata contro la violenza sulle donne del 25 novembre 2013, citata in Marzario M., "Legge sul femminicidio: analisi critica delle scelte terminologiche", in http://www.altalex.com/index.php? idnot $=66398$.

206 Emblematica, in proposito, la cosiddetta teoria dell'unione traumatica, secondo la quale è leggibile una profonda e reciproca dipendenza - psicologicamente, un vero e proprio rapporto simbiotico - tra due soggetti uniti in una relazione caratterizzata da uno squilibrio di potere, potenzialmente uno emotivamente sempre più insicuro, l'altro tendente verso un senso di onnipotenza. Per una breve sintesi su questa e altre teorie interpretative, Azioni, progetti, reti contro la violenza di genere, in http://old.manidistrega.it/tx/ADA/ADA\%202_1.pdf, pp. 31 ss.

${ }^{207}$ Né ciò può imputarsi alle caratteristiche di rischio attribuibili al profilo della vittima di violenza, su cui: Bruno T., "Violenza intrafamiliare e maltrattamento sulla donna", in Il seme e l'albero, 1998, nn. 2-3, pp. 16 ss.

${ }^{208}$ Cfr. Hirigoyen M. F., Molestie morali.La violenza perversa nella famiglia e nel lavoro, Einaudi, Torino, 2000, pp. 99 ss.

${ }^{209}$ Per la genesi giudiziaria della sindrome, in breve, "Battered-Spouse Syndrome", in http://legaldictionary.thefreedictionary.com/batteredchild+syndrome.

${ }^{210}$ Cfr. Aguglia E., Botter V., Riolo A., "La violenza di genere: un problema di salute pubblica", in Rivista di Psichiatria, 2001 n. 2, pp. 89 ss. Leggasi la sindrome anche alla luce delle caratteristiche del disturbo posttraumatico da stress.

${ }^{211}$ In altri termini, anche tutta una serie di caratteri e atteggiamenti che in qualche modo favoriscono le dinamiche violente non posso essere visti (solo) come soprattutto in caso di convivenza, la vittima può aver subito un progressivo allontanamento da propri centri affettivi (a cui ipoteticamente poter richiedere aiuto) derivante, ad esempio, da una sua vergogna rispetto ad alcuni aspetti della relazione o da una sostanziale suo isolamento messo in moto dal reo. Tuttavia, stando comunque così le cose, concentrarsi solo su una parte del rapporto, se può andare bene (se tempestivo) in alcuni casi in cui il soggetto attivo manifesta solo in un secondo momento, e spesso all'esito di una rottura del rapporto, il suo carattere persecutorio e violento, non risolve condizioni relazionali sicuramente patologiche (quantunque ex $\operatorname{pos}^{212}$ ) per le quali appare necessario prestare anche sulla donna un'attenzione qualificata ${ }^{213}$ quanto più possibile solerte $^{214}$, continua, seppur non invasiva ${ }^{215}$.

elementi predisponenti, giacché assai spesso sono (anche) conseguenze dei maltrattamenti patiti.

${ }^{212}$ I disturbi psicopatologici generalmente sarebbero un effetto delle violenze subite per Heise L., Garcia-Moreno C., La violenza da parte del partner, cit.

${ }^{213}$ Ciò, anche tenuto conto che, stando ai riscontri offerti dalla citata ricerca Istat sulla Violenza sulle donne, ben il $64,3 \%$ delle donne che non hanno denunciato la violenza subita nel corso della vita ha affermato di non averlo fatto in quanto non ha ritenuto che si trattasse di un reato grave, non ci ha pensato o ha considerato l'accaduto un fatto insignificante o un caso isolato, $1^{\prime} 8,3 \%$ non voleva che il reo venisse arrestato o che avesse problemi con le forze dell'ordine o ne era innamorata, il $4,9 \%$ ha avuto paura dell'autore della violenza o paura delle conseguenze, il 2,1\% non voleva che la relazione finisse, il 3,4\% per il bene dei bambini.

214 "Mi accorsi che stavo cambiando e che questa relazione non era fatta per me, che questa persona non era adatta. Dopo dei futili litigi da innamorati, decisi di lasciarlo. C'era la convinzione da parte sua di un mio ritorno, ma io ero convinta di non tornare. I primi mesi c'è stato un silenzio assoluto da parte suo, nessun atteggiamento anomalo. I problemi sono sorti quando con il passare dei mesi quel passo indietro non l'ho fatto. Le prime manifestazioni di persecuzione sono state le telefonate continue: mi ricordo 30 o 40 telefonate non al giorno, ma in mezza giornata! Vi sono stati appostamenti e dormite da parte sua in macchina sotto casa. Non avevo detto nulla a casa di quello che stava accadendo perché me ne vergognavo. Non ho detto nulla anche perché la mia relazione non era vista tanto di buon occhio dai miei familiari. Infatti, lui credeva che fosse colpa di terzi la causa della nostra rottura; ma non era così, era una mia 
In quest'ottica, il tema appare interpretabile anche come problema culturale della società, ben poco attenta a elaborare e comunicare una valida

scelta. Come è stata una mia scelta quella di non parlare a casa. Io avevo questo brutto difetto di non parlare, credevo di poter gestire la situazione, ma non si può gestire una cosa del genere da soli, perché poi c'è la degenerazione: degenerazione di quelle telefonate, di quegli appostamenti. Si va oltre, si arriva a lanci di bottiglia contro casa tua, bussate di citofono alle 4 di mattina. Quindi, a un certo punto, devi condividere la cosa con qualcuno, devi raccontare. Io ci ho messo un anno a raccontare e a denunciare, non lo fai subito perché credi che quella persona stia soffrendo e allora rimandi nel tempo" (corsivi nostri). "Mi ha spinto a denunciarlo la violenza che mostrava, la preoccupazione che quella violenza non era più rivolta solo verso di me ma anche verso la mia famiglia. Allora lì ti senti impotente e inizi a pensare e a mostrare questo problema agli altri. Quando io ho iniziato a raccontare era troppo tardi, perché quando ho deciso di dire che ero vittima di questa persona non riuscivo più a sopportare, ero satura di questi comportamenti, mentre gli altri avevano più pazienza, riuscivano a sopportare meglio questi comportamenti". Domanda: "Di che tipo di violenza si trattava?"; Risposta: "In un primo momento solo si pressione psicologica. Poi è diventata fisica. L'ultimo episodio grave, l'ho subito nonostante questa persona avesse due condanne di cui una con pena sospesa. Sono stata aggredita e picchiata in un luogo pubblico, in un parcheggio. Io tuttora nella borsa ho lo spray al peperoncino; grazie a quello sono riuscita a non avere la peggio". D.: "Potresti provare a ricordare e a descrivere i sentimenti che provavi?". R.: "Inevitabilmente si rischia di cadere in uno stato di depressione, di paura, di ansia... Io ho sofferto e soffro ancora a tutt'oggi di attacchi di panico. L'ansia era ai massimi livelli, non volevo stare più sola, non guidavo più, non uscivo più da sola, ero sempre accompagnata. Mi ricordo che anche se accompagnata mi sedevo sui sedili posteriori, mi stendevo per evitare che mi vedesse, anche se, non so come, me lo ritrovavo sempre dietro. Molte volte preferivo dormire a casa di amici proprio per evitare che accompagnandomi a casa potessero incontrarlo e quindi scontrarsi con lui" (dalla menzionata intervista a "Mi.").

${ }^{215}$ Per un approccio "soft", poi, si riferisca alla diffusione in molte nazioni di linee telefoniche gratuite e non registrate di aiuto. Si ricordi che dal 2006 è attivo presso il Dipartimento per le pari opportunità il numero verde gratuito di pubblica utilità " 1522 " dedicato alla ricezione e alla gestione di ogni segnalazione, denuncia o testimonianza su fatti, eventi, realtà, procedure e azioni relativi a violenza di genere nonché allo stalking (su cui, http://www.pariopportunita.gov.it/index.php/numeri-dipubblica-utilita-sezione/117-numero-verde-1522antiviolenza-donna). Ciò necessario, tenuto conto che le donne vittime di violenza possono sentirsi in uno stato di impotenza anche maggiore di quello in cui effettivamente vertono: Domanda: "Potresti provare a ricordare e a descrivere $i$ sentimenti che hai provato in quei momenti?"; Risposta: "Paura, sensazioni di impotenza, nel non potersi opporre a quelle continue violenze quotidiane" (dall'intervista a "M."). e profonda educazione dell'affettività. Chiaro è che qui, come in altri punti, non vogliamo intendere il problema specifico come deterministicamente ascrivibile alla società, altrimenti non troverebbe alcuna spiegazione la risposta differenziata data dalla maggioranza di soggetti non violenti (né i propositi efficaci di evitamento delle violenze). Le carenze socialmente attribuibili, tuttavia, possono tanto essere riscontrate in diffusissimi disequilibri familiari e affettivi non estrinsecati ed estrinsecabili in forma non violenta quanto essere lette come ulteriori precondizioni potenzialmente incidenti sulla 'fragilità' di un soggetto che partecipi ad azioni violente.

Sulla base di quanto detto, va dunque posto l'accento sul rilievo secondo cui l'approccio prescelto dal nostro legislatore pare a tratti culturalmente improprio, nei suoi riverberi pratici. D'altronde, le stesse case "antiviolenza" si sono mostrate scettiche sulla necessità di una denunzia preventiva in capo alla vittima per accedere a un'accoglienza nelle "caserifugio", giacché i tempi di reazione della donna talora sono assai più lenti di quelli premessi dal normatore così come dai tempi della giustizia stessa (tenuto anche conto che il porre fine a una relazione non può essere considerato un singolo atto, quanto piuttosto un processo $\left.{ }^{216}\right)$. Inoltre,

\footnotetext{
${ }^{216}$ Cfr., per esempio, Ellsberg M. C., Winkvist A., Peña R., Stenlund H., "Women's strategic responses to violence in Nicaragua", in Journal of Epidemiology and Community Health, 2001, n. 55 pp. 547 ss., nonché Landenburger K. M., "The dynamics of leaving and recovering from an abusive relationship", in Journal of Obstetric, Gynecologic, and Neonatal Nursing, 1998, n. 27, pp. 700 ss. Analoghe riflessioni scaturiscono dai resoconti prodotti dallo studio Sagot M., Carcedo A., Ruta crítica de las mujeres afectadas por la violencia intrafamiliar en América Latina (estudios de caso de diez Países), 2000, patrocinato dall'Organizzazione panamericana per la salute (leggibile in http://www1.paho.org/spanish/hdp/hdw/rutacritica.pdf).
} 
non si tralasci che la denuncia in realtà ben poche volte sortisce un reale effetto ammonitivo $^{217}$; più spesso scatena una sorta di "risveglio della violenza", generante un atto di vendetta maggiormente violento ${ }^{218}$, che può essere anche letale ${ }^{219}$. Ciò, potrebbe accadere anche nell'ipotesi che un qualunque procedimento, ivi compreso quello ammonitivo

${ }^{217}$ In De Santis R. A., "Femminicidio: la legge e le parole", in http://www.altrenotizie.org/societa/5677femminicidio-la-legge-e-le-parole.html, si riferisce che ben il $70 \%$ delle donne uccise avevano già in precedenza denunciato gli uomini aggressori o molestatori. Da uno studio della Casa delle donne per non subire violenza di Bologna - citato nell'interrogazione parlamentare ante menzionata - sono indicate, invece, cifre inferiori: nel $40 \%$ dei casi le vittime sarebbero state oggetto di precedenti episodi di violenza da parte del proprio carnefice, di cui il $15 \%$ aveva presentato denuncia per stalking.

218 "Ho sempre detto che per denunciare ci vogliono cinque minuti. Ma dopo quei cinque minuti la tua vita cambia, cambia completamente. $\mathrm{Si}$ ha un effetto contrario: mentre la denuncia dovrebbe essere un atto di ammonimento nei confronti di questa persona, diventa una sorta di risveglio della violenza. C'è un atto di vendetta maggiore. Tu denunci per essere protetta e invece ti ritrovi ancora più vittima di quella persona"; "Inoltre, anche dopo la prima udienza, appena usciti dal tribunale, sono continuati gli atti persecutori nei miei confronti" (testimonianza di "Mi.").

${ }^{219}$ Anche alla luce di questo sarebbe opportuno prevedere fondi adeguati per i centri antiviolenza, sì che questi possano intervenire tempestivamente. Si ricordi che, secondo le raccomandazioni provenienti dal Consiglio d'Europa (espresse nel "Meeting sulla violenza contro le donne" tenuto in Finlandia dall' 8 al 10 novembre 1999), si abbisognerebbe di un centro antiviolenza ogni 10.000 persone e di un centro d'emergenza ogni 50.000 abitanti. Inoltre, in Ottaviani E., "Il livello dei servizi di contrasto alla violenza alla luce della nuova Convenzione del Consiglio d'Europa", in Karadole C., Pramstrahler A. (a cura di), Femicidio, cit., p. 81, si riporta, su dati Women Against Violence Europe, Country Report 2010 (www.wave-network.org), che nel nostro Paese "meno di cinque sono i rifugi che fanno servizio 24 ore su 24 , il servizio multi-lingue è presente in una sola casa-rifugio e molte di esse non soddisfano gli standard di sicurezza". In Romanin A., "Vittime ad alto rischio: due progetti europei per il triennio 2010-2012", in Karadole C., Pramstrahler A. (a cura di), Femicidio, cit., p. 98, si afferma, invece, che "il trasferimento da una casa rifugio ad un'altra fuori territorio [...] è reso difficoltoso o impossibile da vincoli amministrativi: case che funzionano a rette, convenzioni che obbligano a ospitare solo residenti o inviate dai servizi sociali, ecc.”. In ogni modo, l'attuale previsione normativa sulla promozione di centri antiviolenza e case rifugio fa esplicito riferimento a tali esigenze (pur risultando insufficiente nelle statuizioni concrete). amministrativo, sia messo in moto su segnalazione di terze parti, esponendo dunque la vittima anche al sospetto di aver compiuto una delazione su quella che è percepita come una dinamica interna alla famiglia. Più in generale, e al di fuori dei casi limite, è opportuno tenere presente che il reo può reputare che agendo violentemente (nell'accezione più ampia possibile) sulla vittima si possa arginare la prosecuzione dell'azione legale. Tutto l'opposto di quel che interessa alla vittima, concentrata innanzitutto sulla cessazione (immediata) della condotta diretta contro di lei, più che all'astratta punizione legale (futura) del colpevole 220 . In questa, come in altre materie, principio generale su cui ci si deve orientare è, invece, quello per cui bisogna agire per tappe (idealmente) successive, anche disposte in relazione al criterio di concreta necessità e orientate nell'ottica del massimo evitamento dell'offesa: first prevention; second protection; third persecution. Vanno coniugate, pertanto, adeguatamente, e innanzitutto nell'ottica di salvaguardia dei soggetti situazionalmente più deboli, l'azione e le esigenze della repressione e della difesa. Insomma, un'attenzione costante va prestata anche al rischio di isolamento e di autoisolamento della donna vittima di violenze ${ }^{221}$,

${ }^{220}$ Arcidiacono D., Crocitti S., "Le risposte del sistema della giustizia penale alle violenze nelle relazioni di intimità", in Creazzo G. (a cura di), Se le donne chiedono giustizia, il Mulino, Bologna, 2012.

221 In quest'ottica, appare certamente opportuna la riformulazione dell'art. 11 d.1. 23 febbraio 2009, n. 11, convertito, con modificazioni, dalla 1. 23 aprile 2009, n. 38 , cosicché le forze dell'ordine, i presidi sanitari e le istituzioni pubbliche che ricevono dalla vittima notizia di questi reati hanno l'obbligo di fornire alla vittima stessa tutte le informazioni relative ai centri antiviolenza presenti sul territorio e, in particolare, nella zona di residenza della vittima. Questi stessi soggetti provvedono poi a mettere in contatto la vittima con i centri antiviolenza, qualora ne faccia espressamente richiesta. 
tenuto pure conto che non di rado questa evita di presentare idonee richieste di aiuto ${ }^{222}$.

Detto questo, pare, ebbene, che vi sia un problema culturale nel medesimo legislatore: emblematicamente, come già da accenni fatti per esempio sul tema della procedibilità penale dell'azione -, sembra essere sostanzialmente prevalso un modello della donna debole in sé223 (si pensi solo a una possibile lettura in tal senso dell'obbligatorietà della comunicazione di modifica o revoca delle misure cautelari ai servizi sociali, e dunque di un loro intervento ${ }^{224}$ ), nonostante, poi, questo modello venga meno proprio quando poteva in parte giovare (per l'appunto, ai fini di un'accoglienza temporanea di una non denunziante). In tutti i modi, comunque, nella riforma pare essere lontani da quella falsariga sulla "vulnerabilizzazione" /"non vulnerabilità in sé"225 della donne accolta dalle

${ }^{222}$ Correlativamente, sebbene l'indagine non sia relativa al nostro Paese, si noti che l'Organizzazione mondiale della sanità, nel suo studio Multi-country Study on Women's Health and Domestic Violence against Women del 2005

(in

http://www.who.int/gender/violence/who_multicountry_s tudy/en/), ha indicato una percentuale altissima di donne che hanno subito abusi sessuali da parte dei propri partner senza mai rivolgersi a figure ed enti di protezione e repressione.

${ }^{223}$ Esplicitamente, nella relazione accompagnatoria di conversione del disegno di legge, ci si riferisce alla finalità di "affrontare, da diverse angolature, una serie di problematiche riguardanti la pubblica sicurezza in una chiave di difesa dei soggetti più deboli ed esposti" (corsivo nostro).

${ }^{224}$ Correlativamente, nella letteratura scientifica sono state criticate le previsioni sull'obbligatorietà della denunzia di possibili casi di abuso contro le donne da parte di operatori dell'assistenza sanitaria, in quanto esautorerebbero la vittima da un suo potere attivo, oltre che la esporrebbero, talora, a maggiori rischi (Jezierski M. B., Eickholt T., McGee J., "Disadvantages to mandatory reporting of domestic violence", in Journal of Emergency Nursing, 1999, n. 25, pp. 79 ss. "American College of Obstetricians and Gynecologists committee opinion: mandatory reporting of domestic violence", in International Journal of Gynecology and Obstetrics, 1998, n. 62, pp. 93 ss.).

225 Una vulnerabilità specifica può essere invece astrattamente ipotizzata qualora la vittima sia minore d'età. Coerentemente, sono stati ampliati (anche in
Convenzioni internazionali, per far posto a un atteggiamento inquinato $\mathrm{da}$ un improprio paternalismo che, incentrato sul binomio "controllo/protezione", rischia di produrre una ri-vittimizzazione delle donne viste come puri "oggetti da difendere"226, mere vittime incapaci di tutelare i propri interessi e agire per il rispetto dei propri diritti227. Ciò, proprio a scapito di una promozione dei diritti della persona offesa, emergente soltanto con chiarezza a proposito dei obblighi summenzionati di avvertire sulle fasi del processo, nonché di procedere a raccogliere le sue dichiarazioni con modalità protette (coerentemente con la direttiva europea 2012/29/UE228 e con i suggerimenti leggibili nella giurisprudenza della Corte EDU sulla protezione delle vittime di reato ${ }^{229}$, nonché in

conformità alla Convenzione di Lanzarote) i casi in cui la polizia giudiziaria può rivolgersi a uno psicologo o uno psichiatra infantile nella raccolta di sommarie informazioni da parte di minori (benché vi siano ancora alcune lacune in ordine alle modalità protette di raccolta di una sua prova dichiarativa). Nondimeno, anche quando la vittima sia maggiorenne ma versi in uno stato di particolare vulnerabilità, è stata prevista la possibilità di una sua escussione in forma protetta.

${ }^{226} \mathrm{Su}$ una impropria concezione di una vulnerabilità in sé poggerebbe l'azione di mettere in sicurezza le donne, locuzione che sembra intendere che una politica in materia debba essere condotta ex post rispetto a una formazione culturale già data. Su un mero paternalismo protettivo della normativa, può vedersi "Femminicidio, il paternalismo della legge", in http://www.ilfattoquotidiano.it/2013/10/22/femminicidiopaternalismo-della-legge/ . In proposito, il testo era già stato criticato nella sua versione provvisoria da parte di associazioni di donne in quanto avrebbe ridotto la violenza contro le donne a "un problema di ordine pubblico" (De Luca M. N., Femminicidio, critiche alla legge, cit.).

${ }_{227}$ Comunque, nella delineazione teorica del femminicidio è insita la classificazione criminologica della donna come un "tipo vittimologico": Battaglia S., "Legge sul femminicidio: modifiche normative e questioni connesse", in http://www.altalex.com/index.php?idnot=65324\#_ftn1.

${ }^{228} \mathrm{Si}$ veda, in particolare, l'art. 6, comma 2, lett. b. Sulla direttiva, in breve, Civello Conigliaro S., "La nuova normativa europea a tutela delle vittime di reato", in http://www.penalecontemporaneo.it/upload/1353580802 CONIGLIARO\%202012a.pdf.

${ }^{229}$ Per esempio, nella sentenza del 28 settembre 2010, nel caso A.S. contro Finlandia, si è persino affermato che ci 
funzione di un incitamento a una partecipazione processuale consapevole della persona offesa). Mentre, quindi, nelle Convenzioni internazionali e regionali, le donne sono soggetti "vulnerabilizzabili" (non fragili tout court, insomma, ma vulnerabili in una specifica dinamica $^{230}$ ), per cui non s'invita a un obbligo di tutela di per sé, ma di rimozione degli ostacoli esistenti per il pieno godimento dei diritti fondamentali231, tra cui uno dei principali è per l'appunto rappresentato dal subire violenza ${ }^{232}$ (sì

possono essere eccezioni al pieno rispetto delle garanzia del contraddittorio, e dunque al diritto a una difesa piena, dinanzi all'insorgere di altri valori costituzionalmente rilevanti, come nel caso in cui si debba accogliere la testimonianza di minori vittime di reati contro la libertà sessuale. Amplius, Agnese A., De Crescenzo P., Fuga G., La tutela della vittima e garanzie dell'imputato. La più recente normativa dell'Unione europea, Aracne, Roma, 2011.

${ }^{230}$ La direttiva 2012/29/UE del Parlamento europeo e del Consiglio del 25 ottobre 2012, che istituisce norme minime in materia di diritti, assistenza e protezione delle vittime di reato, all' art. 17, ricordando che "per violenza di genere s'intende la violenza diretta contro una persona a causa del suo genere, della sua identità di genere o della sua espressione di genere o che colpisce in modo sproporzionato le persone di un particolare genere", e che "può provocare un danno fisico, sessuale, emotivo o psicologico, o una perdita economica alla vittima", sottolinea che "le donne vittime della violenza di genere e i loro figli hanno spesso bisogno di un'assistenza e protezione speciali a motivo dell'elevato rischio di vittimizzazione secondaria e ripetuta, di intimidazione e di ritorsioni connesso a tale violenza". Al successivo articolo, tratteggiando la violenza nelle relazioni strette come "quella commessa da una persona che è l'attuale o l'ex coniuge o partner della vittima ovvero da un altro membro della sua famiglia, a prescindere dal fatto che l'autore del reato conviva o abbia convissuto con la vittima", la qualifica come "problema sociale serio e spesso nascosto, in grado di causare un trauma fisico e conseguenze in quanto l'autore del reato è una persona di cui la vittima dovrebbe potersi fidare": "le vittime di violenza nell'ambito di relazioni strette possono pertanto aver bisogno di speciali misure di protezione; [...] la loro situazione può essere peggiore in caso di dipendenza dall'autore del reato sotto il profilo economico, sociale o del diritto di soggiorno".

${ }^{231}$ Cfr. Spinelli B., Decreto femminicidio, cit. Ivi si parla, in proposito, che gli obiettivi del legislatore "non sono la promozione e la tutela dei diritti delle donne, ma la promozione e la tutela della sicurezza pubblica".

${ }^{232}$ Già nella Raccomandazione generale della CEDAW n. 19 del 1992 tale violenza è declinata come elemento che "compromette seriamente la possibilità per le donne di godere pienamente dei diritti e delle libertà su un piano di da realizzare una uguaglianza de facto ${ }^{233}$ che è del resto armonica rispetto alla perequazione prevista dall'art. 3, comma 2, della nostra Carta costituzionale), nell'analisi tecnico-normativa di accompagnatoria del normativa si esplicita che $\mathrm{i}$ reati considerati destano particolare allarme sociale "per il fatto di essere perpetrati ai danni di soggetti deboli", confermando politiche paternal-protezionistiche ${ }^{234}$ ben presenti nel nostro ordinamento (già nella ricordata normativa del 2001 l'approccio esistente appariva analogo, essendo prescritta la facoltà di comunicare l'adozione degli ordini di protezione ai servizi sociali, anche in assenza di minori $\left.{ }^{235}\right)$. E da dire, tra l'altro, che la considerazione delle donne come soggetto fragile in premessa risente

uguaglianza con gli uomini”. Se si vuole poi interpretare il fenomeno come emergenziale e in ascesa questo può considerarsi indice di "regressione della condizione e dei diritti delle donne" (così l'antropologa Annamaria Rivera, citata in "Stop. Il femminicidio è una violenza per tutta la società", in http://www.donnegeometra.it/software/intervista\%20Pres idente\%20Moscatelli\%20(1).pdf). Tuttavia, forse è più corretto parlare di persistenza piuttosto che di aggravamento di squilibri.

${ }^{233}$ Cfr. Degani P., "Diritti umani e violenza contro le donne: recenti sviluppi in materia di tutela internazionale", in Quaderni del Centro di studi e di formazione sui diritti dell'uomo e dei popoli, 2000, n. 2, p. 26. Sul tema, si veda anche Maffei M. C., "La condizione della donna tra protezione e divieto di discriminazione", in Pineschi L. (a cura di), La tutela internazionale dei diritti umani, Giuffré, Milano, 2006, pp. 173 ss.

${ }^{234}$ In parte, forse paradossalmente, incoraggiate anche da talune richieste di maggior protezione della donna in quanto soggetto sempre (e dunque, di per sé) supinamente vittima in ipotesi di relazioni squilibrate.

${ }^{235}$ Precisamente, secondo l'art. 342 bis c.c. il giudice può disporre, ove occorra, l'intervento dei servizi sociali del territorio o di un centro di mediazione familiare, nonché delle associazioni che abbiano come fine statutario il sostegno e l'accoglienza di donne e minori o di altri soggetti vittime di abusi e maltrattati. Ci si è avvalsi di tale facoltà anche nell'ipotesi di potenziale ricomposizione del nucleo familiare, dando assistenza psicologica a ciascun componente della famiglia coinvolta nella vicenda (si veda il decreto del Tribunale di Barletta del 1 aprile 2008, in Famiglia, persone e successioni, 2008, p. 656, menzionato pure in Giacardi W., "Ordini di protezione contro gli abusi familiari", in http://www.altalex.com/index.php?idnot=57833). 
di una prospettiva mediatica (cui è legata a doppio filo la statuizione di un'immediata risposta penale ${ }^{236}$ ) che ha accompagnato l'informazione e il dibattito sul tema.

Insomma, in relazione a quanto rilevato, emergerebbe quasi la necessità di un nuovo intervento in materia ab imis.

\section{Problemi terminologici.}

Infine, si noti che la normativa introduce per la prima volta in un testo ufficiale la parola "femminicidio" (anche sulla scorta di una oramai diffusa e consolidata segnalazione sociale ${ }^{237}$ ). Tuttavia, il termine ${ }^{238}$ è utilizzato con un certo grado di ambiguità, andando a riferirsi tanto a un'uccisione o aggressione fisica consumata o "preparata"; tanto a un'uccisione fisica che a un" uccisione morale". Il testo normativo, peraltro, non offre preliminarmente una definizione di femminicidio, come peraltro sarebbe stato auspicabile per una buona pratica di legiferazione. Per una esatta chiarificazione sul suo significato si noti che il termine - accolto oramai anche da membri dell'Accademia della Crusca $^{239}$ - viene così illustrato dalle ultime edizioni del Vocabolario della lingua italiana DevotoOli: "Qualsiasi forma di violenza esercitata sistematicamente sulle donne in nome di una

\footnotetext{
${ }^{236}$ Sui rischi di un intervento simbolico del legislatore penale, cfr. Schiaffo F., "Le minime ragioni della legislazione penale simbolica: la criminalità mediata", in Critica del diritto, 2010, pp. 127 ss.

${ }^{237}$ Cfr. Spinelli B., Femminicidio. Dalla denuncia sociale al riconoscimento giuridico internazionale, Franco Angeli, Milano, 2008.

${ }^{238}$ Prescindendo qui da giudizi sulla sua gradevolezza. Per una critica sui "richiami inconsci" del termine: Bossi Fedrigotti I., "Donne uccise, violenza in aumento, ma non chiamatelo più 'Femminicidio'", da il Corriere della sera del 30 aprile 2012.

${ }^{239}$ Paoli M., "Femminicidio: i perché di una parola", in http://www.accademiadellacrusca.it/it/lingua-

italiana/consulenza-linguistica/domanderisposte/femminicidio-perch-parola.
}

sovrastruttura ideologica di matrice patriarcale, allo scopo di perpetrare la subordinazione e di annientare l'identità attraverso l'assoggettamento fisico o psicologico, fino alla schiavitù o alla morte" 240 . In questa definizione, che richiama in via diretta il sistema culturale sociale di riferimento - la donna, quindi, viene fuori come un tipo proprio vittimologico: nel femminicidio si hanno spinte violente in danno alla donna proprio perché donna. Tale spiegazione, tuttavia, non risolve del tutto il problema terminologico, specie relativamente a una sua correttezza sul piano etimologico: il termine, accolto ora nella nostra lingua da un uso introdotto per traduzione di vari testi esteri incentrati sul tema della violenza sulle donne ${ }^{241}$, deriva da "ciduum" per "caedes", "uccisione", che, a rigori, per l'appunto si riferisce esclusivamente all'evento morte $^{242}$, talché la parola indicherebbe letteralmente l'eliminazione di una donna per mano altrui ${ }^{243}$. Tale imprecisione, etimologicamente considerata, fa sì che il termine (la cui genesi internazionale ideologica e "politica", e dunque carica di significati ulteriori rispetto a quelli provenienti da una mera lettura formale, è comunque pacificamente

\footnotetext{
${ }^{240}$ Devoto G., Oli G. C., Vocabolario della lingua italiana, Le Monnier, Firenze, 2013, ad vocem.

241 E non già per declinazione giuridica del termine letterario di costruzione letteraria (cfr. Franchetti A., "Commento alla Giacinta", commedia in cinque atti di Luigi Capuana, in Nuova Antologia di scienze, lettere ed arti, 1888, p. 547; su cui Paoli M., Femminicidio: $i$ perché di una parola, cit.).

${ }^{242}$ Anche il termine "ginocidio", che si ritrova in studi in materia di "annientamento" delle donne avente carattere sistemico, spesso non si riferisce esclusivamente all'uccisione fisica (si veda, per esempio, Danna D., Ginocidio. La violenza contro le donne nel mondo globale, Eleuthera, Milano, 2007).

${ }_{243}$ Peraltro, un prevalente senso culturale aggiuntivo va riconosciuto, giacché già c'è la definizione terminologica così come la fattispecie dell'omicidio e non può pensarsi a una gradazione sanzionatoria in base a un diverso valore di per sé della vita umana (come di seguito richiamato).
} 
riconosciuta $^{244}$ ) sia ora utilizzato per indicare propriamente l'uccisione di una donna (culturalmente orientata) ora per riferirsi a un arco di violenze (anch'esse culturalmente orientate) ben più ampio 245 , cosa che produce una certa dose di ambiguità e incertezza ${ }^{246}$ anche nella comparazione di dati provenienti da fonti

${ }^{244}$ Spinelli B., "Il riconoscimento giuridico dei concetti di femmicidio e femminicidio", in Karadole C., Pramstrahler A.(a cura di), Femicidio, cit., pp. 125 ss.

${ }^{245}$ Tanto che poi, in alcuni articoli che fanno specifico riferimento alle uccisioni, si avverte la necessità di chiarire che nello studio presentato, al di là del titolo specifico e dell'uso che all'interno si fa del termine "femminicidio", ci si occupa della "frazione estrema di suddetta complessa e articolata realtà, quella omicidiaria", distinguendo giustamente termini etimologicamente analoghi: Piacenti F., De Pasquali P., Il femminicidio in Italia nel periodo 2000-2012, cit.

246 Correlativamente, si noti che pure l'espressione "violenza di genere" è talora utilizzato per indicare anche le violenza compiute a danno di minori e non solo quelle con le donne quali vittime, volendosi intendere sostanzialmente la violenza condotta da uomini nell'orizzonte culturale di una società patriarcale. Ciò, tuttavia, costituisce fonte di possibile equivocità quando si rapportano gli effetti delle diverse considerazioni della "violenza di genere" (anche tenuto conto che nel nostro ordinamento non ve ne è una definizione: cfr. Spinelli B. (a cura di), "Rapporto Ombra CEDAW", in www.scribd.com/doc/60859560/Rapporto-Ombra-

CEDAW-2011-ITA-2-1). Di più, è proprio la locuzione "di genere", adottata in molti documenti normativi internazionali, tra cui la Convenzione di Istanbul, riferita "a ruoli, comportamenti, attività e attributi socialmente costruiti che una determinata società considera appropriati per donne e uomini", che risulterebbe di difficile armonizzazione rispetto all'impianto costituzionale italiano, in quanto ritenuta "troppo ampia e incerta"

(http://documenti.camera.it/leg17/dossier/Testi/es0030inf .htm). Cionondimeno, anche in assenza di una definizione formale, nella normativa analizzata appare termine ricorrente. Peraltro, talora adottare sommariamente una prospettiva marcatamente "di genere" dà luogo a evidenti contraddittorietà concettuali. Senza nulla togliere agli interessanti contenuti presentati, si veda l'ambiguità della titolazione del numero speciale di Innocenti Digest, 2006, n. 6, redatto dall'Unicef (a cura di Hawke A.) dedicato a La violenza domestica contro le donne e le bambine (leggibile in http://www.unicefirc.org/publications/pdf/digest6i.pdf), che per l'appunto (quantomeno nella traduzione presentata) sembra volersi riferire (comunque riduttivamente) solo alla violenza domestica agita contro le bambine (e, dunque, per ragioni misogine in senso stretto), ma al cui interno fa più volte riferimento anche a quella a danni di bambini, intesi poi a volte come categoria sessualmente indifferenziata altre volte come bimbi maschi. diverse ${ }^{247}$. Inoltre, va ricordato che alcuni ${ }^{248}$, slegandosi dal dato etimologico e considerando più l'uso rintracciabile nelle diverse fonti, oltre che la necessità di una diversificazione terminologica tra fenomeni combacianti ma non totalmente sovrapponibili, propongono una distinzione tra "femminicidio" e "femicidio"249 (o "femmicidio", mutuato questo dall'omologo vocabolo adottato dalla letteratura in materia spagnola, il primo dalla parola femicide 250 impiegata dalla quella in lingua inglese ${ }^{251}$ ), laddove questi ultimi rappresentano i soli termini relativi alle morti delle donne "in quanto donne"252, mentre molto spesso tutte queste parole sono utilizzate come sinonimi o comunque come termini largamente

${ }^{247}$ In altri termini, quando ci si riferisce al femminicidio (per esempio, al numero di casi relativi) bisogna sempre soffermarsi su come lo specifico autore lo intenda. Viceversa, sarebbe necessaria una terminologia inequivocamente accettata, per modo che si possa apprezzare, dalla comparazione delle differenti ricostruzioni offerte, la reale portata del fenomeno. Più in generale, per una sintesi sui problemi di utilizzo di dati provenienti da ricerche diverse sulla violenza contro le donne (che non solo possono non adottare le stesse definizioni ma anche utilizzare metodi diversi che possono portare a risultati diversi), Creazzo G., "Genderbased violence: le violenze maschili contro le donne", 2011, p. 23, leggibile in www.noino.org/browser_files.php?id=7825.

${ }^{248} \mathrm{Si}$ veda, in merito, Karadole C., "Femicidio: la forma più estrema di violenza contro le donne", in Rivista di Criminologia, Vittimologia e Sicurezza, 2012, n. 1, pp. 17 ss.

${ }^{249}$ Come visto, anche nel già riportato rapporto stilato dal relatore speciale sulla violenza contro le donne delle Nazioni ci si riferisce a "femmicidio e femminicidio" al plurale, come se fossero fenomeni distinti.

${ }_{250} \mathrm{Si}$ ricordi anche l'uso di "Intimate Femicide" per indicare le uccisioni in ambito familiare e affettivo.

${ }^{251}$ Per maggiori approfondimenti sul punto, Karadole C., Femicidio, cit., p. 17.

${ }^{252}$ Sempre Karadole C., in Femicidio, cit., p. 18, ci ricorda, però, che in parte della letteratura criminologica internazionale manca il riferimento a tale causalità, essendo presente un utilizzo letterale del termine. Ivi cita, inoltre, proposte di utilizzo del termine anche nei casi di "rischio sociale di uccisione", così come la non omogenea adozione del vocabolo (p. 21) quando l'uccisore sia egli stesso donna (i cui casi sono distinti, poi, in uccisione per "propri motivi" o su "mandato maschile"). 
intercambiabili ${ }^{253}$. Inoltre, anche con il femminicidio non può, come visto, intendersi semplicemente l'omicidio di una donna, prescindendo dalla cause insite e dai rapporti della vittima intrattenuti con l'esecutore o il mandate dell'uccisione. In questo senso, un utilizzo legislativo differente e anche più ampio rispetto alla sua stretta etimologia appare opportuno, stante ovviamente la preesistenza della fattispecie di omicidio ${ }^{254}$. Sui confini del

${ }^{253}$ Come esempio, Mazzarese T. (a cura di), Diritto, tradizioni, traduzioni. La tutela dei diritti nelle società multiculturali, Giappichelli, Torino, 2013, p. 267, n. 35; Redattore sociale (a cura di), Parlare civile. Comunicare senza discriminare, Bruno Mondadori, Milano, 2013, p. 24; Priulla G., C'è differenza. Identità di genere $e$ linguaggi: storie, corpi, immagini e parole, Franco Angeli, Milano, 2013, p. 28.

254 Nondimeno, se con il femminicidio si volesse semplicemente intendere un particolar tipo di omicidio, magari aggravato (non solo da predeterminazione o da minorata difesa, aggravanti idonee astrattamente per ogni uccisione, ma da motivi ideologico-culturali "univalenti"), riconoscendo però una maggiore gravità nell'omicidio di un genere predeterminato o di una categoria tout court, non solo ciò riporterebbe alla spinosa problematica dei reati culturalmente orientati (e qui si richiamino le previsioni sanzionatorie di cui alla legge 9 gennaio 2006, n. 7 concernente la prevenzione e il divieto delle pratiche di mutilazione genitale esclusivamente femminile, plausibilmente proposta in tal senso per far salva penalmente la pratica religiosa, soprattutto ebraica, musulmana e della chiesa copta, della circoncisione del prepuzio sui bambini), ma ingenererebbe una disparità giuridica insostenibile oltre che inspiegabile. Chiaramente, alcuni omicidi hanno delle caratteristiche, e anche delle conseguenze giuridiche loro proprie, cosa che giustifica e rende utile una loro specifica denominazione (come l'infanticidio, il parricidio, eccetera). L'adozione di un nuovo termine per indicare l'uccisione di donne culturalmente fondata è poi certamente sensata ai fini di una sua più immediata $\mathrm{e}$ precisa identificazione e anche ai fini della pratica di una più efficace politica di prevenzione del fenomeno. Il riconoscimento del particolare disvalore delle motivazioni del reo femminicida, in ogni caso, riteniamo possa essere ricompreso nell'aggravante generale data dalla presenza di motivi abietti e futili nel reato. Correlativamente, si rilevi che il recentissimo d.lgs. 15 giugno 2015 , n. 80 , attuativo dell'art. 1 , commi 8 e 9 , della 1.10 dicembre 2014 , n. 183 , prevedendo all'art. 24 misure di sostegno sul piano lavorativo per le "vittime di violenza di genere" - precisamente, forme di congedo per motivi connessi allo svolgimento del percorso di protezione di cui alla 1. 119/13 -, ritiene consono circoscrivere in premessa l'applicabilità di tali istituti solo a coloro che siano donne, in questo modo non solo disconoscendo la possibilità che vittima possa anche fenomeno, tuttavia, specificamente considerato, non sempre pare adoperato un criterio universalmente condiviso, tenuto conto che taluni studi 255 includono sic et sempliciter nella categoria anche i casi, latamente o strettamente, di eutanasia per mano di un uomo su una donna a lui vicina ${ }^{256}$ (rispetto ai quali andrebbe poi meglio vagliata la riconducibilità della volontà di interrompere una vita assai spesso già funzionalmente compromessa), in quanto questi sono letti come frutto di un "incapacità culturale alla cura e all'accudienza" (ovvero di un'incapacità emotiva alla sofferenza? ${ }^{257}$ ) che attaglierebbe la sfera maschile, secondo una considerazione almeno parzialmente arbitraria e generalmente non condivisa, quantomeno dagli organi di informazione ${ }^{258}$. D'altronde, nel femminicidio/femmicidio, per come generalmente presentato ${ }^{259}$, rientrano casi assai eterogenei, ciascuno dei quali va considerato in relazione alle profonde motivazioni che lo hanno generato, cosa che rende difficile una loro pacifica (benché opportuna ${ }^{260}$ ) armonizzazione categoriale.

Anche questi ultimi appunti, a parer nostro, inducono a ritenere che sia necessario un

essere un uomo (di qualsiasi orientamente sessuale sia) ma viepù creando un evidente problema costituzionale di pari trattamento.

${ }^{255}$ Karadole C., Femicidio, cit., p. 31.

${ }^{256}$ Uomo che poi, non raramente, si uccide anch'esso (per l'insopportabilità di quanto compiuto o per l'insopportabilità di continuare la vita senza la donna?).

257 In proposito, si veda la poetica trasposizione cinematografica fatta in Amour, di Michael Haneke (2012).

${ }^{258}$ Da quelle stesse fonti, insomma, su cui si basano i dati numerici sul femicidio riportati in alcuni lavori da parte dei medesimi autori succitati.

${ }^{259}$ Per esempio, nelle pubblicazioni periodiche promosse dalla Casa delle donne per non subire violenza di Bologna, utili in questo discorso proprio perché accanto ai dati riepilogativi presentano una breve sintesi di ogni caso considerato e mediaticamente proposto.

${ }^{260}$ Cfr. anche Coluccia R., "Ancora su femminicidio", dal Nuovo Quotidiano di Puglia dell'11 maggio 2013. 
maggior impegno in termini di accuratezza e scrupolosità nell'affrontare, astrattamente e operativamente, il problema della violenza contro le donne, senza lasciarsi andare a confusioni mediaticamente indotte $261 \quad \mathrm{O}$ confidando, illusoriamente ${ }^{262}$, nella bontà intrinseca di norme illustrative, magari 'politicamente corrette'263, ma (in una materia che indubbiamente abbisogna di attenzione e di interventi a livelli diversi, e non solo istituzionali) sempre incomplete e provvisorie, come del resto tutte le previsioni giuridiche, troppo spesso presentate o agognate, facilisticamente, come assolutamente, definitivamente efficaci e risolutrici.

\section{Bibliografia di riferimento.}

- Aa. Vv., Amorosi assassini. Storie di violenze sulle donne, Laterza, Roma-Bari, 2008.

- Aa. Vv., Stalking e violenza sulle donne. Le risposte dell'ordinamento, gli ordini di protezione, Franco Angeli, Milano, 2009.

- Alexander F., Staub H., Il delinquente, il giudice e il pubblico, Giuffrè, Milano, 1976.

- Agenzia dell'Unione Europea per i diritti fondamentali, Violenza contro le donne: un'indagine a livello di Unione europea, 2014

\footnotetext{
${ }^{261}$ Sempre più, dunque, vi è il rischio di costruire una mera "fattispecie mediatica", irrispettosa dei suoi stessi principi giuridici (innanzitutto riguardo al suo perfetto nomen iuris, da cui tarare il rispetto del principio di tassatività e di specialità), dacché è impropriamente generalizzatrice di casi diversi accomunati sotto una (superficiale) comunanza definitoria, in linea con i caratteri di strutturazione della mediaticità (imprecisa e sovente fuorviante, purtuttavia adatta e volta a una facile e pervasiva comunicazione). Tali fattispecie rischiano poi di essere avulse dalla realtà (sociale) materiale $\mathrm{e}$ appiattite sulla realtà (sociale) mediatica, dando poi vita a macrofattispecie del tutto slabbrate rispetto ai confini di diritto.

${ }^{262} \mathrm{Cfr}$. Musco E., L'illusione penalistica, Giuffrè, Milano 2004.

${ }^{263}$ Tecnica, peraltro, da valutare socialmente con una certa attenzione, soprattutto per il suo versante (auto)censuratorio: "Ogni volta che una parola diventa proibita, si toglie una pietra dalle fondamenta della democrazia. La società dimostra la sua impotenza di fronte a un problema concreto togliendo le parole dal linguaggio" (Lars von Trier, Nymph()maniac, 2014).
}

(disponibile on-line: http://fra.europa.eu/sites/default/files/fra2014-vaw-survey-at-a-glance it.pdf).

- Agnese A., De Crescenzo P., Fuga G., La tutela della vittima e garanzie dell'imputato. La più recente normativa dell'Unione europea, Aracne, Roma, 2011.

- Aguglia E., Botter V., Riolo A., "La violenza di genere: un problema di salute pubblica", in Rivista di Psichiatria, n. 2, 2001, pp. 89 ss.

- Arcidiacono D., Crocitti S., "Le risposte del sistema della giustizia penale alle violenze nelle relazioni di intimità", in Creazzo G. (a cura di), Se le donne chiedono giustizia, il Mulino, Bologna, 2012.

- Arcidiacono C., Di Napoli I. (a cura di), Sono caduta dalle scale. I luoghi e gli attori della violenza di genere, Franco Angeli, Milano, 2012.

- Bagnara P., Violenza familiare: prevenzione e trattamento. Le radici nascoste dell'abuso su donne e bambini attraverso la clinica dei casi, Franco Angeli, Milano, 1999.

- Baldry A. C., Dai maltrattamenti all'omicidio. La valutazione del rischio di recidiva e dell'uxoricidio, Franco Angeli, Milano, 2006.

- Baldry A. C., Ferraro E., Uomini che uccidono. Storie, moventi e investigazioni, Centro Scientifico, Roma, 2008.

- Baldry A. C., "Gli strumenti di valutazione del rischio", in Karadole C., Pramstrahler A. (a cura di), Femicidio. Dati e riflessioni intorno ai delitti per violenza di genere, Centro Stampa della Regione Emilia-Romagna, Bologna, 2011, pp. 101 ss.

- Bandini T., Gatti U., Traverso G. B., Omicidio e controllo sociale, Franco Angeli, Milano, 1983.

- Bandini T., Gatti U., Gualco B., Malfatti D., Marugo M. I., Verde A., Criminologia. Il contributo della ricerca alla conoscenza del crimine e della reazione sociale, Giuffré, Milano, 2003, vol. II.

- Bandura A., Social Foundations of Thought and Action: A Social Cognitive, Prentice Hall, Englewood Cliffs, 1986.

- Bartholini I., Violenza di prossimità, Franco Angeli, Milano, 2013.

- Battistelli F., Fay Lucianetti L., "La sicurezza urbana tra politics e policy", in Pajno A . (a cura di), La sicurezza urbana, Maggioli, Santarcangelo di Romagna (RN), 2010.

- Bowlby J., Attaccamento e perdita, Bollati Boringhieri, Torino, 1983. 
- Bowlby J., Una base sicura, Raffaello Cortina, Milano, 1989.

- Browne A., Salomon A., Bassuk S. S., "The Impact of Recent Partner Violence on Poor Women's Capacity to Maintain Work", in Violence Against Women, 1999.

- Brownmiller S., Against our Will: Men, Women, and Rape, Seeker \& Warburg, London, 1975.

- Casale A. M., "Il femminicidio", in Casale A.M., De Pasquali P., Lembo M. S., Profili criminali e psicopatologici del reo, Maggioli, Santarcangelo di Romagna (RN), 2014.

- Chappel D., Geis R., Geis G., Forcible Rape: the Crime, the Victim and the Offender, Columbia University Press, New York, 1977.

- Cohen S., Folk Devils and Moral Panics, MacGibbon \& Kee, London, 1972.

- Corradi C., Sociologia della violenza. Modernità, identità, potere, Meltemi, Roma, 2009.

- Costanzo S., Famiglie di sangue, analisi dei reati in famiglia, Franco Angeli, Milano, 2003.

- Danna D., Ginocidio. La violenza contro le donne nel mondo globale, Eleuthera, Milano, 2007.

- Danna D., "Violenza maschile contro le donne e risposte delle istituzioni pubbliche", in Studi sulla questione criminale, n. 2, 2009, pp. 25 ss.

- Degani P., "Diritti umani e violenza contro le donne: recenti sviluppi in materia di tutela internazionale", in Quadermi del Centro di studi e di formazione sui diritti dell'nomo e dei popoli, $\mathrm{n}$. 2, 2000.

- De Donno A., Grattagliano I., Brunetti C., Introna F., "Gli omicidi in famiglia in Italia: un incremento reale o un incremento mediatico?", in Rivista italiana di medicina legale, n. 6, 2008, pp. 1253 ss.

- Dobash R. E., Dobash R. P., Cavanagh K., Lewis R., "Not an ordinary killer just an ordinary guy. Men who kill their intimate female partner", in Violence Against Women, n. 6, 2004, pp. 577 ss.

- Ellsberg M., Heise L., Pena R., Agurto S., Winkvist A., "Researching Domestic Violence. Against Women: Methodological and Ethical Considerations", in Studies in Family Planning, n. 32, 2001, pp. 1 ss.

- Ellsberg M. C., Winkvist A., Peña R., Stenlund H., "Women's strategic responses to violence in Nicaragua", in Journal of Epidemiology and Community Health, n. 55, 2001, pp. 547 ss.
- Festinger L., $A$ Theory of Cognitive Dissonance, Stanford University Press, Palo Alto, 1957.

- Figone A., "Commento alla legge 154/2001", in Famiglia e diritto, n. 4, 2001.

- Gargiullo B. C., Damiani R., Vittime di un amore criminale. La violenza in famiglia: natura, profili tipologici, casistica clinica e giudiriaria, Franco Angeli, Milano, 2010.

- Gelles R. J., "Domestic Criminal Violence", in Wolfgang M. E., Weiner N. A. (a cura di), Criminal Violence, Sage, Beverly Hills, 1982, pp. 201 ss.

- Giannini M. C., "La violenza domestica e i cicli della violenza", in Mastronardi V. (a cura di), Criminologia psicbiatrica forense e criminologia giudiziaria, Antonio Delfino, Roma, 1995, pp. 195 ss.

- Giomi E., Tonello F., "Moral Panic: the Issue of Women and Crime in Italian Evening News", in Sociologica. Italian Journal of Sociology on line, 2013, n. 3 (disponibile online:

http://www.sociologica.mulino.it/journal/a rticle/index/Article/Journal:ARTICLE:709 LItem/Journal:ARTICLE:709).

- Gondolf E. W., Fisher E. R., Battered women as survivors: An alternative to learned helplessness, Lexington Books, Lexington, 1988.

- Gondolf E. W., "A 30-Month Follow-Up of Court-Referred Batterers in Four Cities", in International Journal of Offender Therapy and Comparative Criminology, n. 44, 2000, pp. 111 ss.

- Gracia E., "Unreported cases of domestic violence against women: towards an epidemiology of social silence, tolerance, and inhibition. The 'iceberg' of domestic violence", in The Journal of Epidemiology \& Community Health, n. 58, 2004, pp. 536 ss.

- Graziosi M., "Femminicidio: i rischi delle leggi-manifesto", in Studi sulla questione criminale, n. 2, 2013.

- Gulotta G., Famiglie e violenza, Giuffrè, Milano, 1984.

- Heise L., Garcia-Moreno C., "La violenza da parte del partner", in Violenza e salute nel mondo. Rapporto dell'Organizzazione Mondiale della Sanità, pubblicato in Quaderni di sanità pubblica, 2002 (disponibile on-line: http://whqlibdoc.who.int/publications/200 2/9241545615 ita.pdf).

- Hirigoyen M. F., Molestie morali.La violenza perversa nella famiglia e nel lavoro, Einaudi, Torino, 2000. 
- Hotaling G. T., "Attribution processes in husband-wife violence", in Straus M. A., Hotaling G. T. (edited by), The social causes of busband-wife violence, University of Minnesota Press, Minneapolis, 1980, pp. 136 ss.

- Jezierski M. B., Eickholt T., McGee J., "Disadvantages to mandatory reporting of domestic violence", in Journal of Emergency Nursing, n. 25, 1999, pp. 79 ss.

- Johnson M. P., Ferraro K. J., "Research on Domestic Violence in the 1990s: Making Distinctions", in Journal of Marriage and the Family, n. 62, 2000, pp. 948 ss.

- Kalmuss D. S., "The Attribution of Responsability in a Wife-abuse Context", in Victimology, n. 4, 1979, pp. 284 ss.

- Kantor G. K., Jasinski J. L., "Dynamics and risk factors in partner violence", in Jasinski J. L., Williams L. M. (edited by), Partner violence: a comprehensive revien of 20 years of research, Sage, Thousand Oaks, 1998.

- Karadole C., "Femicidio: la forma più estrema di violenza contro le donne", in Rivista di Criminologia, Vittimologia e Sicurezza, n. 1, 2012, pp. 17 ss.

- Keilitz S. L., Davis C., Efkeman H. S., Flango C., Hannaford P. L., "Civil Protection Orders: Victims' Views on Effectiveness", in National Institute of Justice Washington, gennaio 1998 (sunto disponibile on-line:

https://www.ncjrs.gov/pdffiles/fs000191.p df)

- Landenburger K. M., "The dynamics of leaving and recovering from an abusive relationship", in Journal of Obstetric, Gynecologic, and Neonatal Nursing, n. 27, 1998, pp. 700 ss.

- Lanna M., "Il Femminicidio: un "conflitto di genere'? Un'analisi socio-giuridica”, Rivista Italiana di Conflittologia, n. 21, 2013 (disponibile on-line: http://www.conflittologia.it/Upload/Editor iale/201321/numeroeditoriale.pdf).

- Lisak D., Hopper J., Song P., "Factors in the cycle of violence: Gender rigidity and emotional constrictions", in Journal of Traumatic Stress, 1996, pp. 721 ss.

- Littel K. M. A. (a cura di), Assessing the Justice System Response to Violence Against Women. A Tool for Community-Based Victim Service. Programs Developing Effective Responses, Pennsylvania Coalition Against Domestic Violence, Pennsylvania, 1998 (disponibile on-line:
https://www.ncjrs.gov/pdffiles1/Archive/2 21760NCJRS.pdf).

- Luberti R., Pedrocco Biancardi M. T. (a cura di), La violenza assistita intrafamiliare, Franco Angeli, Milano, 2005.

- Maffei M. C., "La condizione della donna tra protezione e divieto di discriminazione", in Pineschi L. (a cura di), La tutela internazionale dei diritti umani, Giuffré, Milano, 2006, pp. 173 ss.

- Magaraggia S., Cherubini D. (a cura di), Uomini contro le donne? Le radici della violenza maschile, Utet, Torino, 2013.

- Mazzarese T. (a cura di), Diritto, tradizioni, tradurioni. La tutela dei diritti nelle società multiculturali, Giappichelli, Torino, 2013.

- Merzagora Betsos I., Uomini violenti, I partner abusanti e il loro trattamento, Raffaello Cortina, Milano, 2009.

- Ministero dell'Interno, Rapporto sulla criminalità in Italia del 2007, Roma (disponibile on-line: http://www.interno.gov.it/mininterno/exp ort/sites/default/it/assets/files/14/0900 ra pporto criminalita.pdf).

- Musco E., L'illusione penalistica, Giuffrè, Milano 2004.

- Norwood R., Women Who Love Too Much, Pocket Books, New York, 1985.

- Parmiggiani M. C., "Abuso dei mezzi di correzione e disciplina", in Cadoppi A., Canestrari S., Manna A., Papa M., Trattato di diritto penale, Utet, Milano, 2009, pp. 573 ss.

- Piacenti F. (a cura di), Il femminicidio in Italia nell'ultimo decennio. Dimensioni, caratteristiche e profili di rischio, Eures, Roma, 2012.

- Piacenti F., De Pasquali P., "Il femminicidio in Italia nel periodo 2000-2012", in Rassegna Italiana di Criminologia, n. 3, 2014, pp. 181 ss.

- Pitch T., "Violenza e controllo sociale sulle donne", in Villa R. (a cura di), La violenza interpretata, il Mulino, Bologna, 1979, pp. 147 ss.

- Ponti G., Merzagora Betsos I., Compendio di criminologia, Raffaello Cortina, Milano, 2008.

- Priulla G., C’è differenza. Identità di genere e linguaggi: storie, corpi, immagini e parole, Franco Angeli, Milano, 2013.

- Robertson I., Elementi di sociologia, il Mulino, Bologna, 1995.

- Romito P., Un silenzio assordante, la violenza occulta su donne e minori, Franco Angeli, Milano, 2005. 
- Russell D., Radford J., Femicide: The Politics of woman killing, Twayne Publishers, New York, 1992.

- Russo G., "Femicidio, Studio su 82 vittime", in Archivio di medicina legale e delle assicurazioni, 1982, pp. 187 ss.

- Sanmartín Esplugues J., Iborra Marmolejo I., García Esteve Y., Martínez Sánchez P., Violencia contra la mujer en las relaciones de pareja, Centro Reina Sofía para el Estudio de la Violencia, Madrid, 2006 (disponibile online:

http://www.luisvivesces.org/upload/88/18 Linforme.pdf).

- Schiaffo F., "Le minime ragioni della legislazione penale simbolica: la criminalità mediata", in Critica del diritto, 2010, pp. 127 ss.

- Seligman M. E. P., Learned Helplessness, Freeman, San Francisco, 1975.

- Snell J. E., Rosenwald R. J., Robey A., "The Wifebeater's Wife: A Study of Family Interaction", in Archives of General Psychiatry, n. 11, 1964, pp. 107 ss.

- Spinelli B., Femminicidio. Dalla denuncia sociale al riconoscimento giuridico internazionale, Franco Angeli, Milano, 2008.

- Steinmetz K. S., Straus M. A.(a cura di), Violence in the Family, Harper \& Row, New York, 1974.

- Szegò A., "Quando lo stupro è legale: 'la marital rape exemption"', in Rivista italiana di diritto e procedura penale, 1995, pp. 853 ss.

- Traverso G. B., Marugo M. I., "L'omicidio della donna a Genova. I risultati di una ricerca", in Rassegna di criminologia, 1984, pp. 385 ss.

- Ventimiglia C., La fiducia tradita. Storie dette e raccontate di partner violenti, Franco Angeli, Milano, 2000.

- Walker L. E., Battered Woman, Paperback, New York, 1980.

- White J. W., Kowalski R., "Male Violence towards Women: An Integrated Perspective", in Russell G. G., Donnerstein E. (edited by), Human aggression: Theories, Research, and Implications for Social Policy, California Academic Press, San Diego, 1998, pp. 203 ss.

- Wilson M., Daly M., Wright C., "Uxoricide in Canada: Demographic Risk Patterns", in Canadian Journal of Criminology, 1993, pp. 263 ss. 